ENERGY DIVISION

\title{
SUPPORTING INFRASTRUCTURE AND ACCEPTABILITY ISSUES ASSOCIATED WITH TWO NEW GENERATION VEHICLES: P2000 AND ESX2
}

\author{
Sujit Das \\ T. Randall Curlee \\ Gary Davis ${ }^{1}$ \\ Rajive Dhingra ${ }^{1}$ \\ Stanton W. Hadley \\ Donald W. Jones \\ Jonathon Overly ${ }^{1}$ \\ Susan M. Schexnayder ${ }^{2}$ \\ Bruce E. Tonn \\ Amy K. Wolfe

\footnotetext{
${ }^{1}$ University of Tennessee, Center for Clean Products and Clean Technologies

${ }^{2}$ University of Tennessee
}

May 2000

Prepared for the

Office of Advanced Automotive Technologies

Office of Transportation Technologies

U.S. Department of Energy

Washington, D.C.

Prepared by the

Oak Ridge National Laboratory

Oak Ridge, Tennessee 37831-6205

operated and managed by

UT-BATTELLE, LLC

for the

U.S. DEPARTMENT OF ENERGY

under contract DE-AC05-00OR22725 


\section{Table of Contents}

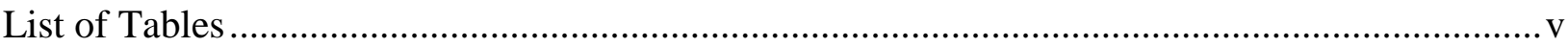

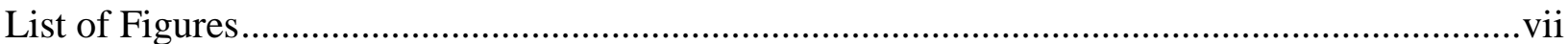

EXECUTIVE SUMMARY ………............................................................................. E-ix

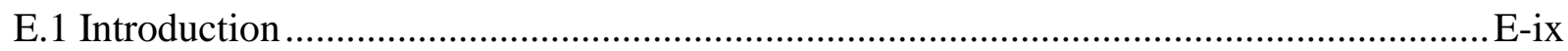

E.2 Materials Availability and Processing ……………………………………………….... E-xi

E.3 Materials Recycling ……………….......................................................................... E-xii

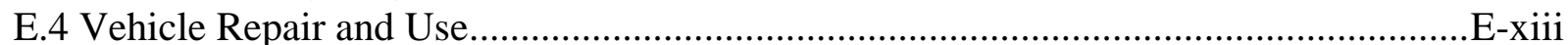

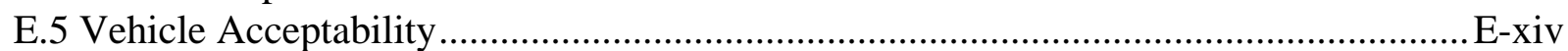

E.5 Life Cycle Environmental Evaluation.............................................................. E-xiv

E.6 Summary Conclusions and Research Needs ............................................................... E-xvii

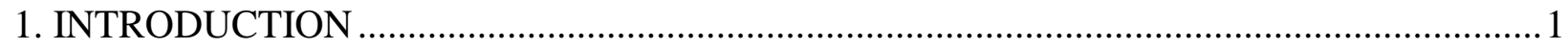

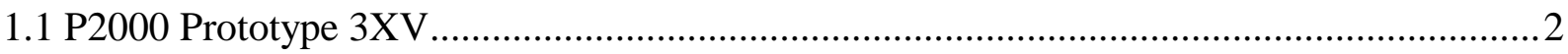

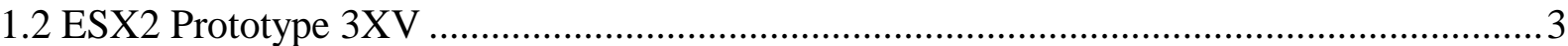

1.3 Projected Market Penetration of 3XVs.......................................................................

1.4 Material Composition: Base and Prototype 3XVs .................................................. 6

1.5 Material Requirements ……..............................................................................

2. MATERIALS AVAILABILITY AND PRODUCTION ISSUES ..................................... 11

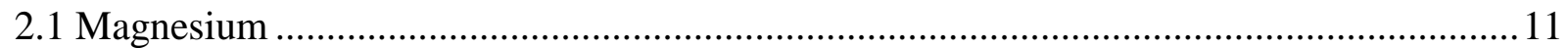

2.2 Carbon Fiber ...........................................................................................13

2.3 Glass Fiber....................................................................................................... 15

2.4 Resin Matrix Material ............................................................................................. 16

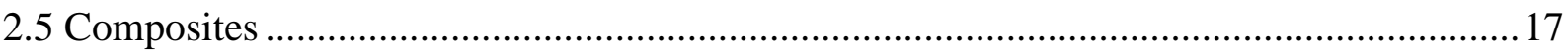

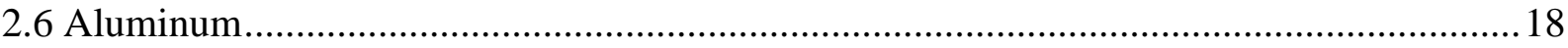

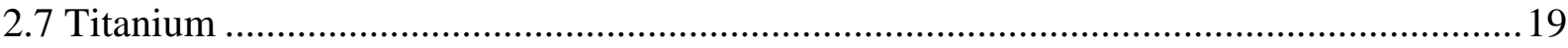

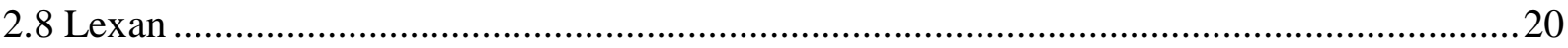

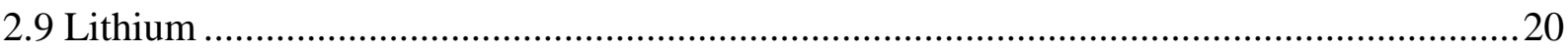

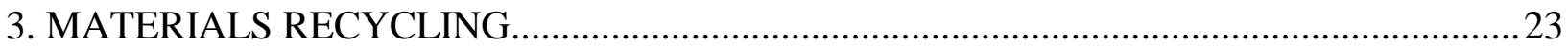

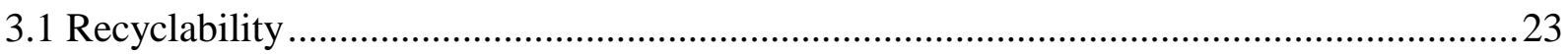

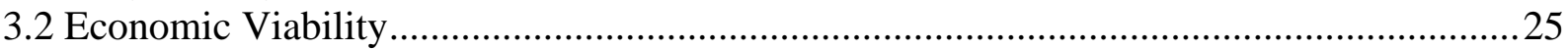

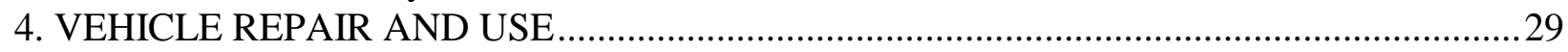

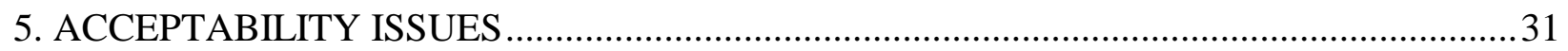

5.1 Weight and Safety: The Only Potential Showstopper ................................................31

5.2 Current Market De-emphasizes Fuel Efficiency ....................................................32

5.3 Competitive Responses May Erode the P2000 and ESX2 Market Share...........................32

5.4 Consumers' Willingness to Trade-off First-cost for Life-cycle Operating Cost ....................33

5.5 Accumulation of Smaller Negatives Can Dampen Market Share Seriously ..........................33

6. LIFE-CYCLE EVALUATION OF THE P2000, THE ESX2, AND THE BASELINE

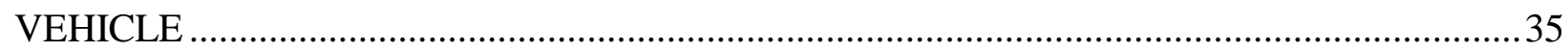

6.1 Introduction ………….........................................................................................

6.1.1 Goal and Scope of the Study …..........................................................................35

6.1.2 Material Composition Scenarios ......................................................................... 36

6.2 Methodology and Assumptions ...................................................................................

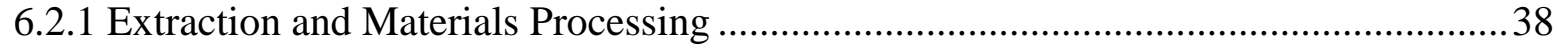




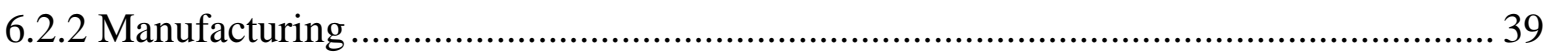

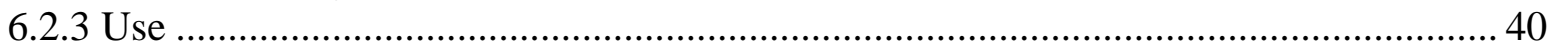

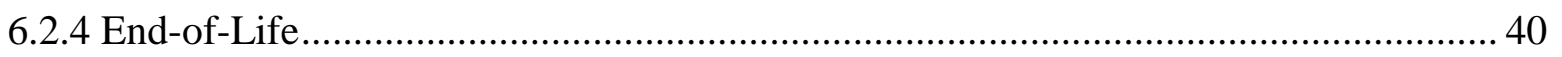

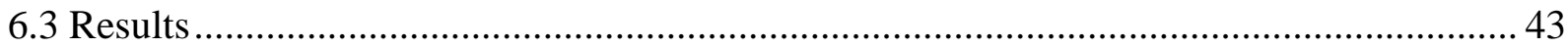

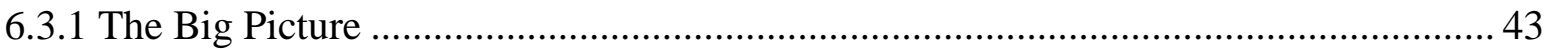

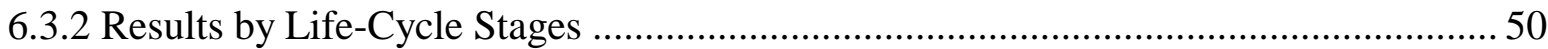

6.4 Lifecyle Evaluation Conclusions and Recommendations for Future Research ...............59

7. CONCLUSIONS AND RECOMMENDATIONS FOR FUTURE RESEARCH .................6 63

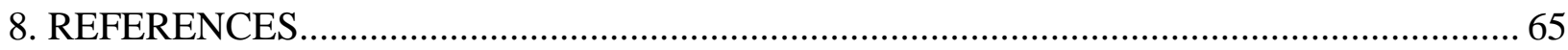




\section{TABLES}

Table 1. Projected vehicle sales and 3XVs' market share, by year 4

Table 2. Material composition scenarios for PNGV infrastructure (lbs. and change from 1994 vehicle)

Table 3. Forms of major materials used by $3 \mathrm{X}$ prototypes and base vehicle (lbs.) ...................... 7

Table 4. Lightweight material requirements for PNGV, 2005-2030 (in '000 tonnes) ..................8

Table 5. Cost Components of Aluminum Sheet....................................................................... 19

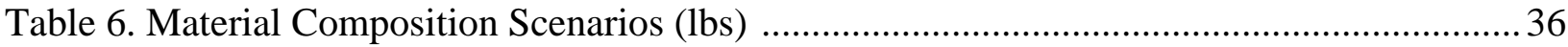

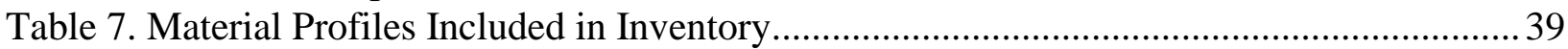

Table 8. Use-stage Emissions Rate (gram/mile) .................................................................... 41

Table 9. Fuel Production Emission Estimated by ANL (gram/mile) .......................................45

Table 10. Inputs and Outputs from Extraction and Materials Processing ..................................50

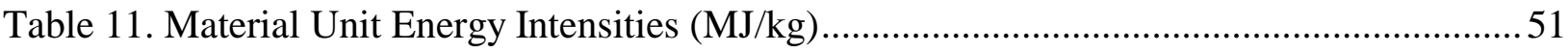

Table 12. Gases that Contribute to GWP in the Extraction and Materials Processing Life-Cycle

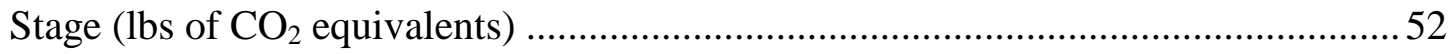

Table 13. Inputs and Outputs of Manufacturing, including Mold-in-Color Savings ..................53

Table 14. Global Warming Potential Effects of Sulfur Hexafluoride $\left(\mathrm{SF}_{6}\right)$............................ 53

Table 15. Lifetime Fuel Requirement (gallons) ..................................................................5 53

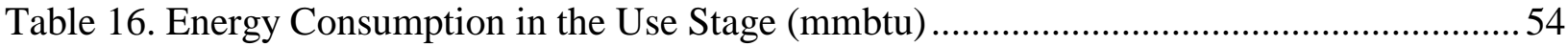

Table 17. Estimated Use-Stage Emissions (lbs/lifetime) .........................................................54

Table 18. Inputs and Outputs from Gasoline/Diesel Production.................................................55

Table 19. End-of-Life Energy Consumption (mmbtu) ................................................................56

Table 20. Air Emissions from Electricity Generation - End-of-Life Stage (lbs) .........................56 


\section{FIGURES}

Figure 1. Market Penetration Rates for 3XVs (2003-2030) 5

Figure 2. Lightweight Material Requirements for 3XVs in 2020, Compared to 1997 U.S.

Consumption 9

Figure 3. ESX2 Lithium Demand Compared to U.S. Lithium Demand and World Production...21

Figure 4. Recyclers Benefit From Higher Non-Ferrous Material Content ....................................2 26

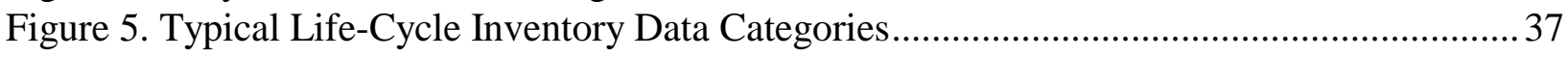

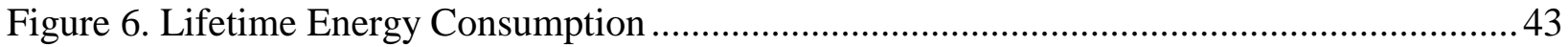

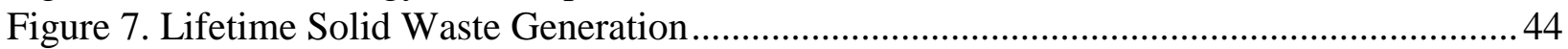

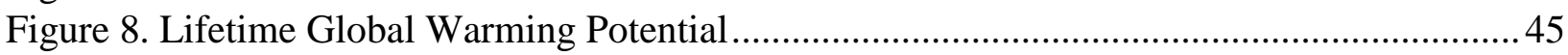

Figure 9. Rural vs. Urban Distribution of GWP Effects and Emissions ......................................46

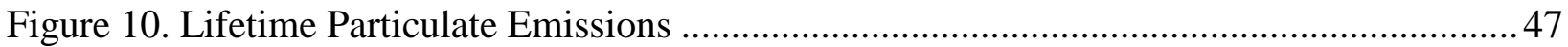

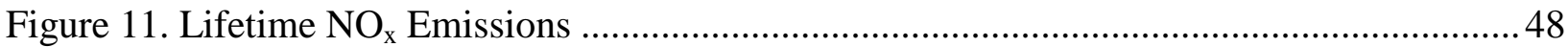

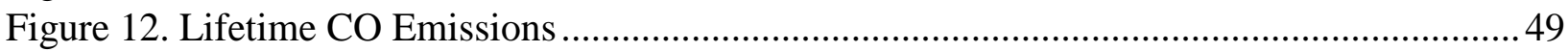

Figure 13. Extraction and Materials Processing Energy Consumption ........................................51

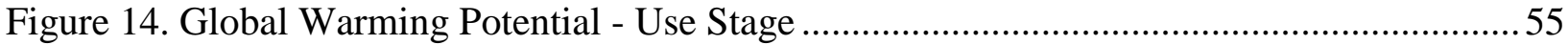

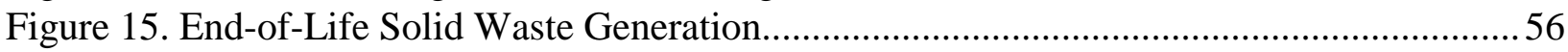




\section{EXECUTIVE SUMMARY}

As the Partnership for a New Generation of Vehicles (PNGV) has been proceeding with the development of designs for high-fuel-economy vehicles, it also has been assessing whether impediments exist to the transition to these vehicles. Toward that end, as materials options and vehicle designs have been developed, Oak Ridge National Laboratory (ORNL) has been conducting analyses related to the attendant materials infrastructure requirements. This report addresses the question, what are the infrastructure requirements, acceptance issues, and life-cycle impacts associated with PNGV vehicles constructed of lightweight materials.

\section{E.1 Introduction}

The Partnership for a New Generation of Vehicles (PNGV)—an initiative involving the "Big 3" U.S. automakers, seven government agencies, and twenty national research laboratories-is working to produce automobiles that use twothirds less fuel but remain comparable to today's vehicles in terms of price, comfort, safety, and performance. One of the means of achieving this goal is to substitute lightweight materials in the place of traditional, heavier materials. Each of the three big U.S. automakers has developed prototype PNGV vehicles. This report focuses on vehicles developed by Ford and Chrysler (now DaimlerChrysler). We refer to these as "3XVs" because of the PNGV goal of increasing fuel efficiency by a factor of three.

The Ford P2000 relies heavily on aluminum in the vehicle's body and engine to reduce vehicle weight, while the DaimlerChrysler ESX2 relies on a composite body and an aluminum chassis (Table E-1). Both prototype vehicles also employ a range of other substitute materials, and both have hybrid powertrains that are likely to rely on lithium-ion batteries. The material composition scenarios for the P2000 and ESX2 are compared to the base (1994) vehicle in Table E-1.

The materials infrastructure requirements of $3 \mathrm{XVs}$ are based on the per/vehicle usage of materials, projections of new light-duty vehicle sales, and the market penetration of the $3 \mathrm{XVs}$. Three market penetration scenarios are considered (Figure E-1). Two forecast market penetration only through 2020; the third forecasts penetration through 2030. The "high" and "low" penetration scenarios are based on Quality Metrics '99 produced by the Department of Energy's Office of Energy Efficiency and Renewable Energy. The third scenario, the "mid" penetration rate, produced by Resolve, Inc. from a policy dialogue about greenhouse gas emissions, was used in ORNL's previous years' 3XV materials studies and by Argonne National Laboratory in its fuels infrastructure study. Both the "high" and "low" scenarios are aggressive compared to the "mid" scenario, but not relatively aggressive when compared to other introductions of new automobile technology, e.g., front wheel drive vehicles. 
Table E-1. 3XV Material Composition Scenarios (lbs. and change from 1994 vehicle)

\begin{tabular}{|c|c|c|c|}
\hline Material & 1994 & P2000 & ESX2 \\
\hline Plastics & 223 & $251(+13 \%)$ & $485(+117 \%)$ \\
\hline Wrought Aluminum & 47 & $462(+883 \%)$ & $330(+602 \%)$ \\
\hline Cast Aluminum & 159 & $271(+70 \%)$ & $120(-25 \%)$ \\
\hline Magnesium & 6 & $86(+1333 \%)$ & $122(+1933 \%)$ \\
\hline Titanium & 0 & 11 (NA) & 40 (NA) \\
\hline Ferrous & 2168 & $490(-77 \%)$ & $528(-76 \%)$ \\
\hline Rubber & 138.5 & $123(-11 \%)$ & $148(+7 \%)$ \\
\hline Glass & 96.5 & $36(-63 \%)$ & $70(-27 \%)$ \\
\hline Lexan & 0 & 30 (NA) & 20 (NA) \\
\hline Glass Fiber & 19 & $19(0 \%)$ & $60(+216 \%)$ \\
\hline Carbon Fiber & 0 & 8 (NA) & 24 (NA) \\
\hline Lithium & 0 & 30 (NA) & 30 (NA) \\
\hline Other & 391 & $223(-43 \%)$ & $303(-23 \%)$ \\
\hline Total Wt. (Lbs) & 3248 & $2010(-38 \%)$ & $2250(-31 \%)$ \\
\hline
\end{tabular}

Note: Numbers inside parenthesis indicate changes in composition from the 1994 vehicle

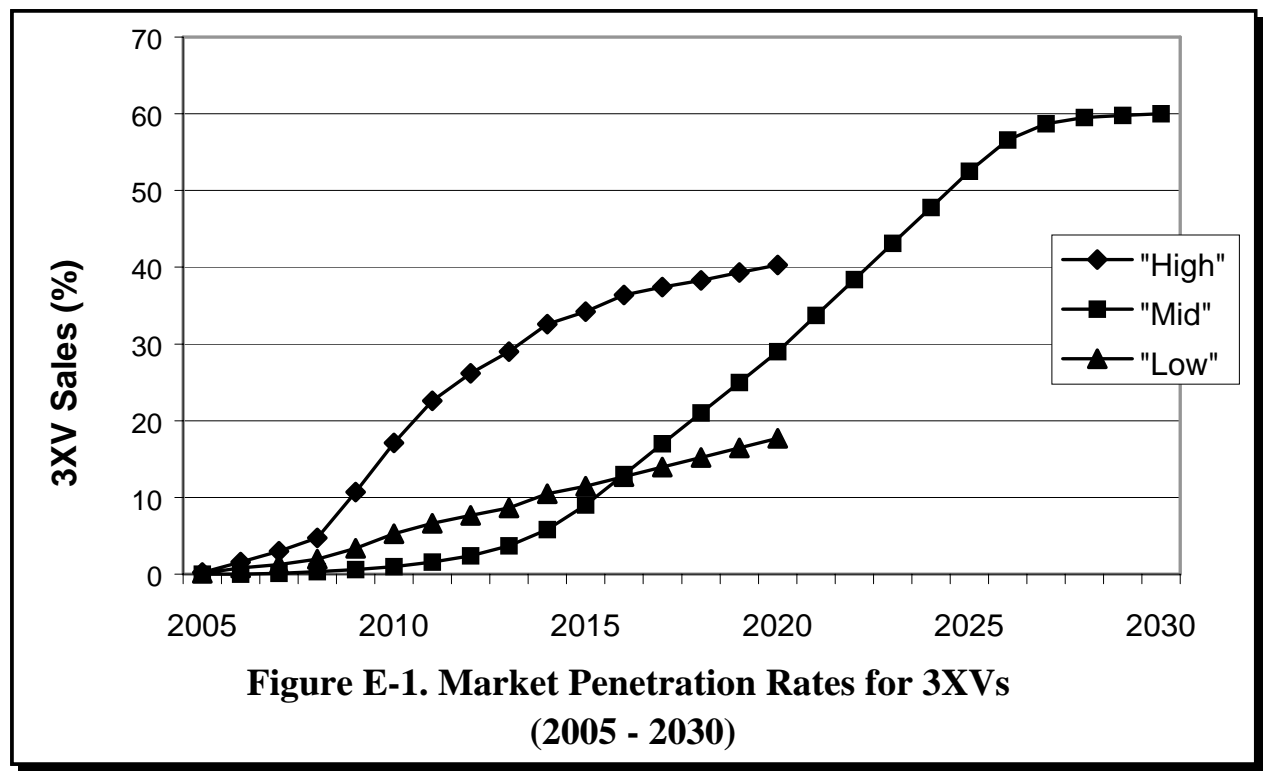

For this analysis, the upper-end material demands are used. These upper-end values are based on the "high" scenario through 2020, the "mid" scenario beyond 2020 , and the $3 \mathrm{XV}$ prototype demanding the most of a given material. It is appropriate to use these upper-end values as they represent the most conservative scenarios for materials infrastructure requirements. The upper-end materials requirements are presented in Table E-2. 
Table E-2. Lightweight material requirements for PNGV, 2005-2030 (in ' 000 tonnes)

\begin{tabular}{|l|l|l|l|l|l|l|l|l|}
\hline \multirow{2}{*}{ MATERIAL } & \multicolumn{2}{|c|}{2005} & \multicolumn{2}{c|}{ 2010 } & \multicolumn{2}{c|}{2020} & \multicolumn{2}{c|}{2030} \\
\cline { 2 - 10 } & P2000 & ESX2 & P2000 & ESX2 & P2000 & ESX2 & P2000 & ESX2 \\
\hline \hline Plastics & 0.04 & 3 & 0 & 288 & 0 & 624 & 0 & 843 \\
\hline Glass Fiber & 0 & 0.6 & 0 & 49 & 0 & 114 & 0 & 168 \\
\hline Carbon Fiber & 0.10 & 0.3 & 10 & 31 & 26 & 77 & 40 & 121 \\
\hline Cast Aluminum & 2 & 0 & 117 & 0 & 239 & 0 & 300 & 0 \\
\hline Wrought Aluminum & 6 & 4 & 528 & 357 & 1291 & 868 & 2014 & 1346 \\
\hline Magnesium & 1.1 & 2 & 103 & 150 & 254 & 370 & 400 & 582 \\
\hline Titanium & 0.2 & 0.6 & 14 & 52 & 35 & 128 & 56 & 202 \\
\hline Lexan & 0.4 & 0.3 & 39 & 26 & 96 & 64 & 152 & 101 \\
\hline Lithium & 0.4 & 0.4 & 39 & 39 & 96 & 96 & 152 & 152 \\
\hline
\end{tabular}

The analyses documented in this report explore the availability of materials and the adequacy of the materials processing infrastructure to meet $3 \mathrm{XV}$ needs. The analyses also model the automobile recycling industry to determine how the new materials will affect automobile recyclability and the recyclers' profits.

Infrastructure issues relating to the use of $3 \mathrm{XV}$ s are explored through primary sources, especially the expert opinions of industry experts. Emphasis is placed on automobile repair and insurance. The report explores issues that could affect consumer acceptance of $3 \mathrm{XVs}$, relying on interviews with automobile sales staff and literature about acceptance of automotive technologies. To determine "cradleto-grave" impacts of the switch to lightweight materials, a life-cycle evaluation of the $3 \mathrm{XV}$ prototypes has been conducted.

\section{E.2 Materials Availability and Processing}

For each substitute material - magnesium, carbon fiber, glass fiber, polyethylene terepthalate (PET), composites, aluminum, titanium, ploycarbonate (Lexan), and lithium - the analysis determines the adequacy of the supply of raw materials and material processing capacity, looking for potential problems. In addition, other factors that might influence the use of lightweight materials at high-production volumes are explored. These factors include cost and the availability of appropriate materials handling technologies.

The analysis found that there will be adequate supply of most lightweight materials, and the level of capital investment will be manageable. However, significant increases in production capacity will be required for a few materials. These materials include carbon fibers, magnesium, and lithium.

Annual growth of $2.8 \%$ and $10 \%$ (by 2015) would be required for precursor fibers and carbon fibers respectively, and growth in the glass-fiber industry is projected to be well below what is needed for growth in the transportation sector, excluding the demands of $3 \mathrm{XVs}$. The projected $1.9 \%$ annual growth (by 2020) needed to meet $3 \mathrm{XV}$ demand for composites is above an already high growth rate forecasted to be necessary for meeting general demand within the transportation sector.

The $3 \mathrm{XV}$ demand for lithium is large relative to current consumption and production. Assuming $30 \mathrm{lb}$. of lithium per battery, the $3 \mathrm{XV}$ requirement for 
lithium would exceed current U.S. lithium consumption by 2006 and worldwide production by 2009. Lithium demand will grow by 50\% per year through 2010 . Although it appears that adequate raw ore exists and lithium is recyclable, the ability to increase production capacity so rapidly is a concern.

Even for some materials for which there is adequate material supply and production capacity, material cost could be problematic. Of concern are aluminum, titanium, and lithium. Aluminum and titanium prices would need to drop $30 \%$ and $50 \%$, respectively, for these materials to be price competitive in the high-volume automobile market. The quantity of lithium required for one battery, at today's lithium prices, would cost $\$ 1200$.

While material availability, production capacity, and cost are primary concerns, other issues are also notable. One such issue is the lack of processing technologies that would allow aluminum to be adopted and used in high production-volume situations. Another is the physical/structural limitations of Lexan that might similarly limit its high-production use. Lastly, the consolidation of parts that would occur if composites are used will likely not hinder adoption of composites, but it will decrease the number of processors and require manufacturing plants to be near original equipment manufacturing sites.

\section{E.3 Materials Recycling}

The recycling rate of current automobiles is $75 \%$-driven by the high ferrous content of automobiles. The PNGV program requires $3 \mathrm{XV}$ s to be $80 \%$ recyclable. This percentage is compared to European Commission directive on reuse and recovery of automobiles, which mandates an 85\% recycling rate in 2005 and $95 \%$ recycling rate by 2015 .

The analysis of materials recycling effects is two-fold. It first qualitatively assesses factors that may be detrimental to achieving the targeted recycling rate. Then, an ORNL-developed model of the automobile recycling industry is used to quantify the economic effects on the existing automobile recycling industry. The model considers the three distinct players in the industry - the dismantler, the shredder, and the non-ferrous separator-and how inputs and outputs from each player would differ based on the material composition of the $3 \mathrm{XV}$ prototypes.

For the P2000 vehicle to achieve the PNGV recycling goal on a total weight basis, 96.8\% of its ferrous, wrought and cast aluminum, magnesium, and titanium content will have to be recycled. For the ESX2, $100 \%$ of these metals will have to be recycled, along with another $115 \mathrm{lbs}$. of additional materials. Achieving the PNGV recycling goal within material categories (as opposed to across the total vehicle weight), will be difficult—for technical or economic reasons-for most non-ferrous materials.

The two predominant materials, aluminum and composites, present recycling challenges. The need for a technology to sort wrought from scrap aluminum is heightened by the increased need for sheet and extrusion product, which have less tolerance for alloying elements than do cast products. Also, the market for mixed scrap is limited to the automobile market. Composites contribute greatly to the volume of automobile shredder residue (ASR), which is currently landfilled 
because of the absence of cost-effective recycling technologies. (This is a concern related only to the ESX2). However, some technologies seem promising and are being pursued by the U.S. Council for Automotive Research (USCAR). Also, ESX2's use of PET may be beneficial from the standpoint of recycling since PET recycling - in the form of plastic bottle recycling - already occurs on a large scale.

The cost model shows that the net revenues of dismantlers, shredders, and nonferrous separators will increase with either of the two $3 \mathrm{XV}$ prototype scenarios (see Figure E-2). The model assumes that removing parts for reuse (by dismantlers) will continue as in the baseline. It also assumes that the share of materials recycled by shredders and non-ferrous separators will be the same as in the base case. Because of the significantly higher amount of non-ferrous metals in the ESX2 and P2000 compared with current vehicles, non-ferrous separators stand to experience the greatest increase in net profits. Shredders will experience the smallest increase- 1.6 times their current net profit in the ESX2 casebecause of higher plastic content. Recyclers will have considerable lead-time to adjust to recycling $3 \mathrm{XVs}$.

\section{E.4 Vehicle Repair and Use}

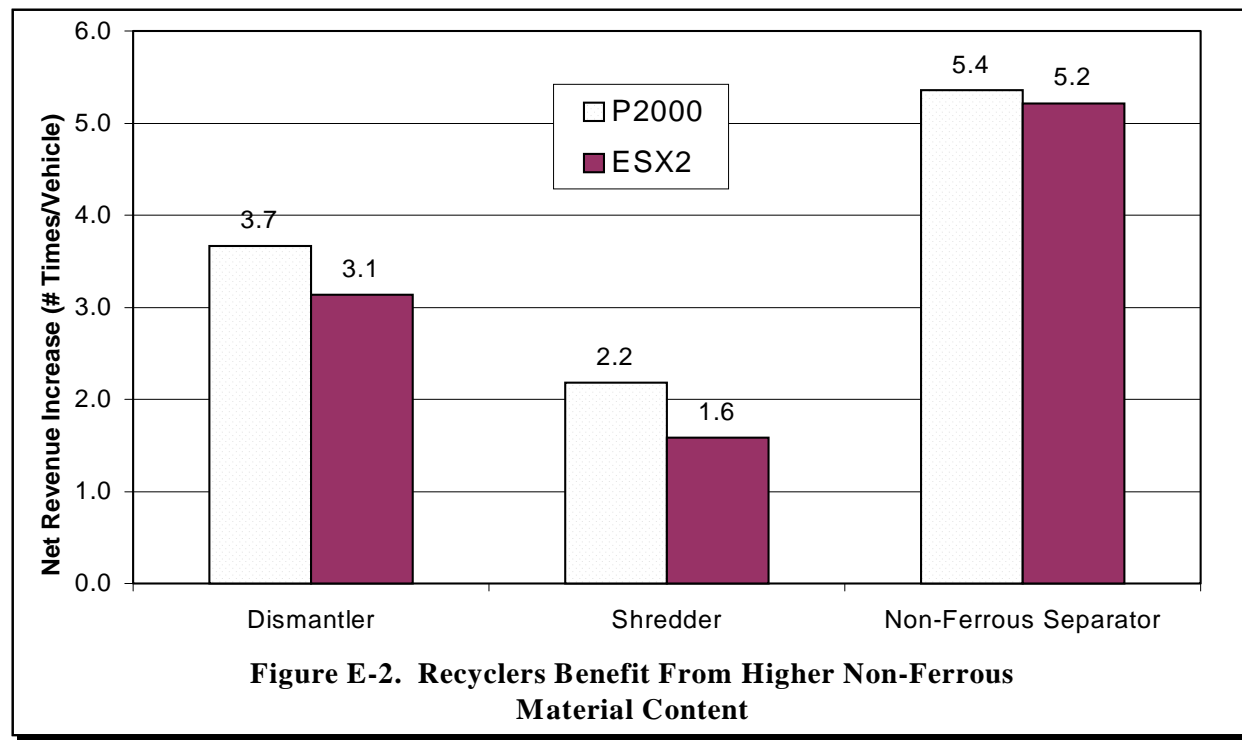

The evaluation of the prototype $3 \mathrm{XV}$ s' effects on the infrastructure associated with vehicle use and repair-namely the insurance and repair industries-is based primarily on interviews of automobile repair and insurance industry personnel, industry publications, and financial and employment statistics.

The overall conclusion drawn from these information sources is that there are no show-stopping barriers to market penetration of $3 \mathrm{XV}$ s related to repair and use. However, in combination, a number of minor issues could act as a significant barrier. These minor issues are summarized here.

- The automobile repair industry is currently facing challenges related to retraining its existing workforce and attracting new service technicians. The 
introduction of $3 \mathrm{XVs}$ is not expected to introduce greater challenges than those already faced.

- Initially, 3XV insurance costs may be higher because of 3XVs greater firstcosts and because insurance companies may charge a premium until data about mechanical and body repair costs become available.

- Collision repair costs may be higher for aluminum- and composite-intensive vehicles. Aluminum is more difficult to work with, and effective "patches" for composite panel damage will have to be developed.

- Collision repair may take more time because of the materials challenges noted above, and, early in $3 \mathrm{XV}$ introduction, it may take time for insurance companies and repair firms to negotiation appropriate reimbursement levels.

- Ease of mechanical repair may be degraded in design tradeoffs that favor reduced manufacturing and assembly costs.

- The introduction of $3 X V$ s may hasten the change in the repair industry from smaller, independent firms to dealers and national vehicle repair chains.

\section{E.5 Vehicle Acceptability}

Relying on information obtained through interviews with automobile sales personnel and other industry representatives, this section considers the two prototype $3 \mathrm{XVs}$ from the standpoint of attributes that could severely impair consumer acceptability.

The only discrete item that could severely impair acceptability is the weight of the vehicles and the potential safety issues that stem from the vehicles' weight. Based on current industry trends toward heavier vehicles - sport utility vehicles, trucks, and vans account for half of new car sales - the likelihood is that crashes involving $3 \mathrm{XVs}$ will be with heavier vehicles. Consumer confidence in the degree to which the vehicles are designed to protect passenger safety may affect their willingness to purchase those vehicles, rather than other vehicles of a similar "class." However, issues of weight, size, and safety are complex, and perceptions of relationships among these features are not easily discerned.

Several other issues that may affect the acceptability of $3 \mathrm{XV}$ s are noted. The longterm lowering of oil and gasoline prices and general improvements in vehicle fuel efficiency have diminished the marginal demand for more fuel-efficient vehicles. The market for fuel-efficient vehicles will likely remain depressed unless economic reinforcement occurs or corporate average fuel-efficiency standards tighten and create a market. There will be, and in fact already are, competitive responses to the $3 \mathrm{XVs}$. A host of advances designed to improve fuel efficiency, including different fuels and major efforts by the steel industry to increase steel's competitiveness with alternative materials, could possibly dampen $3 \mathrm{XV}$ penetration. New research shows that uncertainty associated with new technologies can cause consumers to delay purchase decisions, thus potentially affecting $3 \mathrm{XV}$-market penetration. And, last, in combination, relatively small social acceptance issues could dampen the market.

\section{E.6 Life Cycle Environmental Evaluation}

Whereas the other analyses in this report focus on a specific stage of vehicle life, this section reports a life cycle evaluation that spans four life cycle stages: 
extraction and materials processing; manufacturing; use, which includes fuel generation and fuel use; and end-of-life. The evaluation conducted here includes a life cycle inventory and the extent of life cycle impact assessment that was considered necessary and could be completed given the time constraints of the project. Inputs are vehicle materials and energy; outputs are air emissions, solid waste, and products. ${ }^{-}$The evaluation assumes that $3 \mathrm{XVs}$ are powered by direct injection diesel engines, use lithium ion batteries, and achieve fuel efficiency of $70 \mathrm{mpg}$. A detailed list of assumptions is included in the main body of the report.

Results show that either of the prototype 3XVs (and the ESX2 with mold-in-color $[\mathrm{MIC}]$ ) would produce about a 55\% reduction in lifetime energy consumption, attributed almost entirely to the $70 \mathrm{mpg}$ fuel efficiency of the $3 \mathrm{XVs}$. Reductions occur in fuel use and fuel generation categories, while the $32 \mathrm{mmbtu}$ energy requirement in extraction and materials processing (E\&MP) for the base vehicle is doubled by the $3 \mathrm{XVs}$ (see Figure E-3). The energy use associated with the additional wrought aluminum accounts for most of the increase, with titanium and magnesium also contributing noticeable increases.

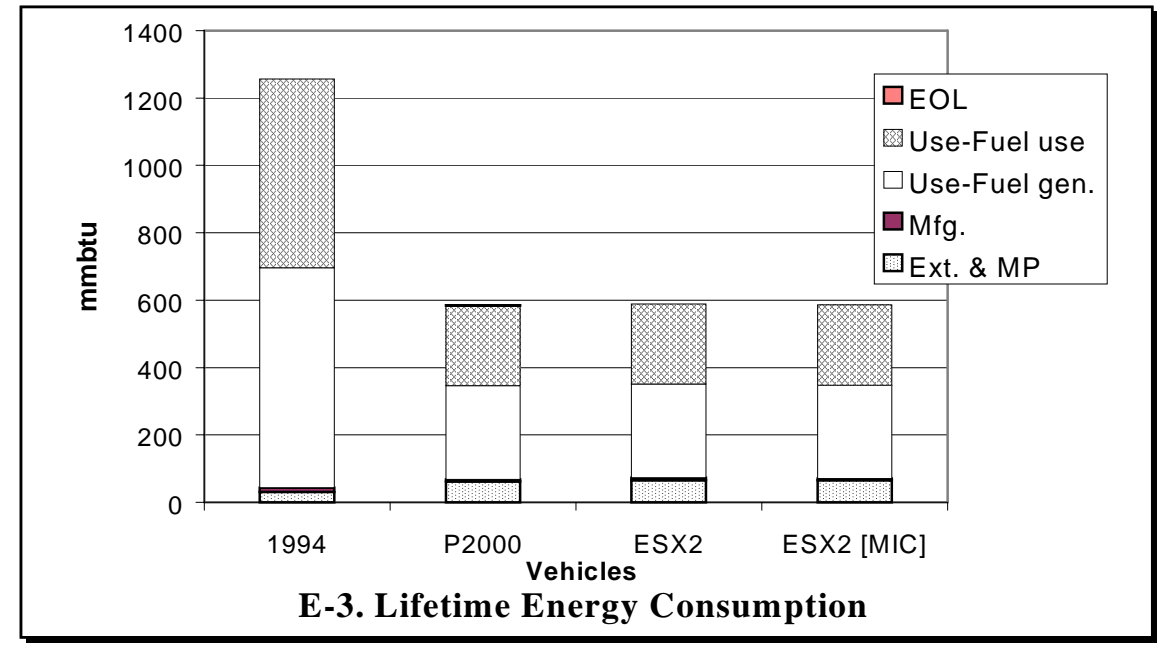

Both $3 \mathrm{XV}$ prototypes will increase solid waste production at the extraction and material processing stage. Solid waste generation at this stage dominates solid waste generation throughout the vehicle's life cycle (see Figure E-4). Without recycling the PET, the ESX2 also shows higher waste generation at the end-of-life stage. Gains to be made in solid waste reduction by increasing automobile recycling at the end-of-life are not significant compared to the increases occurring during upstream processes.

1 The analysis disregarded one input (ancillary materials) and two outputs (water emissions and co-products). 


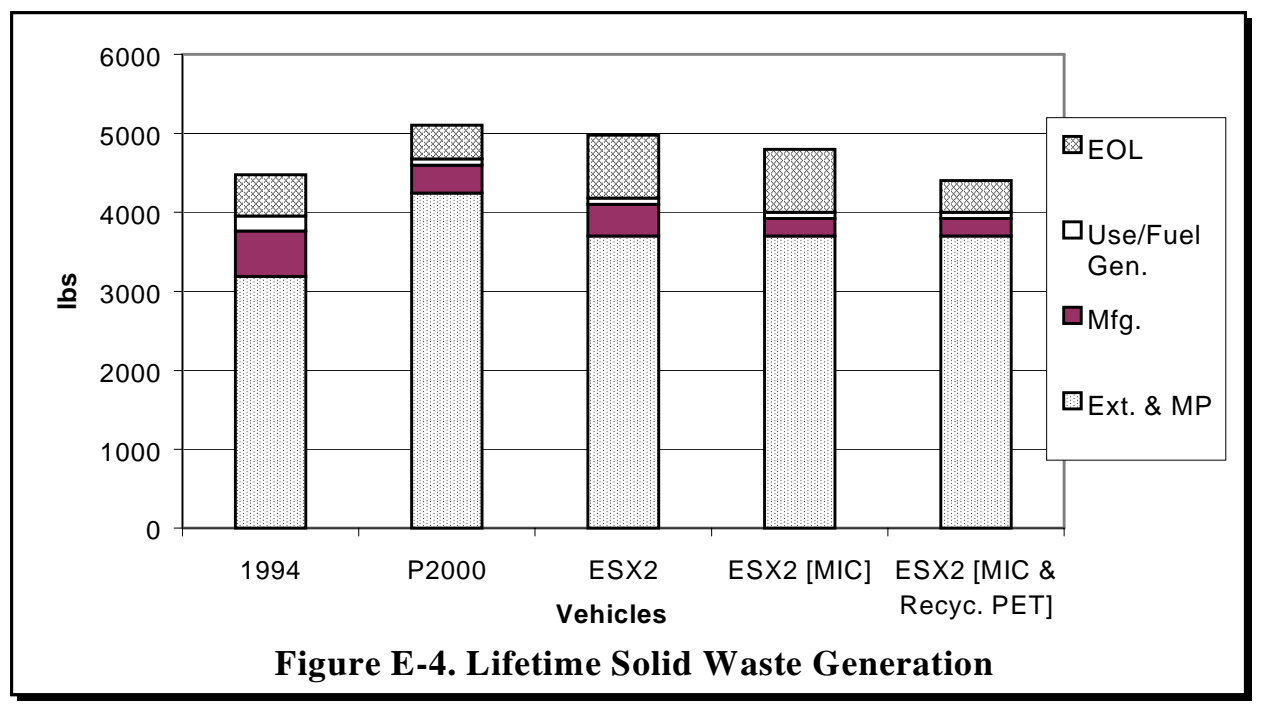

The remaining output examined in this analysis is air emissions. Global warming gases $\left(\mathrm{CO}_{2}, \mathrm{CH}_{4}, \mathrm{~N}_{2} \mathrm{O}, \mathrm{SF}_{6}, \mathrm{CF}_{4}\right.$, and $\left.\mathrm{C}_{2} \mathrm{~F}_{6}\right)$, particulate matter $(\mathrm{PM}), \mathrm{NO}_{\mathrm{X}}$, and $\mathrm{CO}$ were analyzed.

Global warming is addressed by comparing the baseline and $3 \mathrm{XVs}$ ' lifetime global warming potential (GWP), expressed as $\mathrm{CO}_{2}$ equivalents. Both $3 \mathrm{XVs}$ reduce GWP by almost $50 \%$ because of large reductions in the use stage (Figure E-5). However, $\mathrm{SF}_{6}, \mathrm{CF}_{4}$, and $\mathrm{C}_{2} \mathrm{~F}_{6}$ in the extraction stage and $\mathrm{SF}_{6}$ in the manufacturing stage greatly increase the GWP of those life-cycle stages. Magnesium is the primary contributor to this increased GWP, with wrought aluminum (in both prototypes) and PET with glass (in the ESX2) also contributing substantially.

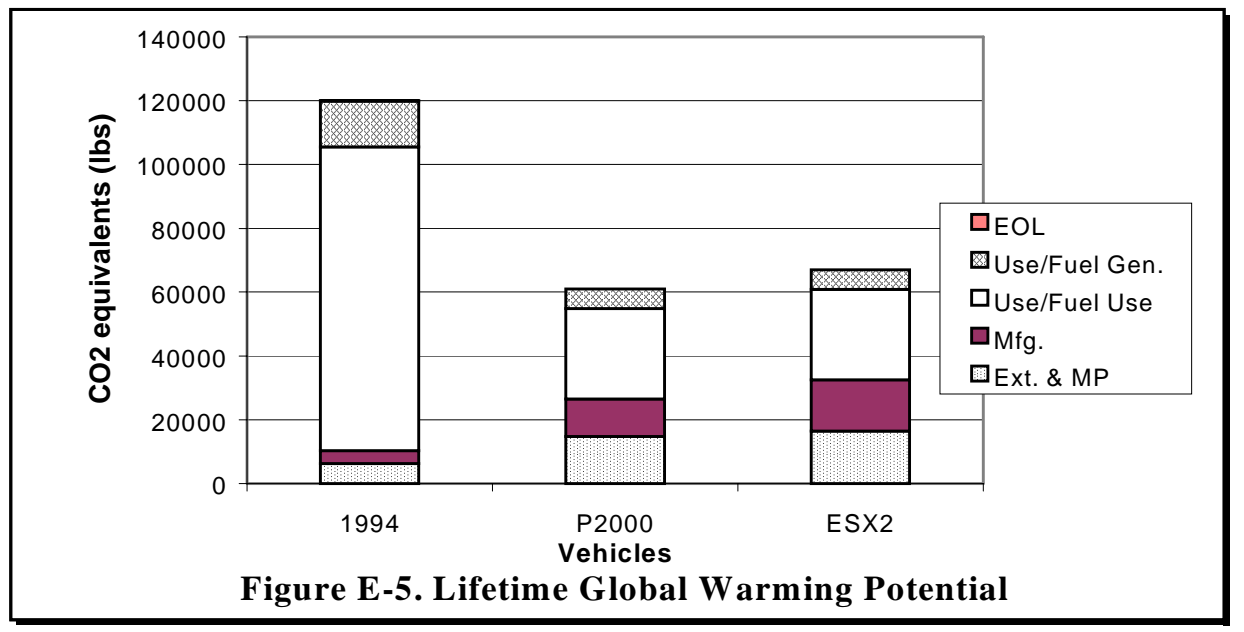

The life-cycle evaluation of vehicle $\mathrm{PM}, \mathrm{NO}_{\mathrm{X}}$, and $\mathrm{CO}$ emissions shows that

- Compared to the baseline vehicle, the $3 \mathrm{XV}$ s will have much higher $\mathrm{NO}_{\mathrm{X}}$ and, especially, PM emissions during the E\&MP stage because of the new 
materials. Ninety percent of PM emissions at the extraction life-cycle stage result from the use of aluminum, magnesium, and titanium. These new materials are also the primary cause of increases of $\mathrm{NO}_{\mathrm{X}}$.

- At the use stage, emissions are sensitive to assumptions about diesel-fuel and diesel-engine emission standards. For $\mathrm{PM}, \mathrm{NO}_{\mathrm{X}}$, and $\mathrm{CO}$, the analysis considers two assumptions. One assumption is that emission of $3 \mathrm{XVs}$ will be similar to current diesel fuel/engine emissions (e.g., $\mathrm{NO}_{\mathrm{X}}$ emission rate is a $0.369 \mathrm{~g} / \mathrm{mile}$ ). The second assumption is that use-stage emissions will be consistent with the average of Low Emission Vehicle standards and Ultra Low Emission Vehicle standards (e.g., $\mathrm{NO}_{\mathrm{X}}$ emissions of $0.073 \mathrm{~g} / \mathrm{mile}$ ).

- Regardless of use-stage assumptions, the $3 \mathrm{XV}$ prototypes will have higher lifetime PM emissions because of the substantial contribution of the E\&MP stage. Whether total $\mathrm{NO}_{\mathrm{X}}$ and $\mathrm{CO}$ emissions increase or decrease depends on the use-stage assumptions.

- Emissions of GWP gases, PM, and $\mathrm{NO}_{\mathrm{X}}$ will shift somewhat from urban areas to rural areas.

In summary, both the P2000 and ESX2 prototypes are less environmentally burdensome than current vehicles, with major gains made in energy consumption and GWP. However, substantial increases in every output, with the exception of $\mathrm{CO}$, in the extraction and materials processing stage are noteworthy. In some cases, the improvements being achieved in the use stage are being partly or totally offset by the extraction and materials processing life-cycle stage. The environmental impacts of aluminum extraction and processing are a primary cause of this. The $\mathrm{SF}_{6}$ increases in both the extraction and manufacturing stages (related primarily to magnesium) and potential increases in $\mathrm{NO}_{\mathrm{X}}$ and $\mathrm{PM}$ are worrisome environmental issues.

\section{E.7 Summary Conclusions and Research Needs}

The analyses address the various infrastructure, environmental, and acceptability issues that might be associated with two prototype $3 \mathrm{XV}$ s to determine whether there exist impediments to vehicle production, vehicle use, or market penetration.

In short, what is required to produce the materials for the vehicles - the raw materials and the production capacity — are available for most alternative materials. In cases where production capacity must be increased, capital investment requirements appear manageable for the respective industry. However, the huge increase in lithium production is potentially problematic, as are prices for some lightweight materials, e.g., aluminum and titanium. Since the program aims to have $3 \mathrm{XVs}$ maintain current prices, it is important to determine how low the prices of new lightweight materials have to be to achieve the vehicle-price goals.

There appear no major issues related to vehicle repair and insurance-two significant infrastructures that support vehicles during their use. However, vehicle repair and insurance costs may be noticeably higher for consumers, especially in the early years of $3 \mathrm{XV}$ introduction.

When examining issues that could affect consumers' acceptability of the vehicles, and thus affect their ability to penetrate the market, no certain showstoppers are 
found. However, there is a possibility that consumers will have serious concerns about the safety of the vehicles, an issue that by itself, or in tandem with several other less significant acceptability issues, could affect consumers' willingness to venture into a new technological market. Future research could reduce the uncertainty in this area. Research focusing on the acceptance of these vehicles would examine how consumers trade-off sticker price for life-cycle costs when purchasing the vehicles, would determine how low the prices of $3 \mathrm{XVs}$ need to be to have them penetrate the market successfully, and would determine if an accumulation of acceptability issues will threaten $3 \mathrm{XVs}$ ' ability to gain market share.

With high rates of vehicle recycling occurring currently, and even higher rates likely, $3 \mathrm{XVs}$ will affect the recycling industry. Each component of the industry stands to experience an increase in its profitability if a number of technical challenges, ranging from improving disassembly to recycling PET, are met.

Examining the $3 \mathrm{XV}$ prototypes potential environmental impacts over the vehicle's lifetime shows that there are positive environmental effects, including significant reductions in GWP and energy consumption. However, the new materials and the diesel-fueled engines will contribute to notable increases in $\mathrm{SF}_{6}, \mathrm{NOx}$, and particulate matter emissions. Negative effects, i.e., an increased environmental burden, occurs for most inputs and outputs in the extraction and materials processing life-cycle stage It is deemed necessary, therefore, to examine ways to reduce those outputs that have significant increases. 


\section{INTRODUCTION}

The Partnership for a New Generation of Vehicles (PNGV) program is working to produce vehicles that will reduce fuel consumption by two-thirds while maintaining price, comfort, safety and performance comparable to current mid-size vehicles. Under this program, Ford and DaimlerChrysler have developed prototype vehicles, the P2000 and the ESX2, respectively. To achieve the fuel consumption goals, these vehicles substitute lightweight materials for heavier materials such as steel and iron that currently dominate the composition of automobile components. These PNGV vehicles combine significant weight reductions with other engineering changes to achieve significant improvements in fuel economy. Adopting these designs on a largescale basis would require both a supporting infrastructure to produce both the substitute materials and automobile components made of them. Large-scale adoption could also have implications for systems that support automobile use, such as repair and insurance.

What major obstacles exist to the production and large-scale use of lightweight, fuel-efficient PNGV vehicles? This report identifies infrastructure, acceptability, and life-cycle issues associated with the transitioning to these vehicles (referred to as $3 \mathrm{XVs}$ because of the PNGV goal of improving current fuel efficiency by a factor of three).

In previous years, Oak Ridge National Laboratory (ORNL) has conducted analyses of supporting infrastructure issues using hypothetical, maximum material substitution scenarios (Das et al. 1997, 1999). Aluminum and glass-reinforced composites, because they were likely choices for large-scale substitutions, were the materials on which previous analyses focused. With the development of prototype vehicles, there exists specific data from which to derive $3 \mathrm{XV}$ material requirements. Accordingly, this year's analysis is based on the material requirements of the $3 \mathrm{XV}$ prototypes and includes aluminum and plastics as well as other, less predominate substitute materials (e.g., Lexan and lithium). Also employed in this year's analysis are new market penetration projections that suggest a more rapid penetration rate, potentially hastening the transition and attendant infrastructure demands. The subsections of this chapter introduce the prototype $3 \mathrm{XVs}$, present the projected market penetration of $3 \mathrm{XVs}$, and address the material requirements of $3 \mathrm{XVs}$.

The subsequent chapters of this report present the analyses. Chapters 2 and 3 focus on materials issues. Chapter 2 addresses material availability and production issues. For each substitute material-magnesium, carbon fiber, glass fiber, polyethylene terepthalate (PET), composites, aluminum, titanium, polycarbonate (Lexan), and lithium - the analyses determines the adequacy of the supply of raw materials and the production capacity, looking for potential problems. The third chapter addresses materials from the standpoint of their recyclability and the bearing their use will have on the existing recycling industry. The analysis addresses three distinct processors in the industry-dismantlers, shredders, and non-ferrous separators-evaluating the ease of recyclability and new materials effects on the net revenues of the three types of processors.

Chapter 4 considers issues of $3 \mathrm{XV}$ use and repair. Using industry representatives as primary sources, the section examines how readily the repair and insurance industries can accommodate the transition to $3 \mathrm{XVs}$, and how $3 \mathrm{XV}$ ownership might differ from current vehicle ownership. 
Issues of public acceptability are explored in Chapter 5. Interviews with automobile dealers and literature about consumer acceptance of new automotive and other technologies inform the discussion. Adopting the perspective of the consumer, the chapter focuses on issues of safety, first-costs, and motivations for purchasing $3 \mathrm{XVs}$.

The sixth chapter is a detailed life-cycle analysis of the two prototype vehicles. The analysis focuses on five input and output types. The inputs considered are the primary materials and energy. Output types considered are the products, air emissions, and solid waste generated. The four life-cycle stages examined are extraction and materials processing, manufacturing, use, and end-of-life.

The final chapter discusses the implications of the findings of the analyses reported in the separate chapter. It considers how the findings relate to each other and addresses potential next steps in the analysis.

\subsection{P2000 Prototype 3XV}

P2000 is an all-new, aluminum, 1.2-liter direct injection, aluminum, through-bolt assembly compression-ignition engine by Ford, which represents a giant advance toward the production of lightweight, environmentally responsible vehicles. The design is a spin-off of currently available Contour Mystique. This vehicle achieves an outstanding economy of 63 miles per gallon (mpg) and emissions levels expected to be the lowest among compression-ignition direct injection vehicles. The through-bolt design is the enabling technology that allows Ford to build a diesel engine block in aluminum. The driveable, next-generation P2000 is a midsize vehicle, about the same as today's Taurus, yet weighs 40 percent less, about 2000 pounds. Three different types of drivetrains are being planned-one conventional and two hybrids. One hybrid is an electric hybrid-powered version similar to the Prodigy HEV. A fuel-cell version of the P2000 is expected by 2000 . The fuel-cell vehicle will use liquid or compressed hydrogen and oxygen from the atmosphere to generate electricity to power the vehicle's motor. Ford's P2000 could use one of two propulsion systems, a low storage requirement powertrain or a post transmission hybridboth of these using lead-acid batteries. Fuel economy projections are estimated to be 59-68 mpg in city and about 70 mpg on highways (Bucholz 1997).

Aluminum is the major lightweight material included in P2000, used for the major components of the body and engine. The car's aluminum body ( $875 \mathrm{lbs}$.) builds on the Ford-Alcan Aluminum Corporation's Aluminum Intensive Vehicle pilot program. The chassis materials include titanium, tubular steel, polypropylene, carbon fiber, and metal matrix composites. The $11 \mathrm{lbs}$. of titanium in P2000 include hundreds of 0.02-lb nuts, replacing 0.035-lb zinc-coated steel nuts, resulting in a $43 \%$ weight reduction for the category of parts. P2000 represents the largest demonstration of magnesium parts ever on a single vehicle. Its magnesium applications include 77 components 
(Bucholz 1997). 2 Compared with today's midsize vehicle containing more than $2000 \mathrm{lbs}$. of steel, P2000 contains only about 500 lbs. of steel.

\subsection{ESX2 Prototype 3XV}

The Dodge Intrepid ESX2 concept car, designed by Chrysler, approaches most of the technical and performance targets set by PNGV. It uses a diesel-electric hybrid approach to meet future environmental targets and achieve $70 \mathrm{mpg}$. ESX2 is the follow-up of the earlier 1996 Dodge Intrepid ESX sports-sedan concept car - the automaker's first attempt at building a hybrid diesel/electric vehicle — which was estimated to have a fuel economy of $55 \mathrm{mpg}$. It combines a 1.5-liter, 3-cylinder direct-injected diesel with an advanced lead-acid battery to achieve its high fuel efficiency. Its design is based on the Chrysler Composite Vehicle (CCV) and Chrysler's Prowler, by combining an injection-molded composite body with a lightweight aluminum chassis, resulting in a family sedan that is 35 percent lighter than the 1998 Intrepid. ESX2 uses the "mybrid" or mild hybrid concept. Hybrid electric vehicles rely on two sources of power, usually (1) a combustion engine and (2) an energy storage device, such as advanced batteries and an electric motor. In traditional hybrid setups, the two energy sources can simultaneously power the car or take turns powering the vehicle so it operates more efficiently. Chrysler's "mybrid" approach uses a small battery to power accessories and provide a boost during hard acceleration, such as a 40-60 mph passing maneuver. The engine is still the prime mover, to minimize the cost and weight of the battery and electric motor. Because of the new hybrid technology, Chrysler estimates that it would add about $\$ 15,000$ to the price of a vehicle.

The ESX2 weighs 2,250 lbs. The full body is made up of six large thermoplastic polyester panels,, compared to approximately 80 steel pieces in today's Dodge Intrepid. The lightweight body material cuts the body weight in half, thereby reducing the needed powertrain size and overall vehicle cost. The design intent is to mold-in-color (MIC) both exterior and interior pieces, which has the potential to eliminate the $\$ 350$ million investment for an assembly paint shop. The aluminum frame supports the plastic body and hybrid propulsion system. The powertrain is made of iron block with aluminum cylinder heads. The hybrid powertrain is 150 pounds heavier than a conventional powertrain primarily because of the 133-pound battery pack. In addition, 75 pounds of aluminum are placed between the inner and outer plastic panels to help meet side impact regulations.

\footnotetext{
${ }^{2}$ Magnesium components include the jack, hood hinge, decklid hinge, seat-bottom assembly, seat-back assembly, windshield wiper arms, front wiper motor, engine cover, intake manifold, oil pan, water pump, starter assembly, spare tire rim, wheel, transmission assembly, clutch housing, clutch pedal, steering column and shaft, steering wheel, alternator, and radio (Bucholz 1997).

${ }^{3}$ The themoplastic polyester is polyethylene terepthalate (PET), which is the same material found in plastic beverage bottles.
} 


\subsection{Projected Market Penetration of 3XVs}

Projected vehicle sales by year are provided in Table 1. Light-duty vehicles include passenger cars, class-1 light-duty trucks, and class-2 light-duty trucks. Total new light-duty vehicle sales estimates are based on projections by the Energy Information Administration (EIA 1998). Lightduty vehicle sales are projected to increase annually 0.6\% during the 1996-2020 period, increasing from 15.58 million vehicles in 2005 to 17.49 million vehicles by the year 2020 . Although initial $3 \mathrm{XV}$ prototypes are targeted at mid-size sedans, actual production of $3 \mathrm{XVs}$ is anticipated to include all light-duty vehicles. Material composition of all light-duty vehicles is assumed to correspond to average material composition of a domestic automobile considered here. We assume that initial production volumes of $3 \mathrm{XVs}$ are limited to the domestic market only and are within the range for the introduction of new models.

Table 1. Projected vehicle sales and 3XVs' market share, by year

\begin{tabular}{|c|c|c|c|c|}
\hline \multirow[b]{2}{*}{ YEAR } & \multirow{2}{*}{$\begin{array}{c}\text { Vehicle Sales } \\
(\mathrm{M})\end{array}$} & \multicolumn{3}{|c|}{ Market Share (\%) } \\
\hline & & High & Mid & Low \\
\hline 2005 & 15.58 & 0.2 & 0.0 & 0.11 \\
\hline 2006 & 15.83 & 1.6 & 0.0 & 0.83 \\
\hline 2007 & 16.02 & 3.0 & 0.1 & 1.27 \\
\hline 2008 & 16.25 & 4.7 & 0.3 & 1.98 \\
\hline 2009 & 16.46 & 10.7 & 0.6 & 3.36 \\
\hline 2010 & 16.65 & 17.1 & 1.0 & 5.26 \\
\hline 2011 & 16.70 & 22.60 & 1.6 & 6.63 \\
\hline 2012 & 16.87 & 26.20 & 2.4 & 7.65 \\
\hline 2013 & 17.03 & 29.00 & 3.7 & 8.65 \\
\hline 2014 & 17.10 & 32.60 & 5.8 & 10.46 \\
\hline 2015 & 17.15 & 34.20 & 9.0 & 11.47 \\
\hline 2016 & 17.12 & 36.40 & 13.0 & 12.72 \\
\hline 2017 & 17.24 & 37.40 & 17.0 & 13.97 \\
\hline 2018 & 17.38 & 38.30 & 21.0 & 15.22 \\
\hline 2019 & 17.51 & 39.30 & 25.0 & 16.47 \\
\hline 2020 & 17.49 & 40.30 & 29.0 & 17.72 \\
\hline 2021 & 17.65 & NA & 33.7 & NA \\
\hline 2022 & 17.75 & NA & 38.4 & NA \\
\hline 2023 & 17.85 & NA & 43.1 & NA \\
\hline 2024 & 17.95 & NA & 47.8 & NA \\
\hline 2025 & 18.06 & NA & 52.5 & NA \\
\hline 2026 & 18.16 & NA & 56.6 & NA \\
\hline 2027 & 18.26 & NA & 58.7 & NA \\
\hline 2028 & 18.36 & NA & 59.5 & NA \\
\hline 2029 & 18.46 & NA & 59.8 & NA \\
\hline 2030 & 18.56 & NA & 60.0 & NA \\
\hline
\end{tabular}


The penetration rates assumed here are based on the Quality Metrics'99 (DOE 1997), conducted annually by the U.S. DOE Office of Energy Efficiency (EE) and Renewable Energy (RE) to assess the energy and environmental benefits potential of EE/RE programs. Using a vehicle size/ consumer choice model (Maples 1998), Quality Metrics estimates market penetrations of four light-vehicle classes based on consumers' stated preferences. The model forecasts, to the year 2020, the future sales of conventional and alternatively fueled light vehicles by size class, technology, and fuel type. Of the six different technology characterizations considered by the model - conventional, advanced diesel, natural gas, flexible alcohol, hybrid, and fuel cell —only the last two types are addressed in this report. The "low" penetration case used in this analysis is from Quality Metrics '99, but the penetration rate during the last five years of the forecast period was modified to reflect an increasing market share that would be driven by continued lower price trends resulting from economies of scale. The "high" penetration case assumes that there are only two technologies - fuel cell and hybrid - competing against the conventional technology, instead of five competing technologies considered under the low penetration case. As shown in Table 1, the maximum penetration of $3 \mathrm{XVs}$ by the end of forecast period under the low case is less than half that under the high case (i.e., $17.72 \%$ vs. $40.3 \%$ ). The low penetration rate case is always lower than the high penetration case, even during the initial years. The growth in the penetration rate under the low case is almost linear, compared to an S-curve for the high case (See Figure 1). Both Quality Metrics-based market-penetration cases are relatively aggressive compared to those considered in the earlier studies (Das et al. 1997, 1999).

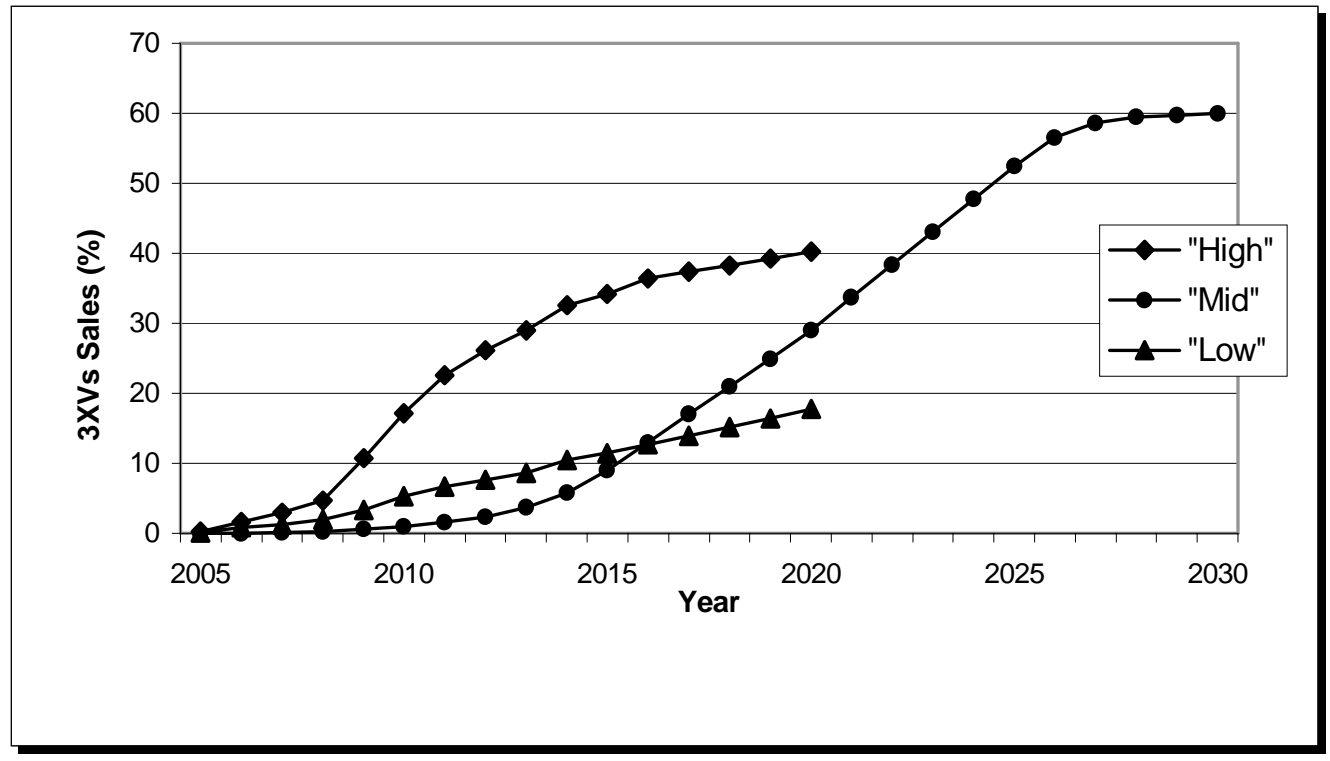

Figure 1. Market Penetration Rates for 3XVs (2005 - 2030)

The "high" scenario of the earlier studies (Das et al. 1997, 1999) had a forecast period extending to 2030, whereas the forecast period for Quality Metrics '99 extends only to 2020. For comparison purposes, the "high" scenario of the previous studies was also included. This scenario (hereafter referred to as "Mid" scenario) was also used as one of the scenarios by Argonne National Laboratory (ANL) in their Phase 2 PNGV fuels infrastructure study (Wang et al. 1998). Under this scenario, 3 XVs account for $0.1 \%$ of U.S. light-duty vehicle production in 
2007 and increase to $60 \%$ by 2030. It is a modified version of the mid-case scenario established for the "Car Talk" (Resolve Inc. 1995). Compared with historical experience of introducing radical new automotive technologies such as front wheel drivetrain and weight reductions, this scenario's market penetration is moderate. For example, the U.S. market share of front-wheel drivetrain vehicles increased between 1976 and 1992 from virtually 0 to $80 \%$ of new passenger cars. Compared to other two scenarios, the "Mid" scenario is even less aggressive than the "low" scenario until 2015 at which point its market penetration rate lies between the Quality Metrics '99 high- and low-penetration rates (see Figure 1).

\subsection{Material Composition: Base and Prototype 3XVs}

Table 2 shows the material composition of the base vehicle (considered here to be the 1994 model year) and the two scenarios considered in this study. Both scenarios indicate considerable progress towards the PNGV goal of reducing vehicle mass by $40 \%$, more so in the case of P2000 with a weight reduction potential of $38 \%$. Both scenarios contain higher amount of various nonmetals, however P2000 is aluminum intensive, whereas ESX2 is composite intensive. The amount of PET in ESX2 is assumed to be 340 lbs., included in the "plastics" category in Table 2. The use of wrought aluminum increases under both scenarios and is about $890 \%$ higher in P2000. In general, with the exception of aluminum, ESX2 contains a higher amount of nonferrous materials - plastics, magnesium, titanium, and glass and carbon fibers-than the P2000. Lexan (commonly known as "polycarbonates") and carbon fibers are not used in automobiles today, but both are projected to be used in the P2000 and ESX2. Although development of lithium-ion batteries is still in its infancy, it is likely that they will be the batteries of choice for any future operating hybrid vehicle on the road. The amount of lithium assumed for batteries in both scenarios is $30 \mathrm{lbs}$.

Since both of the P2000 and ESX2 are concept vehicles, information about the material composition of various subsystems is very limited and not readily available. However, some approximate usage estimates by different material forms is available and are shown on Table 3 . As one would expect, there is a significant decline in the usage of ferrous sheet materials under both scenarios. The increase in aluminum usage in P2000 is mainly in the form of sheet used for body structures, whereas in ESX2 aluminum occurs mainly in forged parts. The use of magnesium continues to be in the form of castings under both scenarios. The maximum usage of titanium by ESX2 is equally distributed between forged and sheet parts.

\subsection{Material Requirements}

The material and infrastructure requirements for $3 \mathrm{XVs}$ are a product of the additional quantity of lightweight material required per vehicle (Table 2), projections of annual sales of new light-duty vehicles, and penetration rates of $3 \mathrm{XVs}$ (Table 1). 
Table 2. Material composition scenarios for PNGV infrastructure (lbs. and change from 1994 vehicle)

\begin{tabular}{|l|c|c|c|}
\hline \multicolumn{1}{|c|}{ Material } & $\mathbf{1 9 9 4}$ & P2000 & ESX2 \\
\hline \hline Plastics & 223 & $251(+13 \%)$ & $485(+117 \%)$ \\
\hline Wrought Aluminum & 47 & $462(+883 \%)$ & $330(+602 \%)$ \\
\hline Cast Aluminum & 159 & $271(+70 \%)$ & $120(-25 \%)$ \\
\hline Magnesium & 6 & $86(+1333 \%)$ & $122(+1933 \%)$ \\
\hline Titanium & 0 & $11(\mathrm{NA})$ & $40(\mathrm{NA})$ \\
\hline Ferrous & 2168 & $490(-77 \%)$ & $528(-76 \%)$ \\
\hline Rubber & 138.5 & $123(-11 \%)$ & $148(+7 \%)$ \\
\hline Glass & 96.5 & $36(-63 \%)$ & $70(-27 \%)$ \\
\hline Lexan & 0 & $30(\mathrm{NA})$ & $20(\mathrm{NA})$ \\
\hline Glass Fiber & 19 & $19(0 \%)$ & $60(+216 \%)$ \\
\hline Carbon Fiber & 0 & $8(\mathrm{NA})$ & $24(\mathrm{NA})$ \\
\hline Lithium & 0 & $30(\mathrm{NA})$ & $30(\mathrm{NA})$ \\
\hline Other & 391 & $223(-43 \%)$ & $303(-23 \%)$ \\
\hline \hline \multicolumn{1}{|c|}{ Total Wt. (Lbs) } & $\mathbf{3 2 4 8}$ & $\mathbf{2 0 1 0}(-\mathbf{3 8 \%})$ & $\mathbf{2 2 5 0}(-\mathbf{- 3 1 \%})$ \\
\hline
\end{tabular}

Note: Numbers inside parenthesis indicate changes in composition from the 1994 vehicle

Table 3. Forms of major materials used by $3 \mathrm{XV}$ prototypes and base vehicle (lbs.)

\begin{tabular}{|l|r|r|r|r|r|r|r|r|r|r|r|r|}
\hline \multirow{2}{*}{ Form } & \multicolumn{3}{|c|}{ Ferrous } & \multicolumn{3}{c|}{ Aluminum } & \multicolumn{3}{c|}{ Magnesium } & \multicolumn{3}{c|}{ Titanium } \\
\cline { 2 - 15 } & $\mathbf{1}$ & $\mathbf{2}$ & $\mathbf{3}$ & \multicolumn{1}{c|}{$\mathbf{1}$} & $\mathbf{2}$ & $\mathbf{3}$ & $\mathbf{1}$ & $\mathbf{2}$ & $\mathbf{3}$ & $\mathbf{1}$ & $\mathbf{2}$ & $\mathbf{3}$ \\
\hline Sheet & 1628 & 102 & 178 & 47 & 417 & 60 & 0 & 0 & 0 & 0 & 8 & 20 \\
\hline Casting & 298 & 174 & 190 & 159 & 271 & 120 & 6 & 86 & 122 & 0 & 0 & 0 \\
\hline Extruded & 0 & 0 & 0 & 0 & 27 & 60 & 0 & 0 & 0 & 0 & 0 & 0 \\
\hline Forged & 22 & 59 & 160 & 0 & 18 & 210 & 0 & 0 & 0 & 0 & 0 & 20 \\
\hline Machined & 220 & 155 & 0 & 0 & 0 & 0 & 0 & 0 & 0 & 0 & 3 & 0 \\
\hline \hline Total & $\mathbf{2 1 6 8}$ & $\mathbf{4 9 0}$ & $\mathbf{5 2 8}$ & $\mathbf{2 0 6}$ & $\mathbf{7 3 3}$ & $\mathbf{4 5 0}$ & $\mathbf{6}$ & $\mathbf{8 6}$ & $\mathbf{1 2 2}$ & $\mathbf{0}$ & $\mathbf{1 1}$ & $\mathbf{4 0}$ \\
\hline
\end{tabular}

Note: 1: Base Vehicle 2: P2000 3: ESX2

Table 4 reports the estimates of annual material requirements of $3 \mathrm{XVs}$ for various years. We have adjusted the conventional vehicle's requirements for lightweight materials to account for vehicle fuel economy improvements that are likely to occur in the absence of $3 \mathrm{XVs}$. This "adjusted" vehicle is referred to as the base vehicle. We assume a $0.2 \%$ per year increase in fuel economy of the base vehicle during the PNGV penetration period (EIA 1998) and calculate weight reductions by employing historical data suggest that a $10 \%$ total vehicle weight reduction yields a 5\% increase in fuel economy (EEB 1992). Reductions in total weight of the base vehicle are assumed to result from materials substitution that maintains the current proportional use per vehicle of that material-aluminum, glass-reinforced composites, and magnesium. Increases in 
lightweight material content are estimated using the replacement factors for the substitution of lightweight

Table 4. Lightweight material requirements for PNGV, 2005-2030 (in '000 tonnes)

\begin{tabular}{|c|c|c|c|c|c|c|c|c|c|c|c|c|}
\hline \multirow[t]{2}{*}{ MATERIAL } & \multicolumn{2}{|c|}{2005} & \multicolumn{2}{|c|}{2010} & \multicolumn{2}{|c|}{2015} & \multicolumn{2}{|c|}{2020} & \multicolumn{2}{|c|}{2025} & \multicolumn{2}{|c|}{2030} \\
\hline & P2000 & ESX2 & P2000 & ESX2 & P2000 & ESX2 & P2000 & ESX2 & P2000 & ESX2 & P2000 & ESX2 \\
\hline Plastics & $\begin{array}{l}0.02- \\
0.04\end{array}$ & $2-3$ & 0 & $\begin{array}{l}89- \\
288\end{array}$ & 0 & $\begin{array}{l}187- \\
556\end{array}$ & 0 & $\begin{array}{l}274- \\
624\end{array}$ & 0 & 778 & 0 & 843 \\
\hline Glass Fiber & 0 & $\begin{array}{l}0.3- \\
0.6\end{array}$ & 0 & $\begin{array}{l}15- \\
49\end{array}$ & 0 & $\begin{array}{l}33- \\
98\end{array}$ & 0 & $\begin{array}{l}50- \\
114\end{array}$ & 0 & 148 & 0 & 168 \\
\hline Carbon Fiber & $\begin{array}{l}0.06- \\
0.10\end{array}$ & $\begin{array}{l}0.2- \\
0.3\end{array}$ & $3-10$ & $\begin{array}{l}10- \\
31\end{array}$ & $7-21$ & $\begin{array}{l}21- \\
64\end{array}$ & $\begin{array}{l}11- \\
26\end{array}$ & $\begin{array}{l}34- \\
77\end{array}$ & 34 & 103 & 40 & 121 \\
\hline $\begin{array}{l}\text { Cast } \\
\text { Aluminum }\end{array}$ & $1-2$ & 0 & $\begin{array}{l}36- \\
117\end{array}$ & 0 & $\begin{array}{l}74- \\
220\end{array}$ & 0 & $\begin{array}{l}105- \\
239\end{array}$ & 0 & 289 & 0 & 300 & 0 \\
\hline $\begin{array}{l}\text { Wrought } \\
\text { Aluminum }\end{array}$ & $3-6$ & $2-4$ & $\begin{array}{l}162- \\
528\end{array}$ & $\begin{array}{l}110- \\
357\end{array}$ & $\begin{array}{l}363- \\
1081\end{array}$ & $\begin{array}{l}245- \\
729\end{array}$ & $\begin{array}{l}567- \\
1291\end{array}$ & $\begin{array}{l}382- \\
868\end{array}$ & 1725 & 1157 & 2014 & 1346 \\
\hline Magnesium & $\begin{array}{l}0.6- \\
1.1\end{array}$ & $1-2$ & $\begin{array}{l}32- \\
103\end{array}$ & $\begin{array}{l}46- \\
150\end{array}$ & $\begin{array}{l}71- \\
212\end{array}$ & $\begin{array}{l}103- \\
308\end{array}$ & $\begin{array}{l}112- \\
254\end{array}$ & $\begin{array}{l}162- \\
370\end{array}$ & 341 & 496 & 400 & 582 \\
\hline Titanium & $\begin{array}{l}0.1- \\
0.2\end{array}$ & $\begin{array}{l}0.3- \\
0.6\end{array}$ & $4-14$ & $\begin{array}{l}16- \\
52\end{array}$ & $\begin{array}{l}10- \\
29\end{array}$ & $\begin{array}{l}36- \\
107\end{array}$ & $\begin{array}{l}15- \\
35\end{array}$ & $\begin{array}{l}56- \\
128\end{array}$ & 47 & 172 & 56 & 202 \\
\hline Lexan & $\begin{array}{l}0.2- \\
0.4\end{array}$ & $\begin{array}{l}0.2- \\
0.3\end{array}$ & $\begin{array}{l}12- \\
39\end{array}$ & $8-26$ & $\begin{array}{l}27- \\
80\end{array}$ & $\begin{array}{l}18- \\
53\end{array}$ & $\begin{array}{l}42- \\
96\end{array}$ & $\begin{array}{l}28- \\
64\end{array}$ & 129 & 86 & 152 & 101 \\
\hline Lithium & $\begin{array}{l}0.2- \\
0.4\end{array}$ & $\begin{array}{l}0.2- \\
0.4\end{array}$ & $\begin{array}{l}12- \\
39\end{array}$ & $\begin{array}{l}12- \\
39\end{array}$ & $\begin{array}{l}27- \\
80\end{array}$ & $\begin{array}{l}27- \\
80\end{array}$ & $\begin{array}{l}42- \\
96\end{array}$ & $\begin{array}{l}42- \\
96\end{array}$ & 129 & 129 & 152 & 152 \\
\hline
\end{tabular}

materials for ferrous materials (e.g., $x$ pounds of substitute material replaces $y$ pounds of ferrous). It is estimated that due to low forecasted improvements in fuel economy (i.e., $0.2 \%$ per year) the base vehicle in 2020 will contain about 200 lbs. less ferrous materials, but 37 lbs. and 12 lbs. more of cast and wrought aluminum, respectively.

The material requirements estimates are reported in the form of a range through year 2020 (Table 4 ), with the lower- and upper-end values corresponding to the "low" and "high" penetration rates of 3XVs. After 2020, a single estimate of material requirements based on the "mid" scenario is provided. The maximum material requirements in 2020 as compared to 1997 U.S. total consumption are shown in Figure 2. Except for lithium and carbon fiber, all other material requirements (even for 2020) are considerably lower than the current U.S. total consumption. During the early years of PNGV, the lightweight material requirements are low because of the low penetration rates assumed for $3 \mathrm{XVs}$ in the automobile market. Lightweight material requirements are highest for wrought aluminum under the P2000 scenario during the entire forecast period-reaching a maximum level of 1,291 thousand tonnes by the year 2020. There are three instances, i.e., plastics and glass fiber for P2000 and cast aluminum for ESX2, where there are no additional material requirements for PNGV. The increase in material requirements for $3 \mathrm{XVs}$ is not as great as those for base vehicles due to the anticipated fuel efficiency improvements. For example, an increase of approximately 13\% in plastics usage in P2000 is forecasted (Table 2), which is low compared to that estimated for the base vehicle even by the year 2005. In the subsequent chapters while examining the infrastructure issues related to lightweight materials supply, the upper-end values are usually considered, irrespective of the scenarios. It is most appropriate since they represent the most conservative scenarios for the material supply requirements. 


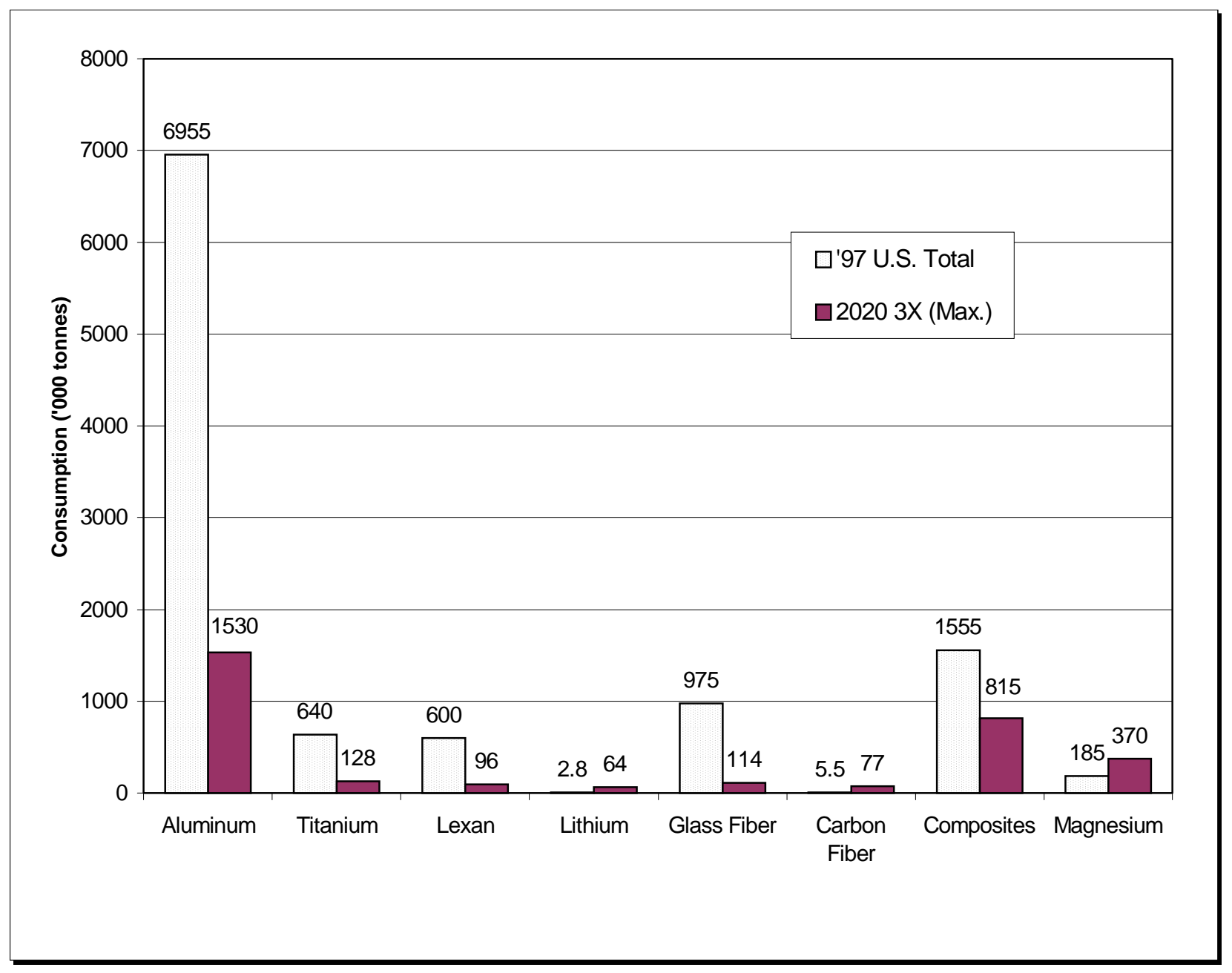

Figure 2. Lightweight Material Requirements for 3XVs in 2020, Compared to 1997 U.S. Consumption 


\section{MATERIALS AVAILABILITY AND PRODUCTION ISSUES}

The purpose of this study was to determine any issues surrounding the use of certain materials in $3 \mathrm{XV}$ s. All primary potential replacement materials were studied, as were some major secondary materials. The materials examined are magnesium, carbon fiber, glass fiber, PET, composites, aluminum, titanium, polycarbonate (Lexan), and lithium. To determine the maximum impact, each assessment focuses on the scenario that would result in the greatest demand for the material, namely high penetration of the $3 \mathrm{XV}$ that uses the most of that particular material.

\subsection{Magnesium}

The use of magnesium in either of the $3 \mathrm{XVs}$ considered here is projected to be considerably higher-in the range of 80-122 lbs./vehicle - than the $6 \mathrm{lbs}$. per vehicle currently used. The maximum usage of $122 \mathrm{lbs} . /$ vehicle is projected to be for ESX2. Considering the maximum magnesium usage and the high-penetration case, its annual requirements are estimated to increase from 1,639 tonnes in 2005 to 307,874 tonnes in 2015, and almost 369,541 tonnes by 2020. By the end of 2030, its annual requirements are estimated to be about 1.6 times higher than in 2020. The 3 XV requirement for about 370,000 tonnes/year of magnesium by the year 2020 is $100 \%$ greater than the estimated U.S. current consumption level of 185,000 tonnes/year. The U.S. consumption would grow by $3 \%$ annually to meet the 2020 requirements, or $3.5 \%$ annually to meet the requirements in 2030.

Magnesium is recovered from seawater, well and lake brines, and bitterns, as well as from minerals such as magnesite, dolomite, and olivine. Resources from which magnesium may be recovered range from large to virtually unlimited and are globally widespread. Magnesiumbearing brines are estimated to constitute a resource in billions of tons, and magnesium can be recovered from seawater at places along world coastlines where salinity is high. Domestic magnesium metal production is derived from natural brines and dolomite (high-purity dolomite deposits are found in many states in the United States), and reserves of this metal are sufficient to supply current and future $3 \mathrm{XV}$ requirements. The availability of magnesium from the raw material point of view appears to be no major concerns.

The United States has been the world's largest producer of metallic magnesium since World War II, and in most years since then, it has been a net exporter of magnesium. It continues to lead the world in production and production capacity of primary magnesium, with about $39 \%$ of the world production, and about $28 \%$ of total world production capacity.

With cheap sources of magnesium (e.g., from Commonwealth of Independent States [CIS]) available in the world market since early 1990s, U.S. magnesium imports have quadrupled in five years, from 11,800 tonnes in 1992 to 46,600 tonnes in 1996 (USGS 1998). The U.S.

consumption of imported magnesium increased from $25 \%$ in 1993 to $35 \%$ in 1997. It is projected that there will be more than sufficient capacity to meet the future demand but all of potential greenfield capacity additions-about 350,000 tonnes per year between 1995 and 2005 are planned outside the United States (CRU 1996). In addition, most of these capacity additions are linked with the alliances being formed between auto manufacturers and magnesium producers. 
Examples are VW's interest in the Dead Sea plant, Toyota's interest in the Magnola project, Ford's agreement with Australian Magnesium Corporation, General Motor's multi-year agreement with Hydro Magnesium, as well as its reported supply arrangement with the Russian producer, Solikamsk. These multi-year contracts provide a secure steady supply of magnesium from a reliable source. Planned brownfield capacity expansions in the United States are relatively small and will increase domestic production by 35,000 tonnes annually during the period 19952005 (CRU 1996). The production shift to outside the United States is mainly due to either a low-cost energy source, or rich ore deposit locations. Thus, it is likely that future magnesiumproduction capacity additions necessary to meet the demand for 3XVs will come from outside the United States. Major supply sources may include Israel, Australia, Norway, Canada, China, and the CIS. Although there is concern about adequate domestic supply of magnesium ingots, once the material is available, formal supply arrangements will likely assure material availability, and, more importantly, sufficient excess die casting capacity exists to process the metal into automotive components.

The capital cost of potential greenfield projects has been recently estimated to be about $\$ 10,000$ per tonne for electrolytic plants having capacities around 50,000-60,000 tonnes per year (CRU 1996). To meet the $3 X V$ requirements in the year 2020, a maximum $\$ 3.7 \mathrm{~B}$ level of investment will be necessary. This estimate does not consider that a significant portion of demand will be met by secondary production, which continues to increase, accounting for $30 \%$ of total production in 1993 and 39\% of total production in 1997 (USGS 1998). Most of the secondary production currently is used as an alloying element in aluminum can stock.

Magnesium's principal use as an alloy to aluminum accounted for $51 \%$ of domestic primary metal use in 1996; whereas, castings and wrought magnesium products accounted for $24 \%$ of U.S. consumption of primary metal (USGS 1998). About $85 \%$ of the die-casting market is automotive. Forecasted market growth is strongest in die casting, expected to be about $10 \%$ per year (CRU 1996). Due to low demand volume, the production of magnesium components is currently not well established, and this has limited the extent of the supply base. Leading suppliers of magnesium materials have taken a key part in promoting the use of magnesium components by having formal supply arrangements. For example, Norsk Hydro owns a share in Meridian Technologies - a supplier of cast products - and Scanmag, a producer of magnesium wheels.

Magnesium casting shipments accounted for about $1 \%$ of the 2 million tonnes of non-ferrous casting shipments in the United States in 1996 (DOC 1997). The capacity utilization rate of the nonferrous die-casting industry (which includes all nonferrous metals except aluminum) was estimated at $82 \%$, compared to the aluminum die-casting industry utilization rate of $77 \%$ in 1996 (DOC 1998). Magnesium die-castings can also be manufactured in existing aluminum diecasting facilities. Spartan Light Metal Products, for example, manufactures both aluminum and magnesium die-cast products. Over the years, with the market demand, the company has successfully shifted its products from aluminum to magnesium. Currently, sales of magnesium products account for $75 \%$ of sales volume, whereas, as recently as 1992 , aluminum products accounted for $75 \%$ of sales (Pinfold 1998). In 1996, there were 153 facilities capable of die casting aluminum, compared to 14 for magnesium. Lower utilization rates at aluminum die- 
casting facilities are expected to provide 183,000 tonnes of capacity for magnesium, in addition to the magnesium-specific capacity already available.

It is likely that at least a small fraction of total magnesium use in $3 \mathrm{XV}$ s will be in the wrought form, which is non-existent in today's automobile. Wrought magnesium alloy products are produced most commonly by extrusion, but rolling and press forging also are used. Magnesium is easy to form, but because of its crystal structure it must be fabricated at elevated temperatures requiring significant new equipment investments. Since hot processing is not popular with U.S. manufacturers, there is strong resistance towards the use of magnesium by the industry. Although demand will be small compared to primary magnesium metal and die casting, a new infrastructure for wrought magnesium manufacturing will be needed. Difficulty in attracting needed, skilled labor to the relatively "low-tech" metal casting industry could dampen its growth.

\subsection{Carbon Fiber}

The forecasted production of $3 \mathrm{XVs}$ could have a major impact on carbon fiber production in the United States, as well as worldwide. Forecasts of the amount of carbon fiber included in each $3 X V$ vary from 8 to 24 lbs. The Ford P2000 uses 8 lbs. of carbon fiber, while the Chrysler ESX2 uses 24 lbs. per vehicle. Given the ESX2's usage and the high penetration rate, annual requirements are estimated to increase from 340 tonnes in 2005 to 63,985 tonnes in 2015, about 77,000 tonnes by 2020 , and to 121,000 tonnes by the end of the forecast period.

Textile acrylic fibers (obtained from acrylonitrile) used in the carbon fiber production are known as precursor fibers. Approximately 2.2 units of precursor fiber produce 1 unit of carbon fiber. Precursor fiber production has been small during the first half of the decade, but growing rapidly. Carbon fiber manufacturer's quality requirements are high; therefore, almost all carbon fiber manufacturers currently produce their own precursor fibers. The cost of precursor fiber is one of the key factors contributing to the higher cost of carbon fibers today. The limited worldwide capacity of low-cost, precursor fibers necessary for low-cost, high volume commercial grade carbon fibers is based primarily in Europe and Japan; only Monsanto and Cytec produce the fibers in the United States (Prescott 1996). Nevertheless, availability of these precursor fibers is not expected to be a problem once the carbon fiber manufacturers feel confident about strong demand in the marketplace.

Assuming a 45\% yield of precursor fibers, it is estimated that by the year $20203 \mathrm{XV}$ annual demand for polyacrilonitrile precursor fibers will be approximately 171,000 tonnes. Precursorfiber production capacity in the United States totaled about 200,000 tonnes per year in 1996 (Prescott 1996). 3XV demand will require an increase of $86 \%$ above the 1996 U.S. production capacity, or an annual growth rate of $2.6 \%$. Today the four worldwide suppliers of large-tow carbon fiber buy their precursors from Courtaulds European Fibres. The availability of low-cost precursor is a big issue with the industry, and it is securing its supply through long-term arrangements. For example, Akzo Nobel and Zoltek have recently bought Courtaulds and Magyar Visoca, respectively, as their carbon fiber precursor suppliers. Depending on the type of production technology used, some of the existing textile acrylic fiber production capacity could be converted to produce precursor fibers of the quality needed for automotive applications. 3XV demand for carbon fibers is likely to stimulate large producers of low cost precursor fibers, but 
new facilities could be located outside the United States (where labor is cheaper) to achieve lower production costs. At higher production volumes, it also is likely that integrated facilitieswhere precursor and carbon fiber are both produced—may be cost effective (DeLong 1994).

Most of the carbon fiber use to date has been limited to aerospace and military applications, and increasing amounts have been used for sporting goods. Aerospace applications require premium grade fibers of tow counts $12 \mathrm{~K}$ or less with costs averaging between $\$ 26$ and $\$ 300$ per pound or higher for specialized uses. The larger tow carbon fiber $(<12 \mathrm{~K})$ has averaged $\$ 10$ to $\$ 12 / \mathrm{lb}$. in 1997. In 1992, total production of carbon fiber for the twelve major manufacturers worldwide was estimated to be 6,554 tonnes. Since then production has been on the increase, and it is estimated to have been 13,000 tonnes in 1997 (Werst 1998). At the same time, total U.S. carbonfiber production was estimated to be around 5,500 tonnes per year. About 25\% of today's global carbon fiber supply are large tow, with the majority of market penetration in the United States (HPC 1998). In comparison, this is only about $1 \%$ of the glass-fiber production level today. Only three manufacturers-Akzo Nobel and Zoltek in the United States and R. K. Carbon in the United Kingdom - have production capacity for commercial grade carbon fibers that have potential for larger volume, lower cost applications.

Although commercial-grade carbon-fiber production has been increasing rapidly worldwide, the current worldwide production capacity of 13,000 tonnes represents only a fraction of the 77,000 tonnes required for $3 \mathrm{XVs}$ in 2020 . Capacity would have to increase by $8 \%$ annually (about $7 \%$ annually for 2030) to meet $3 \mathrm{XV}$ demand. A sharp drop in demand hurt the industry in the early 1990s due to shrinking aerospace and defense markets. Since then there has been a surge in production capacity due to the burgeoning potential for commercial grade carbon fiber in highvolume infrastructure, automotive, and industrial machinery applications. Due to expansions taking place at no fewer than 11 sites worldwide, it is anticipated that worldwide capacity in all markets for all types of carbon fiber will be above 45,000 tonnes by $2000,60 \%$ of which will be of commercial grade (HPC 1998). Zoltek alone is planning to have 18,000 tonnes of commercial grade carbon fiber capacity by 2000 . The recent ramp up of production capacity indicates that it is unlikely that there will be any shortage of carbon fiber supply for $3 \mathrm{XVs}$ as long as the strong commitment by the industrial market continues. This also shows that a single new producer can boost output by a significant amount, percentages almost unheard of in other industries. Due to a small number of carbon fiber producers worldwide, the feast or famine cycle will be more prevalent in this industry in the future. In fact, tremendous recent capacity additions may cause a surplus of fibers in the post-1998 era.

Carbon-fiber manufacturing is capital intensive for the following reasons: (1) uniform high temperature processing at greater than 1,000 degrees $\mathrm{C}$; (2) costly materials of construction; (3) difficult-to-handle, reactive, toxic chemical products, i.e., acrylonitrile and cyanides; (4) custom designed, one-of-a-kind equipment; and (5) inert atmosphere during processing (DeLong 1994). Based on information on the BASF carbon fiber plant in Rock Hill, South Carolina, it is estimated that an investment of $\$ 30$ million (not including the investment required for precursor fiber) will be needed to add production capacity of 900 tonnes of fiber per year (Prescott 1996). Thus, a projected investment level of $\$ 2.6$ billion will be needed to meet the demand for carbon fibers from $3 X V$ s by the year 2015. Carbon-fiber production technology is highly automated and 
requires neither large nor highly skilled workforce. Production has to be on a continuous basis (i.e., 24 hours/day) for a cost-effective, efficient operation.

\subsection{Glass Fiber}

ESX2 is projected to have $60 \mathrm{lbs}$. of glass fiber per vehicle compared to $19 \mathrm{lbs}$. in vehicle today. The P2000 does not use any more glass fiber than the current vehicle, so 3XV demand for glass fiber will result only from the ESX2. Under the maximum penetration scenario, the projected demand for glass fibers increases from 48,910 tonnes in 2010 to 113,743 tonnes by 2020, and 168,000 tonnes by the end of forecast period.

In contrast to the carbon-fiber industry, the glass-fiber industry is both large and mature. Because of its consistent quality, low cost, easy availability, and high processability, glass fiber is currently the most widely used fiber in structural composites, accounting for $99 \%$ of all fibers used in the composites industry. The glass fibers expected to be used are lower-grade E-glass fibers that cost as much as five times less than high-performance S-glass fibers. The total worldwide market for glass fiber in composites is estimated at $\$ 4.7$ billion, with annual volume growth of 4 to 5 percent expected for at least the next several years (OFC 1998). The annual growth rate in the more established markets of North America and Western Europe if forecast to be 3 to 4 percent, compared to a 10 percent growth rate in the fastest growing Asia Pacific region. The total glass-fiber market in North America in 1997 was 975,000 tonnes and forecasted to be 1.15 million tonnes by 2001 (OFC 1998). Building construction is largest end-use market for glass-fiber composites, accounting for $35 \%$ of the market. Transportation and electrical/electronics markets follow closely, each holding $20 \%$ of the market. More than $80 \%$ of transportation-related composite materials are used in automotive applications. To meet the anticipated 3XV demand of 113,743 tonnes by 2020, the North American glass-fiber market must grow about $0.5 \%$ annually. This low growth required for $3 \mathrm{XVs}$ is significantly small compared to the anticipated overall market growth, and thereby glass-fiber supply should not be any concern for $3 \mathrm{XVs}$.

Although the long-term supply of glass fibers has not been a major concern in the industry, the industry has experienced several short-term feast and famine cycles in the past. For example, compared to the excess supply situation today, the demand for glass fiber was greater than supply between 1994 and mid-1996. The global glass industry continues to operate near full capacity due to steady growth in demand for composites. Production of glass fibers for composites is both capital intensive and technologically sophisticated, driving a heavy industry concentration. The industry has three major global producers with full product offerings-Owens Corning, Vertotex (a unit of St. Gobain of France), and PPG Industries. These three producers serve more than 60 percent of the global market, with the remainder served by a number of small regional suppliers, especially in Asia Pacific and Eastern Europe. Thus, capacity additions are in large increments and have a big lag time, causing the imbalance between supply and demand situation in the industry.

The glass industry is characterized by high fixed costs, lending itself to significant economies of scale. Based on an investment of $\$ 200 \mathrm{M}$ for production capacity of 110,000 tonnes of glass fiber per year (Leach 1995), an investment of \$207M would be needed by 2020 to meet the demand 
from 3XVs. These new production facilities may be located within the United States as well as outside the United States due to lower production cost. For example, Owens Corning, which accounts for more than $50 \%$ of the total capacity additions planned during this decade, is adding incremental furnace capacity to each of its facilities in and outside of the United States. It is also starting new furnaces, half of which would be abroad, e.g., in Brazil, Korea, and India (OFC 1996).

\subsection{Resin Matrix Material}

Only the ESX2 scenario contains a significantly higher amount of plastics than the vehicles today. The increase is driven largely by the use of PET as a body structural material. The PET content in ESX2 accounts for 340 lbs. of 485 lbs. of plastics used. Other resin materials are used in small quantities, and therefore are not considered further in the analysis. Assuming the maximum $3 \mathrm{XV}$ penetration scenario, the PET demand is projected to be 440 thousand, 1,089 thousand, and 1,721 thousand tonnes by the years 2010, 2020, and 2030 respectively. The automotive industry accounts for $3-5 \%$ of all plastics usage.

Today, about $8 \%$ of petroleum supply goes into plastics. The basic feedstocks used are naphtha (used for ethylene) and olefins (used for propylene). Although there are no raw material supply concerns for plastics, suppliers have little control over prices and there is always a possibility of large swings in price.

The domestic consumption of PET in 1997 is estimated to have been 3,396 million lbs. - the plastic bottle market accounted for $76 \%$ of the total consumption (Modern Plastics 1998). Comparatively, PET application in the transportation sector is very insignificant today. PET production has been growing at an annual compound growth rate of 13\% during the period 19861996 (SPI 1998). At a rate of 12\% per year during 1992-1996, domestic consumption growth has been comparatively slower than production growth (SPI 1998) and slower than the projected global industry compound growth rate of $15 \%$ per year to 2000 (Modern Plastics 1998). Through 1996, the industry had a high capacity-utilization rate ranging in the 90 s. Total world container resin capacity for 1997 is estimated to have been about 6 million tonnes compared to a demand level of 4 million tonnes. This excess capacity helped to keep prices down last year. It is estimated that the current domestic production needs to grow annually by $2.3 \%$ to meet the requirements of $3 \mathrm{XVs}$ in the year 2020. Thus, growth required to meet the demand of $3 \mathrm{XVs}$ is insignificant compared to the future growth anticipated by the industry.

Currently, there are small numbers of resins suppliers (less than a dozen) and end-use specifiers that dictate the market. Also, the high degree of concentration of plastic suppliers causes the supply base to be too narrow for comfort. Eastman Chemical, the world's leading supplier of PET for container packaging, plans to double its PET resin capacity (to 3.4 billion lbs./year) by 2000 (Modern Plastics 1996). It is likely that there may be shortages in the near-term due to mismatch between demand and large capacity additions by large manufacturers; however, longterm supply of PET should not be a concern for $3 \mathrm{XVs}$. 


\subsection{Composites}

Of the two prototypes, only ESX2 has significantly higher requirements for composites than current vehicles (569 lbs./vehicle vs. 242 lbs./vehicle). Maximum ESX2 requirements for composites are estimated to be 736, 1823, and 2880 thousand tonnes by the years 2010, 2020, and 2030, respectively. This estimate also includes carbon-fiber composites, which forms relatively a small share of the total requirements. The Society of the Plastics Industry's Composites Institute estimates that composites shipments in 1997 reached 1,555 thousand tonnes for a $6.1 \%$ more than 1996 and 50\% more than 1991 (CI 1998). The largest consumer of composites continues to be the transportation sector, estimated to have required 498,000 tonnes in 1997, accounting for about $32 \%$ of total shipments. A continued strong growth for the composites industry is forecasted with the renewed emphasis on energy efficient vehicles, a surging bull market, and successful commercialization of infrastructure applications. The transportation sector is estimated to grow more than 5\% per year during the coming decade. The current domestic composites shipments is sufficient to meet the requirements of $3 \mathrm{XVs}$ for 2020 alone and needs to increase to a small extent for to meet 2030 requirements. Hence, the industry growth required for $3 \mathrm{XVs}$ forms a significant share of the composites industry's forecasted growth.

The U.S. composites industry is currently valued at $\$ 24.7$ billion with about 4,300 primary processing facilities (McDermott 1998b). The number of custom plants-about $80 \%$ of the total-dominates over captive processing in the reinforced plastics sector. A recent study on the demographics of the composites industry indicates that there is sufficient capacity at all levels, but having profitable assets in the right place at the right time is a continuing challenge (McDermott 1998b). The number of companies that manufacture plastic components for the automotive industry is much less, but those that remain now tend to either to produce exclusively for or to dedicate a large proportion of their output to the car industry. Nearly all of the traditional thermoset and fiberglass suppliers are participating in worldwide consolidation of the industry, reducing the number of struggling players and extending the reach of the best technologies by either technology transfer or greenfield development. Many companies, while viable, have found they lack the critical mass to compete in the global marketplace. The demand for increased specialization and sophistication in all functions has resulted in a decline in the total number of companies and facilities whose primary business is composites processing. High tooling costs have played some part in reducing the number of processors, but the main reason has been a fundamental change in the partnership relationship between the processors and car makers. Relationships are longer-term, with suppliers becoming involved in the development stage of a component (e.g., Chrysler's Extended Enterprise approach). This partnership concept further promotes the current oligopolistic market trend. Plastic component suppliers will tend to become larger and more specialized. In some cases, manufacturers will deal with far fewer suppliers and out-sourcing will be the general trend among domestic businesses.

The ESX2 design is based on the CCV; its full body consists of six large injection molded panels made of PET. With U.S. demand for injection molded thermoplastics reaching 251,000 tonnes in 1996, injection molding is second only to the spray-up process in contributing to the total 1,474 thousand tonnes of thermoplastics (McDermott 1998a). However, in terms of number of molders, injection molding ranks the list, accounting for $28 \%$ of total 8,366 U.S. plastic molders today. 
Injection molding is well established as the benchmark for high-speed, reproducible, and clean processing technology. High investment costs, long lead times for production of molds, and the need to use complex machinery that is very large relative to the molded part are some of the drawbacks of the technology.

The current injection molding production volume needs to be doubled by 2010 to meet the ESX2 requirements. Because the ESX2 parts are large, 9000-ton molding machines using 160-ton weight molds will be necessary. Molding machines greater than 400-ton capacity are sparse. In fact, the 9000-ton capacity machine used for the CCV is the only one available in North America. Also because of the relatively large size of body structures, parts manufacturing plants will be located at or near the original equipment-manufacturing site.

The CCV design concept used for ESX2 helps to reduce the number of pieces required to produce the vehicle by $75 \%$, reducing the vehicles assembly time from 19 to 6.5 hours per car. The design also allows everything to be done in engine, stamping, and assembly plants under one roof. The assembly plant of ESX2 would be a modular, $12,000 \mathrm{ft}^{2}$ facility for a production volume of 120,000 vehicles/year-one-tenth the size needed for equivalent assembly, stamping, and engine plants (Oswald 1998). In addition to reduction in vehicle assembly time from 19 hours per car to 6.5 hours per car, plant investment is estimated to be in the range of $\$ 50$ $\$ 75 \mathrm{M}$ - about one-third of typical investment for assembly, stamping and engine plants combined (Oswald 1998).

Since large structural thermoplastic injection molded body parts are molded in color with matte finish, painting is not needed. The $\$ 350$ million investment usually required for a painting facility is not needed. The supply of primary colorants associated with MIC technology needs to be developed. Producers of primary colorants, for example, Hoechst Celanese, Holland Colors, Kerr-McGee, Cabot, and PMS Consolidated, report that they have no colorant products geared specifically to in-mold processing due to lack of demand today (Graff 1995). To date, adhesive bonding and mechanical fastening continue to face technical challenges during the vehicle assembly of composite-intensive vehicles.

\subsection{Aluminum}

Other than cost, no major supply issues were identified that could impede the use of aluminum at the levels specified. The highest demand for aluminum, 1530kt (thousand metric tonnes) in 2020 for the P2000, represents 22\% of U.S. total consumption in 1997 (Plunkert 1998). The aluminum requirements in the P2000 high-penetration scenario would increase the aluminum consumption growth rate in the United States by less than $1 \%$ per year. New smelting capacity can be added in less than four years, so that supply capacity should be able to easily absorb that increase.

The average content of aluminum in vehicles is projected to be $250 \mathrm{lb}$. in 1999 (Ducker Research Company 1998). Cast aluminum currently makes up the bulk of aluminum used in vehicles, representing $77 \%$ of the 1999 aluminum content in vehicles. The main uses of aluminum in vehicles are for engines, transmissions, wheels, and heat exchangers. Future growth areas for aluminum are in the body structure and exterior panels. These will require changes in body 
design, manufacturing processes, and/or reductions in the cost of aluminum. Aluminum and auto manufacturers have been developing the manufacturing processes to use aluminum and Audi already has an aluminum-based vehicle on the market. This vehicle, the Audi A-8, is a lowvolume luxury automobile. High volume vehicles use manufacturing processes that currently favor steel construction (Politis 1995).

Prices for aluminum sheet need to drop about $30 \%$ - from roughly $\$ 1.50 / \mathrm{lb}$. to $\$ 1.00 / \mathrm{lb}$. on a long-term basis - for it to be price-competitive in the high-volume auto market (Katrak et al. 1997). The major components of the cost of aluminum sheet are show in Table 5.

Table 5. Cost Components of Aluminum Sheet

\begin{tabular}{|l|r|}
\hline \hline Ingot & .70 \\
\hline Alloys & .02 \\
\hline Freight - Ingot & .03 \\
\hline Hot Rolling & .15 \\
\hline Cold Rolling & .27 \\
\hline Heat Treating & .30 \\
\hline Freight \& Handling - Sheet & .03 \\
\hline \hline Total & $\$ 1.50$ \\
\hline
\end{tabular}

Source: Katrak, et al. 1997

American Metal Market reported prices for ingot in early 1999 dropped to a five-year low of $56 \varnothing / \mathrm{lb}$. due to the weak international market. However, steel costs have also declined significantly. Other cost reductions will need to be made through minimization or elimination of major steps in the process. For example, heat-treating is required to strengthen certain aluminum alloys. Different alloys are being examined that may not require this process and expense. Nontraditional sheet manufacturing techniques, such as continuous casting or belt casting, may reduce the amount of hot and cold rolling required.

\subsection{Titanium}

No major issues were identified (beyond cost) that could impede the use of titanium at the levels specified. The highest demand for titanium, 128,000 tonnes in 2020 for the ESX2, represents $20 \%$ of U.S. total consumption in 1997 (Ober 1998). The industry should be able to increase capacity fast enough to supply this need.

There are three main categories of vehicle components in which titanium may compete. The most likely category is specialized parts for engines, such as valves and valve springs. Prices for titanium must drop roughly $50 \%$ or more for it to be competitive in the auto market to any significant extent. Larger components (e.g., mufflers, springs, and chassis parts) require even lower prices for titanium to penetrate (Sherman 1997). Most proposed research and development projects estimate lowering costs by around 30\%, although a few, such as plasma quench and induction melting, may provide greater savings (Hadley et al. 1998). 
Two firms that have focused their effort on supplying the high margin, but lower volume, aerospace, recreation, and other specialty fields dominate the U.S. titanium industry. Several other potential markets (military, oil drilling) would absorb increased titanium production at higher price-points before the auto market.

\subsection{Lexan}

No major issues were identified that could impede the use of polycarbonate at the levels specified. The highest demand for polycarbonate, 96,000 tonnes in 2020 for the P2000, represents no more than 10\% of world capacity in 1998 (Plastic Distributor and Fabricator 1998). The industry should be able to increase capacity fast enough to supply this need.

Polycarbonate is currently available as windows for specialty vehicles (e.g., golf-carts, quad-allterrain vehicles, rebuild car kits). It is also used as lens covers in some high-end automobiles. However, inadequate scratch-resistance (impairing visibility) and excessive flexibility (making side windows difficult to roll up while the car is moving) may limit their use in high-production vehicles. Specialized coatings may alleviate the scratchability issue.

\subsection{Lithium}

Lithium requirements for vehicle batteries could greatly exceed current capacity for lithium production (Figure 3). If a PNGV vehicle requires $30 \mathrm{lb}$. of lithium for its hybrid batteries, then demand for lithium will be over 96kt by 2020. In only the second year of PNGV introduction, 2006, lithium demand will be $3.5 \mathrm{kt}$. This exceeds current U.S. consumption of lithium of $2.8 \mathrm{kt}$, of which only $7 \%$ is for batteries (Ober 1998). Worldwide lithium production in 1997 was around $11 \mathrm{kt}$. PNGV demand would exceed this by 2009. In the first six years of $3 \mathrm{XV}$ production, lithium demand will grow by over $50 \%$ each year. Such a ramp-up in production would be difficult to sustain for any industry over multiple years.

Lithium is recyclable and there appear to be adequate world reserves of the ore. Current costs of lithium metal, around $\$ 40 / \mathrm{lb}$., mean the metal alone in a battery set for a $3 \mathrm{XV}$ would be $\$ 1200$. Battery manufacture will increase the total cost more. It is unknown what the market prices will be with the large demand increases forecasted and new industry capacity required. 


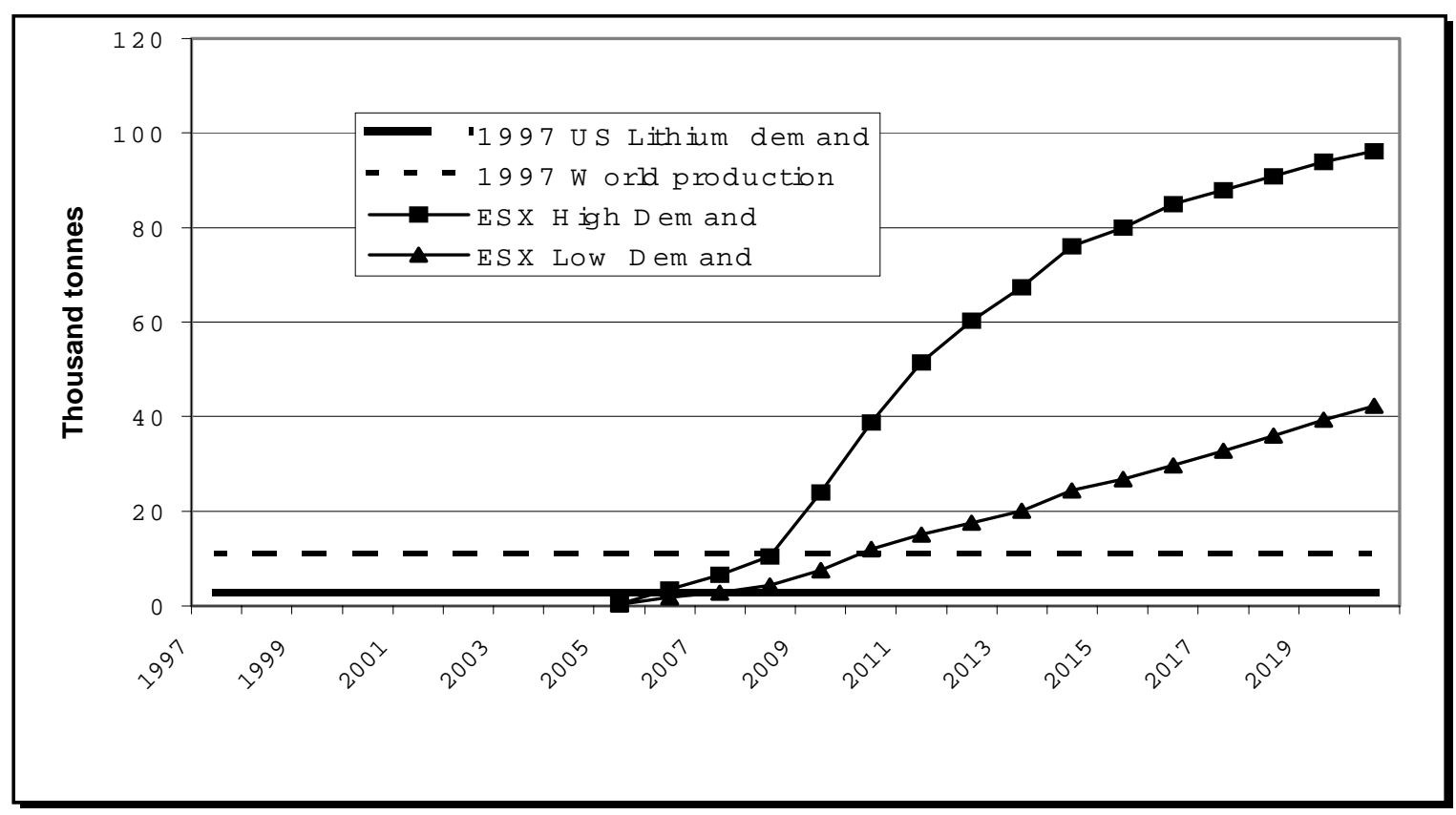

Figure 3. ESX2 Lithium Demand compared to U.S. Lithium Demand and World Production 


\section{MATERIALS RECYCLING}

The recycling rate for automobiles is currently about $75 \%$, a rate greater than that of any other product. The automobile recycling rate is driven largely by the recovery of a large amount of ferrous materials. The amount of recycled ferrous content in the parts of a typical passenger car today is as follows:
axle, undercarriage, outside shell... 28\%
springs, engine blocks............ 57\%
brake shoes....................... $75 \%$
drive shafts.................... 100\% (AAMA 1997).

In addition to maintaining the performance, size, utility, and cost of ownership and operation of today's vehicles, the PNGV program requires $3 \mathrm{XV}$ s to be $80 \%$ recyclable - up from $75 \%$ industry average today. The $80 \%$ recycling goal becomes very important when considered in the light of the proposed European Commission directive on the reuse and recovery targets of endof-life vehicles. The reuse and recovery rate is proposed to increase to $85 \%$ in 2005 , and to $95 \%$ by 2015 . With significantly higher amounts of non-ferrous materials considered for $3 \mathrm{XVs}$, it becomes an interesting question whether (1) the $80 \%$ recycling goal can be achieved and (2) how the economic viability of the existing recycling infrastructure will be affected, if at all. The following paragraphs discuss these issues. First, a qualitative assessment of the factors that may be detrimental to achieving the $80 \%$ recycling goal is provided. Second, a recently developed (Das et al. 1999) spreadsheet automobile recycling infrastructure model is employed to assess and quantify potential impacts of the major shift in the material composition of $3 \mathrm{XVs}$. The model was adapted to examine economic impacts on three distinct players (i.e., dismantler, shredder, and non-ferrous separator) of the industry for the two specific 3XV scenarios considered here.

\subsection{Recyclability}

To achieve the $80 \%$ recyclability goal, it is estimated that $1,608 \mathrm{lbs}$. of the P2000 and 1,800 lbs. of the ESX2 vehicle need to be recyclable. The analysis assumes recycling is limited to five major material categories identified in Table 2-ferrous, wrought and cast aluminum, magnesium, and titanium - as well as 60 lbs. of copper and zinc included in the "other" category. If the recycling goal is to be achieved on a total weight basis, rather than within individual material categories, the recycling rate particularly of non-ferrous materials will need to be significantly higher that it is today. To achieve the PNGV recycling goal, the required recycling rate of the five major material categories identified above is estimated to be $98.6 \%$ for P2000. For the ESX2, 100\% recycling within the major categories and another $115 \mathrm{lbs}$ of additional materials will be necessary. This contrasts with the current recycling rate of up to $95 \%$ of the total automobile's ferrous and non-ferrous metal content, which achieves the $75 \%$ recyclability rate. Although other materials such as batteries and fluids are recycled today, their recycling will not contribute significantly to the recycling goal and thus will not greatly lower required recycling rates of the major categories of materials. Achieving the PNGV recycling goal on a specific material basis, i.e., within each category of materials (see Table 2), may be more desirable. Doing so is possible for the five material categories identified above, but for most of 
the other materials present in smaller amounts (e.g., fibers, lexan), recycling will be difficult both technically and economically. Thus it will be difficult for the P2000 and the ESX2 to achieve the PNGV recycling goal given the existing recycling technology infrastructure. In fact, with the exception of highly recycled ferrous materials, all materials face major challenges at higher recycling rate. The following paragraphs discuss some detriments to achieving a higher recycling rate of non-ferrous materials.

More than $85 \%$ of automotive aluminum scrap is reclaimed in North America today, and the product of recycling — secondary foundry alloy castings - constitutes fully $60-70 \%$ of the aluminum used on vehicles today. With both $3 \mathrm{XV}$ scenarios using more wrought aluminum in vehicle bodies and panels, the challenge of automotive recycling will be to source castings from scrap while recovering the value of wrought alloys. The sheet and extrusion scraps that form the minority portion of the total vehicle weight today are recycled into casting alloys because secondary castings in general have a greater tolerance for alloying elements and impurities than do sheet or extrusion products. With increased use of sheet and extrusions, there will be a need to separate sheet, extrusions, and castings during the recycling process. A recent study indicates that $80 \%$ closed-loop recyclability of aluminum scrap (i.e., each part is recycled into a new part of the same type) for the PNGV can be achieved with improved dismantling and shredder separation technologies as well as knowledge of alloy selection ( $\mathrm{Ng}$ et al. 1999). Development of aluminum separation technologies is also applicable for the open-loop recycling, as the projected growth in the primary casting alloys (i.e., sourced from virgin primary metal) between 1990-2010 will be $451 \%$, significantly higher than the $79 \%$ projected for secondary castings (Tessieri 1997). In addition, the market for mixed scrap is limited to the automotive market. Developing costeffective technologies to sort scrap from wrought aluminum will be crucial to achieving the recycling goal because it will allow recycled aluminum to be used in many other non-automotive applications, such as steel deoxidation, furniture, small motor housings, lawnmowers, etc. Separation will enhance the value of each alloy separated; the extent of premium value obtained will be determined to a large extent by how large quantities of aluminum from automobiles affect aluminum primary and secondary markets.

The recyclability of composites is a matter of concern only for ESX2, which has a composites content double that of current vehicles. Currently, no cost-effective composites recycling technology exists. Consequently, composites are landfilled as automotive shredder residue. Several recycling options for automobile shredder residue (ASR) have been investigated. They include energy recovery (combustion), recovery of organic components for fuel and feedstock applications (pyrolysis), chemical recycling such as glycolysis and hydrolysis, separation of individual plastics, recycling ASR into composite materials utilizing thermoplastic processing or isocyanate-based binders, and utilization of ASR in concrete and asphalt for road applications. Lately, two plastics-separation technologies for recycling (i.e., skin flotation and density separation) are actively being considered by the United States Council for Automotive Research (USCAR 1999). The skin flotation technology is suitable for recovery of high value engineering plastics ABS, PC, and PA (nylon). The use of recyclable thermoplastic PET as the matrix material may be beneficial with regard to ESX2 recycling. Only $21 \%$ of the total 1.7 million tonnes of PET waste generated is being recycled today (EPA 1998). The most widely used PET - the form used in soft drink bottles—is collected as a municipal solid waste stream and 
PET recycling - mostly soft drink bottles - is a case in which public sector initiatives have been the key to success. The bottle deposit laws, in combination with individual concerns about the disposal of PET bottles, have been sufficient incentives to overcome the consumer barriers to recycling, i.e., the inconvenience, source separation, storage, and the cost of transportation to a deposit refund center. However, the recycling of automotive PET may pose concerns since no technology currently exists which can cost-effectively separate the fibers from the matrix material. So far there has been little progress in recycling the waste fiberglass back into body panels and other components. An alliance has been formed among Phoenix Fiberglass Inc. (the recycler), SMC Automotive Alliance, and Owens Corning to recycle the post-industrial glass fiber waste (Sorge 1995).

The infrastructure for recycling magnesium scrap is somewhat developed. In 1996, secondary production represented $35 \%$ of total U.S. production, and much of that was in the form of an alloying element in aluminum can stock (USGS 1998). Industrial magnesium scrap is generally sold to a secondary smelter, which then remelts and refines it for resale. There is significant potential to increase the quantity of industrial magnesium scrap recycling. Tied to the forecast of increased use of diecastings is a forecast of a strong increase in the recovery and use of magnesium scrap. Growth in magnesium recovery and reuse should parallel growth in magnesium use. However, because of economics, very little magnesium is currently recycled from scrapped automobiles. The material mostly ends up mixed with aluminum and copper in the nonferrous stream. It would be possible to separate the magnesium from other nonferrous metals either manually, or in a sink/float operation if sufficient quantities were present. Magnesium is perceived to be highly flammable, thus its safety during recycling is questioned. The concern arises from magnesium's high conductivity and the potential for combustion to result from small chips and shavings.

Other major non-ferrous metals such as titanium and lithium are recyclable, but their use is so limited that they are not recycled today. That lithium is used only in batteries eases its recovery and, thus, recycling. Post-consumer titanium is so limited today that it is not commercially viable to recycle.

\subsection{Economic Viability}

A spreadsheet cost model of the automobile recycling infrastructure was developed recently to assess and quantify potential impacts of the major shift in the material composition of $3 \mathrm{XVs}$ on three distinct players (i.e., dismantler, shredder, and non-ferrous separator) in the automotive recycling industry (Das et al. 1999). This model was used to examine similar economic impacts for the two specific $3 \mathrm{XV}$ scenarios considered in this study. The model is represented as sequential processing stages_-dismantler, shredder, and non-ferrous separator-where outputs of each of the three processing stages depends on the mass of the input. The mass of the input is affected by the change in the materials composition of the automobile and/or the mass of the material separated for disposal at preceding process steps. To estimate cost and revenues at each processing stage, the model considers the material composition of the input and the portions that are recycled and landfilled. Details of the model are discussed in a recent report (Das et al. 1999). 
For the two scenarios considered here, parts made of substitute materials continue to be recycled for parts reuse at the dismantling stage; whereas the recycling share of the remaining materials at the next two recycling stages is assumed to be the same as under the base case. The reduction in ferrous material recycling at the dismantling stage is compensated by the increase in non-ferrous materials recycling (i.e., mainly aluminum and composites). For example, under the P2000 scenario, it is estimated that at the dismantling stage recycling of an additional $280.2 \mathrm{lbs}$. of cast aluminum, $75.6 \mathrm{lbs}$. of wrought aluminum, and $33.6 \mathrm{lbs}$. of composites will occur, replacing $731.4 \mathrm{lbs}$. of ferrous materials in current vehicles.

Figure 4 shows the impact on net revenues of dismantlers, shredders, and non-ferrous separators under the P2000 and ESX2 scenarios. Dismantlers and non-ferrous separators gain more than shredders under both scenarios. Since both scenarios contain a significantly higher amount of non-ferrous materials, non-ferrous separators would experience the most net revenue gain. The significantly greater aluminum content of the P2000 causes a greater increase in net revenues than that caused by the ESX2 scenario. A higher content of plastics in ESX2 limits the net revenue increase for shredders to only 1.6 times.

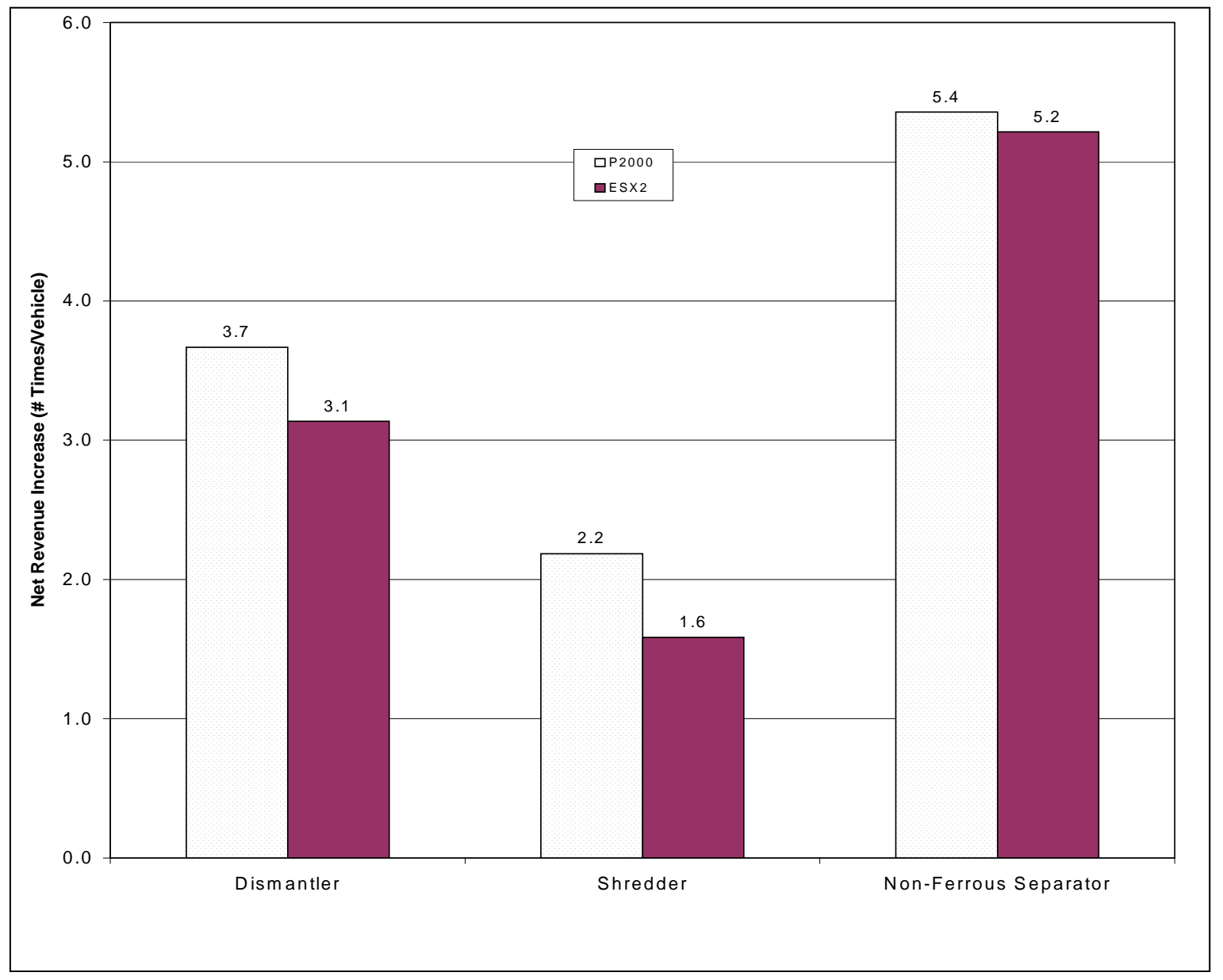

Figure 4. Recyclers Benefit From Higher Non-Ferrous Material Content 
The PNGV $80 \%$ recyclability goal will be difficult to achieve for the two $3 \mathrm{XV}$ s considered here without the development of separation technologies and associated infrastructure. To increase the recycling rate of aluminum, new separation technologies are needed to extract the higher value wrought aluminum alloys. A complete new infrastructure needs to be developed for other nonferrous metals with the exception of magnesium. The recyc8ling of composites poses severe challenges because of the absence of any cost-effective recycling technologies. However, particularly dismantlers and non-ferrous separators might financially gain from the higher content of valuable lightweight non-ferrous material contents. Since $3 \mathrm{XV}$ s are anticipated to be introduced in the market in 2005 and have a useful life of 10-12 years (similar to vehicles of today), the recycling industry has enough lead time to adjust to be able to recycle these vehicles. 


\section{VEHICLE REPAIR AND USE}

This section describes potential barriers to the $3 \mathrm{XV}$ market penetration related to vehicle repair and use. The observations below are based mainly on in-depth conversations with people in the automobile industry with expertise in mechanical repair, collision repair, collision repair cost estimation, automobile insurance, automobile sales, and 3XV development (at Chrysler and Ford). Industry publications on the future of the automobile repair industry were also reviewed. Financial and employment statistics and data were drawn from Census and Bureau of Labor Statistics databases and from example annual financial reports from mechanical repair and collision repair companies.

The overall conclusion is that there are no show-stopping barriers to market penetration of $3 \mathrm{XVs}$ related to vehicle repair and use. However, there are numerous minor issues that could in combination act as a significant barrier.

The automobile mechanical and collision repair industries are extremely resilient and adaptable. This is a period of time in these industries where firms routinely acquire and adapt to new technologies in response to automobile makers worldwide incorporating new materials and computerized systems into innovative unibody automobile designs. Back-of-the-envelop calculations on capital requirements for firms to purchase new technologies to service $3 \mathrm{XVs}$ indicate that these investment expenditures would be well within the industries' financial wherewithal and current investment behaviors.

There are concerns today in the vehicle repair industry related to retraining the existing workforce and attracting new service technicians. These problems are not expected to be any better or worse with respect to $3 \mathrm{XV}$ s. In fact, one could hope that new training systems and access to training and repair information over the World Wide Web might help reduce the problem throughout the industry at the time $3 \mathrm{XVs}$ appear in the market. In summary, experts in the automobile industry do not anticipate that servicing $3 \mathrm{XVs}$ will demand capital investments or retraining programs for the vehicle repair beyond the challenges now being faced by the industry.

However, one can build an argument that vehicle repair and use costs to consumers will be higher than costs for non-3XV automobiles, at least for the first several years $3 \mathrm{XV}$ s will be available in the marketplace. It is likely that automobile insurance costs will be higher, both because the $3 \mathrm{XV}$ s may cost more than comparable non-3XV automobiles and because automobile insurance companies may charge consumers a premium until several years of data are available to better estimate expected mechanical repair and, especially, collision repair costs.

Collision repair costs are likely to be higher for both the aluminum-intensive and compositeintensive cars. In the former case, automobile repair experts who already have experience in working with aluminum body cars (e.g., the Audi A8 and the Acura NSX) report that it is more difficult and time consuming to work with aluminum. For example, welding is more of a challenge because if aluminum is overly heated, it will disintegrate. In some collision situations, aluminum can lose so much strength that the parts become useless. Thus, one can predict that more body panels will need to be replaced outright (rather than fixed) than steel body cars. 
Typically, experts report, replacing parts costs more than repairing parts. It is also likely that composite body panels will also need to be replaced at a higher rate. Lastly, collision repair technicians will need to traverse up the learning curve with respect to repairing aluminum-body and composite-body cars. In most cases, learning is achieved through experimentation. For example, it was reported that each collision repair firm will develop its own approaches and methods for working with patches and adhesives for repairing composite panels. One can expect some experiments to fail, leading to somewhat higher collision repair costs in the short-run than in the longer-run.

One can also predict that $3 \mathrm{XV}$ collision repair might take more time. Given that it was indicated to us that insurance companies typically balk at paying for replacement parts versus repairs, consumers may experience an increase in the time needed to repair $3 \mathrm{XVs}$ as collision repair firms and the consumers' insurance companies negotiate appropriate reimbursement levels. As noted above, aluminum is a difficult material to work with, which would add time to collision repair efforts. Lastly, failed experiments will result in more time spent on collision repair. Increased collision repair time will further inconvenience consumers and may require additional out-ofpocket costs for rental vehicles.

It is unclear whether mechanical repair costs will be higher or lower. These costs may be higher if $3 \mathrm{XVs}$ require additional specialized tools, alignment systems, etc. Also, several experts observed that in many instances, newly designed cars have subsystems that are difficult to repair. One reason is because the nuts, bolts and fasteners for these systems can be inaccessible to service technicians. Oftentimes, other subsystems need to be removed or disassembled before service technicians can access the subsystems needing repair. Thus, repair costs might increase if service technicians need to spend more time in repairs. Design trade-offs to reduce manufacturing and assembly costs can lead to these types of problems.

As a final point, the introduction of $3 \mathrm{XV}$ s may hasten structural changes in the vehicle repair industry. For many, many years, vehicle repair was dominated by small, independent "mom and pop" firms. Several trends in the industry have been working to shift market share from these firms to dealers, national vehicle repair chains, and other large companies. For example, the sophistication of automobile systems and vehicle repair technologies and training requires investments in time and money that small firms find hard to afford. New environmental regulations have also required additional technology and training investments. 3XVs will continue the sophistication trend and may entail the need for additional environmental technologies. Therefore, $3 \mathrm{XVs}$ will mostly likely support the current trend in the industry from small firms to larger vehicle repair companies. 


\section{ACCEPTABILITY ISSUES}

For the two $3 \mathrm{XVs}$ at issue in this report and other $3 \mathrm{XVs}$ to be "successful," it is clearly essential to be able to manufacture, distribute, and service these vehicles on a large scale. However, the success of these vehicles is at least equally dependent upon people's willingness to purchase them. This section considers these two vehicles from the standpoint of issues or attributes that with respect to consumer acceptability could constitute "showstoppers."

One can anticipate a transition curve that starts with the introduction of new vehicle types and rises over a period of some years to the point of reaching a steady or gradually growing portion of the market share. This section considers those issues and attributes of the two prototype $3 \mathrm{XVs}$ that can change the shape of that transition curve, such that the resulting market share is lower than currently anticipated.

\subsection{Weight and Safety: A Complex Issue}

In analyzing market acceptability issues for the two PNGV vehicles of concern, only one discrete item appears to have the potential to severely impair consumer acceptability. That item is the weight of the vehicles and the safety issues that stem from the vehicles' weight. Issues of vehicle size, weight, and safety are complex, and consumers' perceptions of the relationship among these factors are not easily discerned.

A key way in which all 3XVs will achieve their tremendous gains in fuel efficiency is by reducing the weight of the vehicles. However, current trends in the United States are toward heavier vehicles - sports utility vehicles, trucks, and cars. While there are regulatory efforts to improve the emissions profiles of these vehicles, there are no apparent trends for reducing their numbers on the road. In crashes between light-weight $3 \mathrm{XVs}$ and cars, trucks, or sport utility vehicles that weigh at least twice as much, the weight differential alone can make the $3 \mathrm{XV}$ s more vulnerable to damages and their passengers more susceptible to injuries. It is possible to design $3 \mathrm{XV}$ models in ways that maximize the passenger compartment protection, though the damage to the cars may be significant. In fact, the P2000 and ESX2 are projected to have these design features that confer protection to passengers. Nevertheless, based on current trends, the likelihood is that crashes involving $3 \mathrm{XVs}$ will be with heavier vehicles.

Consumers' confidence in the degree to which the vehicles are designed to protect passenger safety may significantly affect their willingness to purchase those vehicles rather than other vehicles of a similar "class." Take, for example, a scenario in which the consumer is choosing between Taurus-like vehicles and P2000-like vehicles. If consumers believe that the heavier Taurus-like cars provide considerably higher levels of passenger safety in crashes, then consumers may opt for the heavier vehicles rather than the lighter ones especially if first-costs of these vehicles are similar. This situation likely would be amplified if the regular-weight alternative were a Taurus-like car whose first cost is thousands of dollars less than a P2000-like car. Although there is currently a market for lighter vehicles, current market demand tends to be for either low-end vehicles or high-end, specialty vehicles. The literature on the P2000 and the 
ESX2 portrays them as a new-generation of mid-sized family cars. Therefore, the appropriate comparison with regard to weight, safety, and consumer preferences is with a similar class of vehicle.

\subsection{Current Market De-emphasizes Fuel Efficiency}

With the long-term lowering of the price of oil and gasoline and the general improvement in the fuel efficiency of vehicles, the marginal demand for more fuel-efficient vehicles has weakened. Certainly, rising incomes have played a role also in the demand for larger vehicles with a wider array of powered capabilities, and that can carry not only a large number of people but large quantities of possessions for leisure-related trips. Currently, the categories of sport utility vehicles, vans, and light trucks account for around half of new car sales. While the philosophical leaning toward fuel efficiency on environmental grounds has not disappeared, much of the immediate economic reinforcement of the conservation attitude has eroded. As a market niche, fuel efficiency for its own sake has become smaller than it was in the early- and mid-1980s. Unless fuel prices make a sustained and substantial increase, or corporate average fuel-efficiency standards tighten sufficiently to rein in the size increases in the larger and heavier portions of the vehicle market, $3 \mathrm{XV}$ s will be competing with a shrinking portion of the total vehicle market.

\subsection{Competitive Responses May Erode the P2000 and ESX2 Market Share}

The automobile industry in this country and abroad is taking multiple approaches to achieving dramatically greater fuel efficiency and reducing noxious air emissions. While the $3 \mathrm{XVs}$ embody an important set of responses, other avenues already being explored could provide notable competition for the $3 \mathrm{XVs}$ that eventually are manufactured. It is unclear whether the predictions for $3 \mathrm{X}$ market penetration include the possible dampening effects of competition from other vehicles that achieve greater fuel efficiency - though perhaps not quite to the level projected for $3 \mathrm{XVs}$ - through other designs and technologies.

For example, both the ESX2 and the P2000 are expected to use diesel fuel, perhaps as part of a mild hybrid, or "mybrid" with a battery. However, a host of different fuels—ranging from reformulated diesel or gasoline, to renewable alternative fuels, to fuel cells-are being developed to reduce air emissions and fuel consumption. Some of these alternatives, such as reformulated gasoline, would not require major automobile redesign. The availability of cleaner fuels in a familiar kind of automobile may erode the market for dramatically different P2000 or ESX2 vehicles.

Similarly, efforts are also underway to develop new gasoline engines that improve fuel efficiency without adversely affecting a vehicle's power. Also, other portions of the automobile industry are trying to reduce automobile weight by developing strong, lightweight steel. These kinds of activities, if successful, may achieve PNGV goals, but compete with the technologies and vehicles promoted directly by the program. Both new gasoline engines and lightweight steel may have the relative advantage among consumers of using familiar fuels and materials. Regardless, particularly for individuals concerned with fuel efficiency, it is reasonable to assume that the P2000 and ESX2 will compete with vehicles using a variety of fuels, engine designs, and frame 
and body materials. Market penetration projections for the two PNGV vehicle types should consider these types of competition, which would erode the market share for any particular vehicle.

\subsection{Consumers' Willingness to Trade-off First-cost for Life-cycle Operating Cost}

Simply comparing the present discounted values of alternative units of equipment has not yielded a good predictor of the choices consumers will make. This result has emerged in consumer responses to energy-efficiency improvements in refrigerators, clothes washers, air conditioners, and entire HVAC systems. The discount rates that market purchases have appeared to impute to consumers in their durables purchases frequently have been as high as $40-50 \%$, far higher than the cost of funds in the consumer credit market. Recent developments in investment theory, and applications of these developments to some consumer appliances have restated the investment question to one of the timing of the investment rather than just whether an investment is made or not. This timing issue approaches the real opportunities that investors face more closely than an all-or-nothing hypothesis. But possibly the clearest contribution of this new view of investment is the role it offers to technological uncertainty surrounding an investment situation where the investor cannot re-sell the item easily and at little loss if it disappoints expectations. This new approach to investment highlights the potentially pivotal role of technological uncertainty in consumers' $3 \mathrm{XV}$ purchase decisions, particularly in the early stages of market penetration, when field performance data are scarce.

\subsection{Accumulation of Smaller Negatives Can Dampen Market Share Seriously}

Each model risks introducing some unfamiliar features in its effort to reduce weight and increase fuel efficiency. These features include egress style — passenger entry and exit — trunk space, road handling under various conditions (rain, ice, wind), possibility of maintenance or, especially, repair problems, and probably even more minor matters such as "where do I put my coffee cup?" In a market filled with vehicles with familiar features, a vehicle with only one relative advantage (high fuel efficiency), has fewer unique, desired features to trade off against features that are not desired. Looking for a single feature that qualifies as a "showstopper" can miss the cumulative "small cuts" that could erode the markets for these vehicles below what is viable. 


\section{LIFE-CYCLE EVALUATION OF THE P2000, THE ESX2, AND THE BASELINE VEHICLE}

\subsection{Introduction}

The environmental impacts associated with a new vehicle design can be accurately assessed only if all the life-cycle stages are considered. For instance, the use of certain materials that seem benevolent to the environment in a particular life-cycle stage might require huge amounts of energy to produce in one of the upstream stages, rendering their selection unjustifiable. Furthermore, a seemingly large reduction in emissions during one stage might be rendered inconsequential by a hefty increase in another stage.

Since the environmental consequences are greatly dependent upon the materials and manufacturing processes chosen for the production of a particular vehicle, it is important to incorporate life-cycle considerations into the design process. Life-cycle design, therefore, is a proactive approach that prevents the imposition of unforeseen burdens on the environment by providing information on potential impacts at the design stage itself.

\subsubsection{Goal and Scope of the Study}

The goal of this study is to conduct a life-cycle-based environmental evaluation of the aluminumintensive Ford P2000 and the plastic composite-intensive Chrysler ESX2, comparing them against the generic 1994 mid-size, North American-built passenger car, which is the baseline vehicle for the study. This life-cycle-based environmental assessment conducted by the University of Tennessee Center for Clean Products and Clean Technology (The Center), forms part of the ORNL study of $3 \mathrm{XV}$ issues.

Typical life-cycle assessments (LCAs) can take from one to several years to complete and are highly dependent on the complexity of the product of interest. The LCA will usually include developing the goals and scoping of the project, obtaining all the necessary data for the life-cycle inventory (LCI), performing a Life-Cycle Impact Assessment (LCIA), and lastly, assessing the results of the LCI and LCIA, or performing the Life-Cycle Improvement Analysis. Because of the short time frame over which this project was to be completed, a "complete-as-possible" LCI was performed, as was a limited amount of LCIA work considered feasible. With a simple product as the focus of an LCA (e.g., paper clip, water bottle, concrete blocks), it is possible to complete an assessment in a relatively small amount of time. However, with a complex product like an automobile that contains on the order of several thousand parts, it was possible to perform only a life-cycle based environmental evaluation, given the constraints of this project.

The functional unit for the purpose of this study is the U.S.-built passenger car (as defined above), driven for 120,000 miles. Four life-cycle stages, spanning the entire life of the vehicles, were chosen for analysis and include: 
- Extraction and Materials Processing. Activities related to the acquisition of natural resources from the Earth, and their subsequent processing to yield usable materials for the manufacturing stage.

- Manufacturing. Production of automobile parts and assemblies by manufacturers and their suppliers; assembly of automobiles by automakers.

- Use. Use of vehicles for the intended purpose (safe and comfortable on-road transportation for up to five occupants per vehicle), over the expected life span of 120,000 miles.

- End-of-Life. Disposition of vehicle parts and components at the end of its useful life, including the recycling of the majority of each vehicle's materials and landfilling of the residuals.

The assumptions and analytical results for each life-cycle stage are discussed separately in latter sections of this report.

\subsubsection{Material Composition Scenarios}

The material composition scenarios upon which this evaluation is based are provided in Table 2 (Chapter 1). For the purposes of the LCA, the PET portion of the "plastics" category is combined with the "glass fiber" category for a total of $400 \mathrm{lbs}$ of glass-reinforced PET per vehicle; the remainder of "plastics" is categorized as "other plastics" for purposed of the LCA. The changes in categorization are reflected in Table 6.

Table 6. Material Composition Scenarios (lbs)

\begin{tabular}{|l|r|r|r|}
\hline \multicolumn{1}{|c|}{ Material } & 1994 Vehicle & P2000 & ESX2 \\
\hline PET (glass reinforced) & 0 & 0 & 400 \\
\hline Other Plastics & 223 & 251 & 145 \\
\hline Wrought Aluminum & 47 & 462 & 330 \\
\hline Cast Aluminum & 159 & 271 & 120 \\
\hline Magnesium & 6 & 86 & 122 \\
\hline Titanium & 0 & 11 & 40 \\
\hline Ferrous & 2168 & 490 & 528 \\
\hline Rubber & 138.5 & 123 & 148 \\
\hline Glass & 96.5 & 36 & 70 \\
\hline Lexan & 0 & 30 & 20 \\
\hline Glass Fiber & 19 & 19 & 0 \\
\hline Carbon Fiber & 0 & 8 & 24 \\
\hline Other & 391 & 223 & 303 \\
\hline Total Weight & $\mathbf{3 , 2 4 8}$ & $\mathbf{2 , 0 1 0}$ & $\mathbf{2 , 2 5 0}$ \\
\hline
\end{tabular}


In the case of the "composite-intensive" ESX2, the body panels are made of a composite material, glass fiber-reinforced PET. The glass fiber content is 15\%. The ESX2 also contains more carbon-fiber composite than the other vehicles. The P2000 contains the largest quantity of aluminum and is, therefore, termed "aluminum intensive." The ferrous content in both the P2000 and the ESX2 is considerably less than in the 1994 vehicle. Moreover, it is observed from Table 1 that the $3 \mathrm{XV}$ s use more of the newer materials, titanium and magnesium.

\subsection{Methodology and Assumptions}

The methodology for performing the life-cycle evaluation and the major assumptions made are presented here. The evaluation's major assumptions about $3 \mathrm{XVs}$ are that they

- use a hybrid power supply that is a combination of a conventional direct-injection diesel engine and an electric motor powered by a lithium-ion battery; and

- achieve a fuel efficiency of $70 \mathrm{mpg}$ (slightly less than the PNGV goal of $80 \mathrm{mpg}$ ).

For each unit process considered, typical LCAs will focus on either all the input and output types shown in Figure 5, or select the ones in which the largest environmental burdens are found and focus on those alone. Again, due primarily to time limitations, we focused on five specific input and output types for this life-cycle evaluation: the primary (or vehicle) materials and energy consumed on the input side, and the products, air emissions, and total solid waste generated on the output side. For the air emissions, only the primary pollutants of particulate matter (PM), $\mathrm{NO}_{\mathrm{x}}, \mathrm{CO}, \mathrm{CO}_{2}$ and $\mathrm{CH}_{4}$ were included, primarily due to the lack of other speciated pollutants information for all of the life-cycle stages. In addition, only those ancillary materials that had substantial environmental burdens were considered.

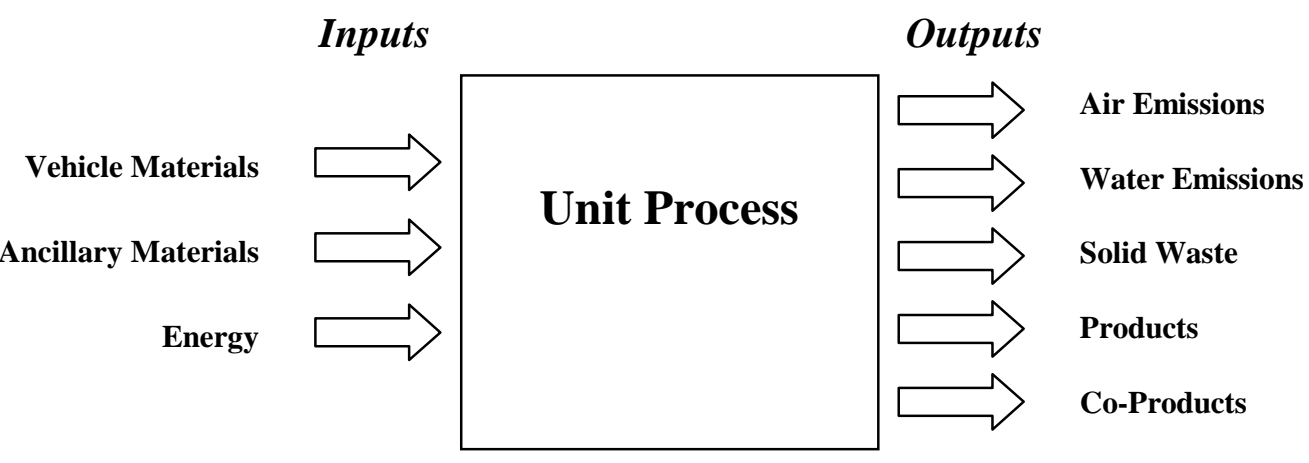

Figure 5. Typical Life-cycle Inventory Data Categories 
The methodology and assumptions made for each individual life-cycle stage are detailed in the following four sub-sections. It should be mentioned that in this evaluation the inputs and outputs for transportation of materials and parts were included within each process within each life-cycle stage, and not relegated to one particular "transportation" life-cycle stage (as done in some LCAs).

\subsubsection{Extraction and Materials Processing}

The extraction and materials processing life-cycle stage encompasses the removal of true raw materials (e.g., iron ore, bauxite, rutile) from the earth and subsequent initial processing of these raw materials to yield materials that are usable in various manufacturing processes (e.g., iron, steel, aluminum, titanium, plastic resin). For this life-cycle stage, the data utilized were a proprietary, in-house set of environmental profiles for the extraction and materials processing of various materials.

The data for this life-cycle stage are of medium quality, mainly because:

- all processing, transportation, and energy use during the extraction and initial processing stages is included;

- data on energy and primary and secondary material inputs as well as on air, water and land releases as outputs is included; and

- emissions are somewhat speciated into specific compounds.

The drawbacks of the data used for this stage are:

- most of the data are of European origin;

- a dataset for secondary (containing recycled materials) processes was excluded; and

- a profile for lithium production (for the battery) was not available.

The inventory for this life-cycle stage begins with the materials breakdown (Table 6) that includes all of the materials distinguishable for each vehicle and an "Other" category that includes those materials not able to be broken out (e.g., items such as car stereos). The categorization of materials as presented in Table 6 differs slightly from the categorizations in the proprietary data. Thus, the inventory of materials in the proprietary data was re-categorized to be consistent with the categories in Table 6 . To that end, several edited processes were created.

Table 7 presents the material inventories that were utilized in this study split into three categories: unedited processes, source-merged processes, and material-merged processes. The source-merged processes are those that required the blending of primary (virgin) and secondary (recycled) production information, to yield process environmental data that more closely resembles the actual inputs and outputs of those processes used in the automotive industry today. Additionally, the material-merged processes were those processes that required blending multiple unedited material inventories. For example, the edited "PET with glass fiber" (or glass-reinforced PET) process was a combination of the unedited processes of PET production and glass fiber production, using the reported $15 \%$ glass fiber found in that particular plastic composite to create the edited process. 
Table 7. Material Profiles Included in Inventory

\begin{tabular}{lll}
\hline Unedited Processes & Source-Merged Processes & Material-Merged Processes \\
\hline Titanium & Aluminum, Wrought & Ferrous \\
Lexan (Polycarbonate) & Aluminum, Cast & PET with Glass Fiber \\
Glass & Magnesium & Other plastics \\
Glass Fiber & & \\
Gasoline/Diesel & & \\
\hline
\end{tabular}

In some cases, several processes were augmented with additional emissions information for particularly environmentally burdensome emissions. These included adding emissions data on two perfluorocarbons (PFCs) generated during the production of primary aluminum (emitted as by-products of the smelting process); and, adding data on $\mathrm{SF}_{6}$ emissions during the production of primary and secondary magnesium (used as a protective covergas during casting of molten magnesium in both primary production processes and the subsequent downstream manufacturing processes). Each of these compounds is a potent greenhouse gas.

For this life-cycle stage, inputs and outputs associated with electricity generation were already included in each profile. Because the electricity inputs and outputs could not be separated from these profiles, it was not feasible to substitute U.S. electric grid data for the predominantly European grid data contained in these profiles.

\subsubsection{Manufacturing}

In this evaluation, the manufacturing life-cycle stage includes the final assembly of the automobile and the manufacturing processes from one to two tiers upstream of vehicle assembly (e.g., powertrain production, body frame, panel fabrication). Due to time and resource constraints, as well as the lack of available data on the manufacturing of these prototype car designs, the analysis uses existing data from a previous study of a U.S. vehicle manufacturing facility to represent the manufacturing stage. This study was also conducted by The Center.

Data from this LCI were scaled on the basis of total vehicle weight to obtain manufacturing lifecycle stage data for the three vehicles of interest in this study. This method did not bring to light the true manufacturing differences that are inherent in the different materials used in each of these vehicles. However, the impacts of the manufacturing stage as a whole and the differences in manufacturing impacts for the three car designs are generally much less than those in the other life-cycle stages. Furthermore, using generic manufacturing-process data would have almost certainly brought as much, if not more, error into the $3 \mathrm{XV}$ input and output values because of variations in machine age, size, and efficiency at different manufacturing facilities, as well as the variations in specific facility process efficiencies (e.g., extent of automation, human factors).

The original vehicle manufacturing LCI data quality was high in that facility-specific information was obtained, including the use of much directly measured information about plant operations. Though quality was reduced somewhat by scaling it to the $3 \mathrm{XV}$ s by total vehicle weight, overall data quality should be considered to be about as high as can be attained outside of direct 1994 vehicle and $3 \mathrm{XV}$ facility inventorying. It should be kept in mind that the two $3 \mathrm{XVs}$ are not 
production level vehicles yet. And, although there have been discussions about new technologies and processes that are to be used to produce various components of the two $3 \mathrm{XV}$ prototypes, there is currently little available data on the inputs and outputs for these technologies and processes.

In addition to the three profiles that were generated in this life-cycle stage, a fourth profile was generated to include an analysis that encompassed molding the ESX2's body panels in color (in lieu of painting them). The Center had previously conducted an environmental analysis on molding specific automotive body parts in color (Kelly 1998), and this study was used to show the energy and environmental benefits of reducing the need for the painting process, a big contributor to the automobile's environmental profile.

The use of electricity during the manufacturing life-cycle stage was also included, utilizing a U.S. electric grid environmental profile developed by The Center.

\subsubsection{Use}

The use life-cycle stage begins with the initial post-manufacturing operation of the vehicle and ends with the vehicle attaining 120,000 miles of service (the mileage assumed for this analysis). This stage includes the energy consumed in driving the vehicle and in the production of fuel. The fuel production profile used includes environmental effects of electricity generation; thus, the use of the U.S. electric grid was not needed for analysis of this life-cycle stage. The limited time frame of this project did not allow for vehicle maintenance and repair to be addressed.

In estimating the lifetime fuel requirement during use, the only variable was the fuel efficiency, which was assumed to be $70 \mathrm{mpg}$ for the $3 \mathrm{XVs}$ and $26.6 \mathrm{mpg}$ for the 1994 vehicle. Although the PNGV goal for $3 \mathrm{XVs}$ is $80 \mathrm{mpg}$, it was prudent to use a (currently) more realistic fuel efficiency. The $26.6 \mathrm{mpg}$ used for the 1994 vehicle is consistent with the value specified for the baseline vehicle in the PNGV document stating the goals of the partnership (Technology Administration 1999).

Emissions for the baseline vehicle are based on available Environmental Protection Agency data on certification testing of 1994 Taurus and Intrepid vehicles (EPA 1999a), and averaging the emissions provided. As PM and $\mathrm{CH}_{4}$ emissions were not provided in the EPA data for the 1994 Taurus and Intrepid vehicles, they were calculated from relationship obtained using Tier 0 Emission Certification standards.

The analysis considers two $3 \mathrm{XV}$ emissions profiles in detail. The first is based on current dieselengine performance. A vehicle with a small-sized diesel engine (the 1998 Volkswagen Passat diesel) was chosen to simulate the emissions from $3 \mathrm{XVs}$. However, the $3 \mathrm{XVs}$ are powered by a hybrid power system that combines a diesel engine and a battery-powered electric motor. The diesel engine gets help from the battery at different times during vehicle operation, resulting in increased fuel efficiency and lower emissions.

Since the 43-mpg fuel efficiency of the 1998 Passat (EPA 1999b) was much lower than the 70 mpg assumed for the P2000 and the ESX2, the emissions were adjusted accordingly by reducing 
them proportional to the difference in fuel efficiency (i.e., multiplied by 43/70). Also, since $\mathrm{CO}_{2}$ emissions were not provided in the EPA data for the 1998 Passat, they were estimated by establishing a relationship between the $\mathrm{CO}$ emissions from the Passat and those from similarsized Fiat diesel engine (Raffelsberger et al. 1995). Assuming that $\mathrm{CO}_{2}$ emissions vary proportionately to $\mathrm{CO}$ emissions, the $\mathrm{CO}$ relationship was then applied to the $\mathrm{CO}_{2}$ emissions from the Fiat to calculate the $\mathrm{CO}_{2}$ emissions for the Passat. Additionally, the resulting $\mathrm{CO}_{2}$ emission value was checked against some other emission values and was within the range found in other data.

The second profile is based on an ANL estimate that averages Low Emission Vehicle (LEV) and Ultra-low Emission Vehicle (ULEV) standards for both near-term and long-term baseline vehicles. The emission rates estimated by ANL for the direct injection diesel vehicle (long term) are used here and shown along with the Passat-derived values in Table 8. ANL estimates for fuel-production-related emissions also have been used in this second scenario (see Table 9).

Table 8. Use-stage emission rates (grams/mile)

\begin{tabular}{ccc}
\hline Emission type & Passat-derived values & LEV-ULEV values \\
\hline $\mathrm{NO}_{\mathrm{x}}$ & .369 & .073 \\
$\mathrm{PM}$ & .043 & .010 \\
$\mathrm{CO}$ & .307 & 2.15 \\
\hline
\end{tabular}

Table 9. Fuel production emissions estimated by ANL (grams/mile)

\begin{tabular}{cc}
\hline Emission type & Emissions* \\
\hline $\mathrm{NO}_{\mathrm{x}}$ & .128 \\
$\mathrm{PM}$ & .013 \\
$\mathrm{CO}$ & .089 \\
\hline
\end{tabular}

* Includes feedstock and fuel values

A third scenario that puts $\mathrm{NO}_{\mathrm{X}}$ emissions at $.030 \mathrm{~g} / \mathrm{mile}$ is briefly addressed. This scenario assumes that several, potential emissions-reducing measures are implemented, and, as such, the scenario is speculative. The measures include

- a direct injection, aluminum, through-bolt assembly engine;

- sulfur-free diesel fuel;

- cooled EGR and advanced fuel systems;

- a catalyzed soot filter; and

- a $90 \%$ absorption $\mathrm{NO}_{\mathrm{x}}$ catalyst.

\subsubsection{End-of-Life}

The last life-cycle stage, end-of-life, was defined in this project to encompass the processing of a vehicle after its useful life into reusable components, recycled materials, and landfilled ASR.

Data for the end-of-life stage are based on a study conducted previously by The Center, involving visits to and collection of data from vehicle end-of-life processing facilities. For this life-cycle stage, the ESX2 has been evaluated using two scenarios—one assuming that the PET body 
panels are being landfilled along with the other plastics and the other assuming that they are recycled. These two scenarios are termed "ESX2" and "ESX2 with PET Recycling," respectively. Whether or not the PET body panels are recycled depends upon two things: how easy, and thus economical, it is to dismantle them and whether the presence of glass fiber in the material hinders their recyclability. In this stage, the "Mold-in Color" scenario for the ESX2 is assumed to have no effect and is therefore left out of the comparisons.

At the end of their useful lives, automobiles are usually sold to automotive dismantlers who remove the still useable parts for reuse or remanufacture, and dispose of the hazardous materials (usually consisting of vehicle fluids) in an appropriate manner. The remaining hulks, often flattened to facilitate transportation, are sent to automobile shredders, who use hammermills to break them into fist-sized fragments. Most of the ferrous metals are recovered by magnetic separation, while the lightweight waste material or "fluff" (ASR), composed mainly of foam, textiles, plastics and dirt, is removed by air cyclone separation. The ferrous metal scrap is sent to steel mills for recycling, and the fluff is landfilled. The remaining mixture of high density, nonmagnetic materials is rich in nonferrous metals. It is usually sent to nonferrous metal separators for the recovery of metals such as aluminum, zinc, copper, brass, magnesium, and stainless steel. The processes employed by the nonferrous separators are water elutriation, eddy current separation, and heavy media separation. The waste material that remains, consisting mainly of dirt and fines, is landfilled.

Through discussions with professionals (Lindell 1998) in the automotive recycling field, it was determined that the following parts are commonly removed at dismantling, either for safety reasons or because they can be easily dismantled and have a resale/salvage value:

Tires and wheels

Battery

Powertrain (Engine + Transmission)

Fuel tank
Fluids

Air bags

Radiator

Catalytic converter.

Of the hulk that is transported to the shredding operation, it is assumed that all the ferrous metals are recovered for recycling, while the subsequent non-ferrous metal separation processes result in the recovery of the following constituent weight fractions:
Aluminum:
$70.0 \%$
Zinc:
$18.5 \%$
Copper and Brass: $\quad 10.0 \%$
Stainless Steel: $\quad 1.5 \%$

The environmental issues of concern in the End-of-Life stage are the solid waste generated (ASR) and landfilled and the energy consumed in operating the machinery used in the end-of-life processes. 
Additionally, in order to accurately assess the impact of electricity used in the end-of-life processes, the inputs and outputs associated with electricity generation have been included via The Center's in-house electric grid process.

\subsection{Results}

\subsubsection{The Big Picture}

The following three sections discuss in detail the results from the life-cycle evaluation broken down by the major types of inputs and outputs considered: energy consumption, total solid waste generation and major air emissions. Following this section will be a discussion of the major and minor impacts within each life-cycle stage.

\subsubsection{Energy}

Figure 6 shows the lifetime energy use for each vehicle arranged by life cycle stage. In general, a reduction of almost 55\% can be seen in the 3XVs over the 1994 vehicle, primarily due to higher fuel efficiency in the use stage. The life-cycle stages of manufacturing and end-of-life are relatively insignificant, and the extraction and materials processing (E\&MP) energy use is relatively small compared to the Use stage. While 3XV's E\&MP energy use is twice that of the 1994 vehicle, this increase only increases total 3XV lifetime energy consumption by $5 \%$.

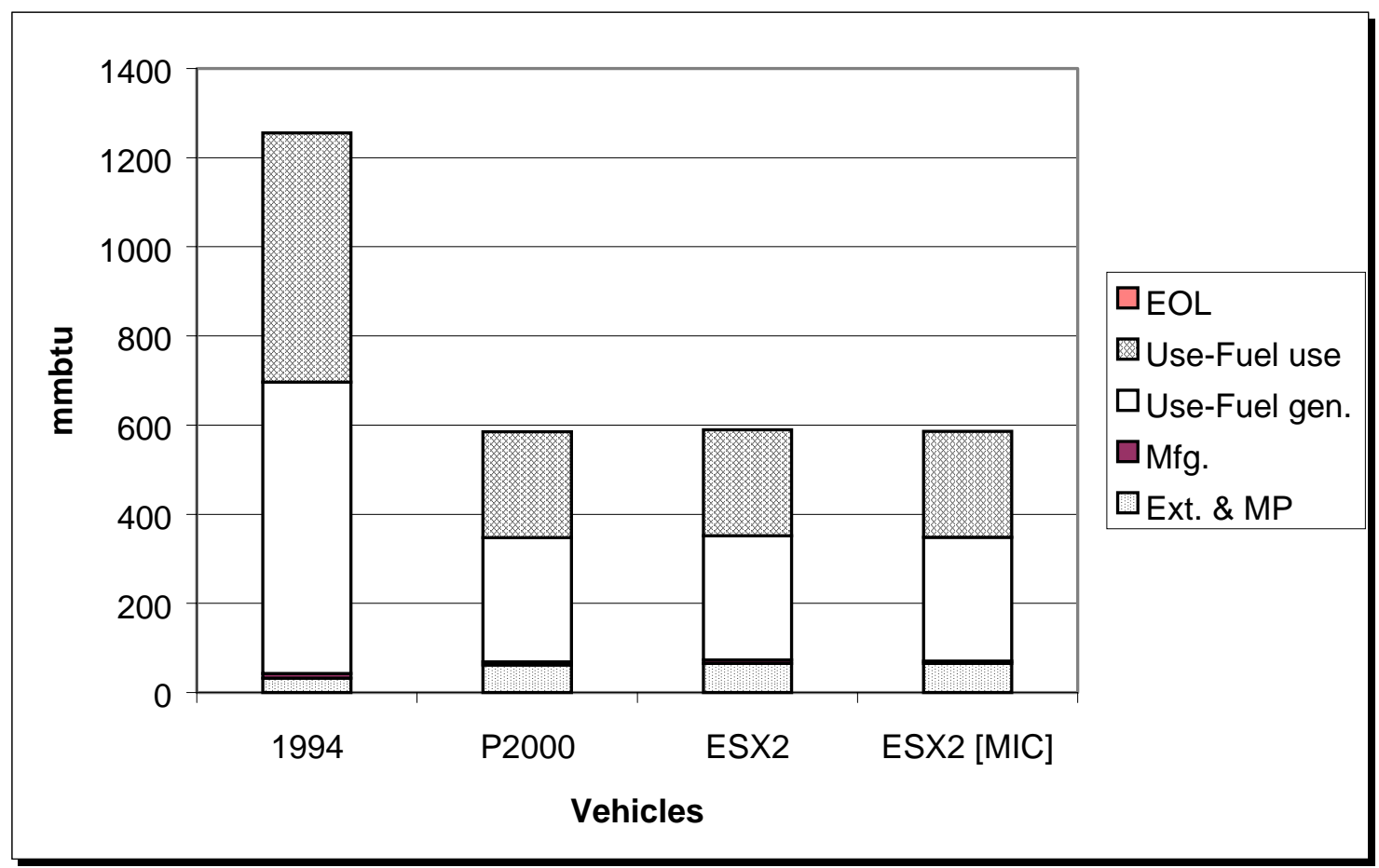

Figure 6. Lifetime Energy Consumption

The savings realized in this impact category can be almost completely attributed to $3 \mathrm{XVs}$ ' 70 mpg fuel efficiency in the use stage, which the prototype version of the ESX2 has supposedly already achieved. When the $3 \mathrm{XV}$ s reach the PNGV goal of $80 \mathrm{mpg}$ fuel efficiency, almost 
another $13 \%$ savings will be realized over the 1994 vehicle, including additional savings from the fuel generation and use facets of the use life-cycle stage. The potential savings to be realized in this life-cycle stage will be a big step toward achieving the PNGV goals. 


\subsubsection{Solid Waste}

The second impact category analyzed in this evaluation was that of solid waste generation. Figure 7 shows the impacts from solid waste generation for each vehicle broken down by life-cycle stage. Clearly, the E\&MP life-cycle stage dominates, with each $3 \mathrm{XV}$ scenario showing a small total life-cycle increase in solid waste. The P2000 represents a reduction in all life-cycle stages except for E\&MP, where the increase overshadows the savings achieved elsewhere. For the ESX2 with molded-in-color body panels and subsequent recycling of those panels at the vehicle's end-of-life, the solid waste reductions achieved in manufacturing and end-of-life are basically negated by the increase in solid waste generated in E\&MP.

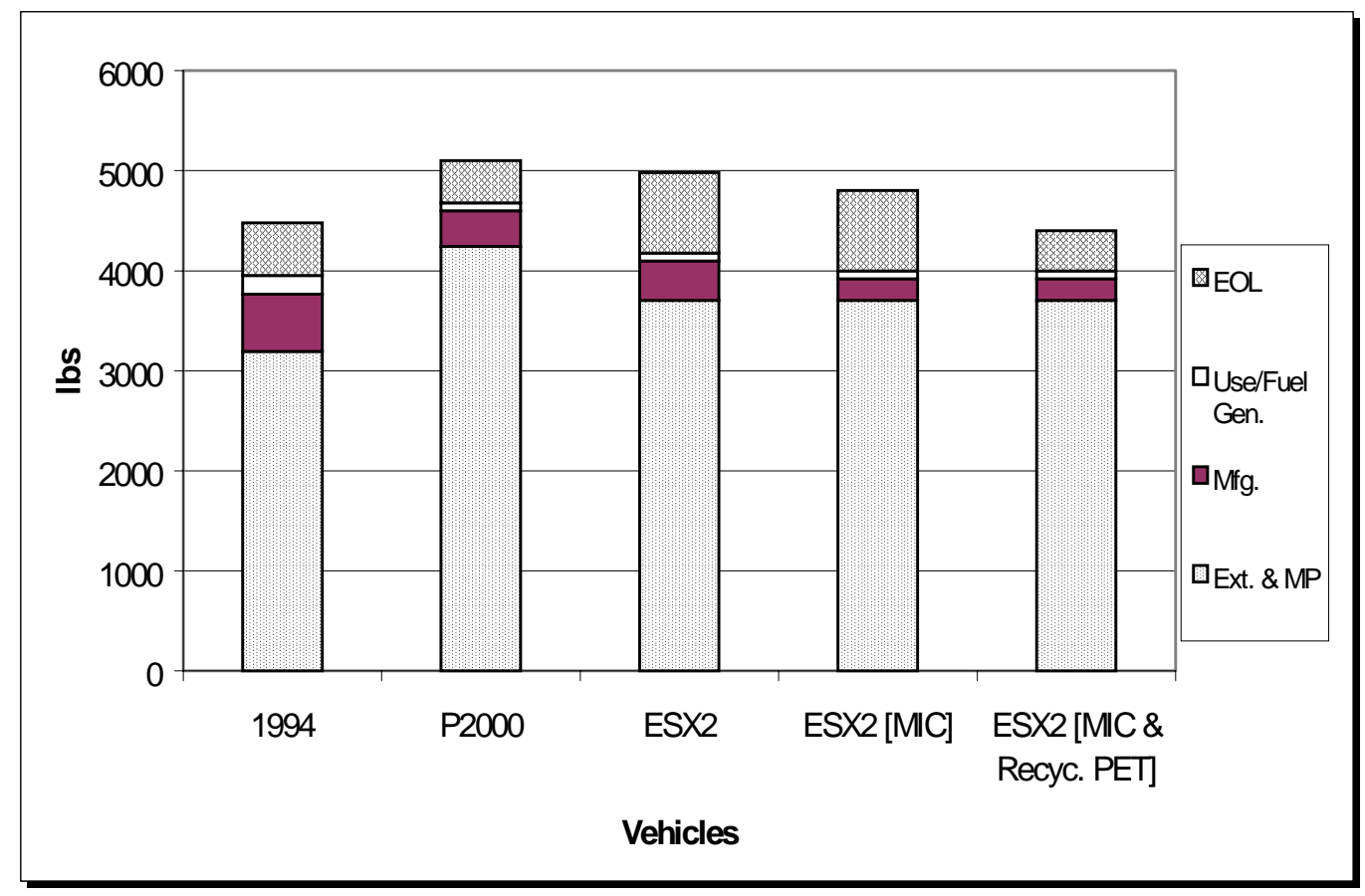

Figure 7. Lifetime Solid Waste Generation

Thus, there remains a need for work in the solid waste generation impact category, and that work needs to be focused on either using more recycled material as raw material or attempting to find raw materials that produce less waste to reduce solid wastes produced during upstream processes.

\subsubsection{Air Emissions}

The remaining pollutants evaluated are all air emissions: $\mathrm{CO}_{2}, \mathrm{CH}_{4}, \mathrm{~N}_{2} \mathrm{O}, \mathrm{SF}_{6}, \mathrm{CF}_{4}$ and $\mathrm{C}_{2} \mathrm{~F}_{6}$, which are all greenhouse gases, and $\mathrm{PM}, \mathrm{NO}_{\mathrm{x}}$ and $\mathrm{CO}$, which are criteria air pollutants. All of these are of the utmost importance to the PNGV goals. It is primarily this output type for which government regulations currently exist for automobiles, and because these pollutants have effects within some of the most potentially damaging impact categories: acute and chronic human health effects and global warming.

\section{Greenhouse Gases}

Figure 8 reveals the life-cycle GWP of the emissions of the above- mentioned six gases expressed as $\mathrm{CO}_{2}$ equivalents. The MIC and recycled PET options are omitted because they 


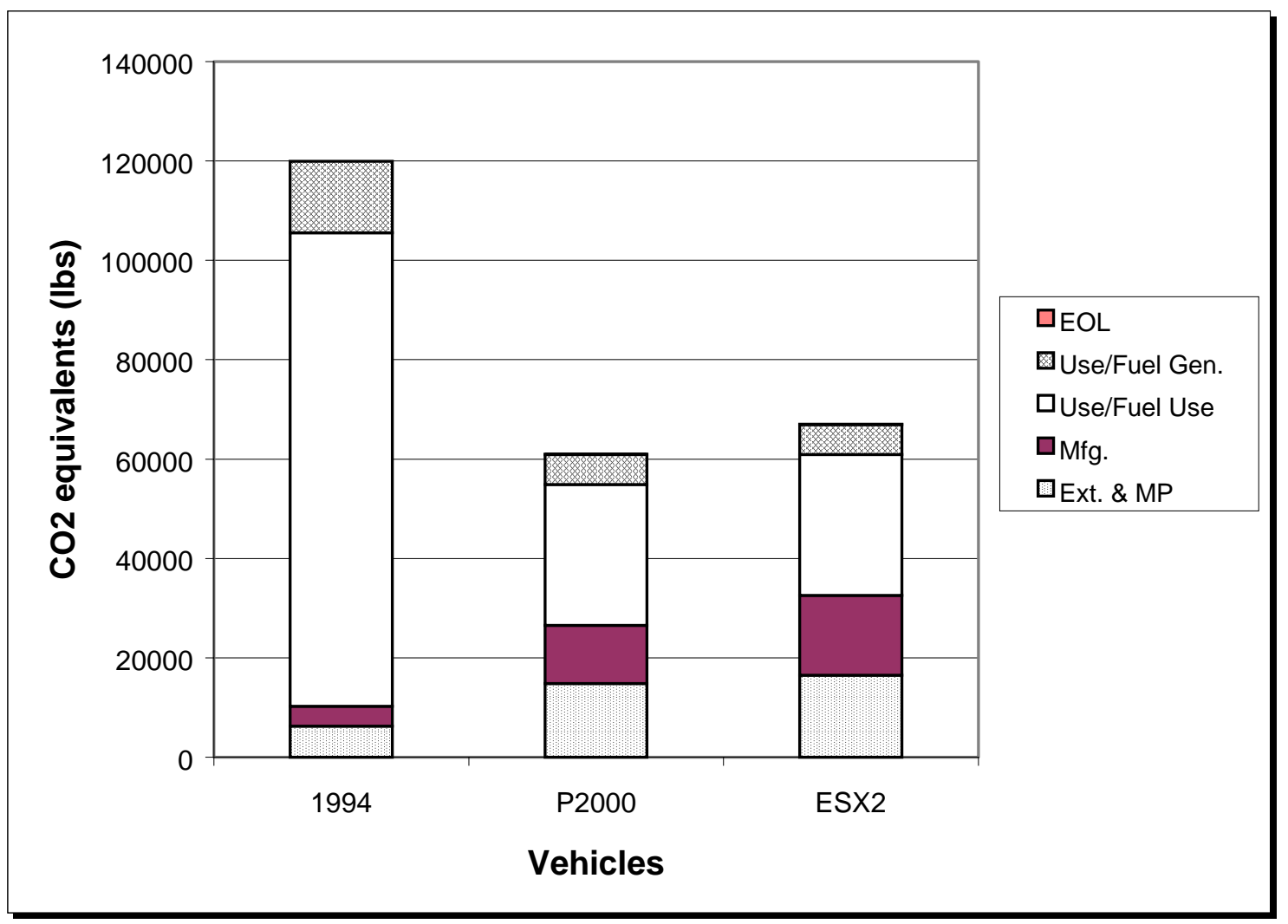

Figure 8. Lifetime Global Warming Potential

contribute an insignificant effect on GWP. (This is also the case for the remaining air emissions). In short, the $3 \mathrm{XVs}$ would reduce GWP for the automobile by almost $50 \%$ on average. The use of newer materials to help achieve weight reduction, however, causes notable increases in the GWP of emissions from $\mathrm{E} \& \mathrm{MP}$ (due specifically to $\mathrm{SF}_{6}, \mathrm{CF}_{4}$ and $\mathrm{C}_{2} \mathrm{~F}_{6}$ ) and manufacturing (due to $\mathrm{SF}_{6}$ ) life-cycles stages. However, the greater gains realized from the large decrease in the use-stage GWP more than compensate for those increases. If the industries that utilize and generate these fluoride emissions can find ways to better control them, then even greater improvement should be realized in the GWP for the $3 X V$ s.

Figure 9 shows the geographic distribution—by urban or rural area—of the global warming potential emissions. (The figure also shows the distribution for $\mathrm{NO}_{\mathrm{X}}, \mathrm{PM}$, and $\mathrm{CO}$, under the LEV-ULEV standard.) Substantial reductions are projected for both urban and rural emissions, but the reduction in urban areas is far more significant because GWP there will be halved. 

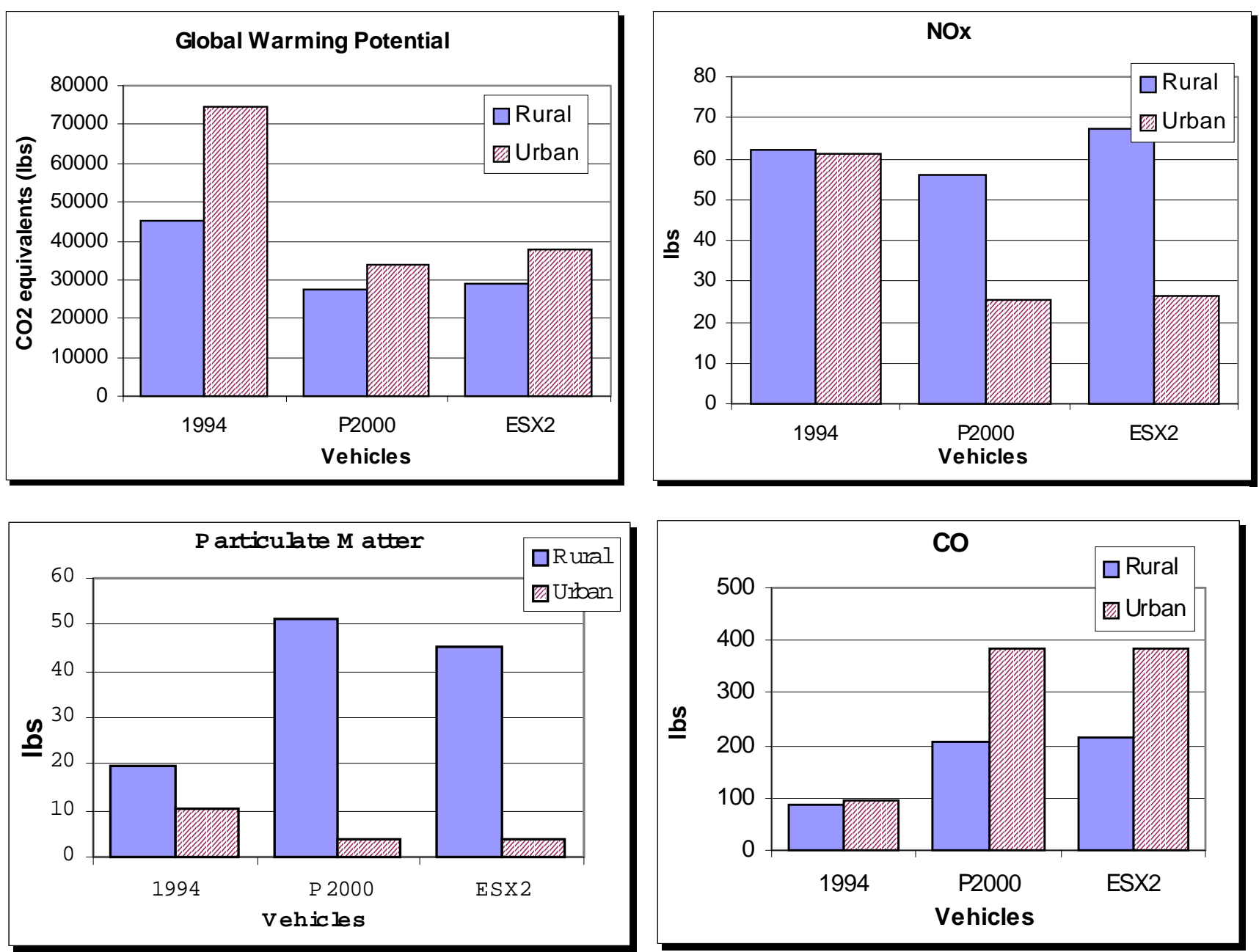

Figure 9. Rural vs. Urban Distribution of GWP Effects and Emissions

Particulate Matter

Figure 10 shows the lifetime PM emissions for each vehicle broken down by life cycle stage. Data are presented for both emissions profiles: one based on the Volkswagen Passat diesel engine, the other an average of the low emission vehicle (LEV) and ultra-low emission vehicle (ULEV) standards. The increases in PM during the E\&MP stage are substantial—more than doubling the E\&MP emissions of the 1994 vehicle. With respect to the E\&MP life-cycle stage, the bulk of the PM generation is due to the use of aluminum, magnesium and titanium. In the $3 \mathrm{XVs}$, $90 \%$ of the PM emissions generated in this life-cycle stage are a result of utilizing those three materials. These increases overshadow the emissions reductions achieved in the manufacturing and Use/fuel generation. 


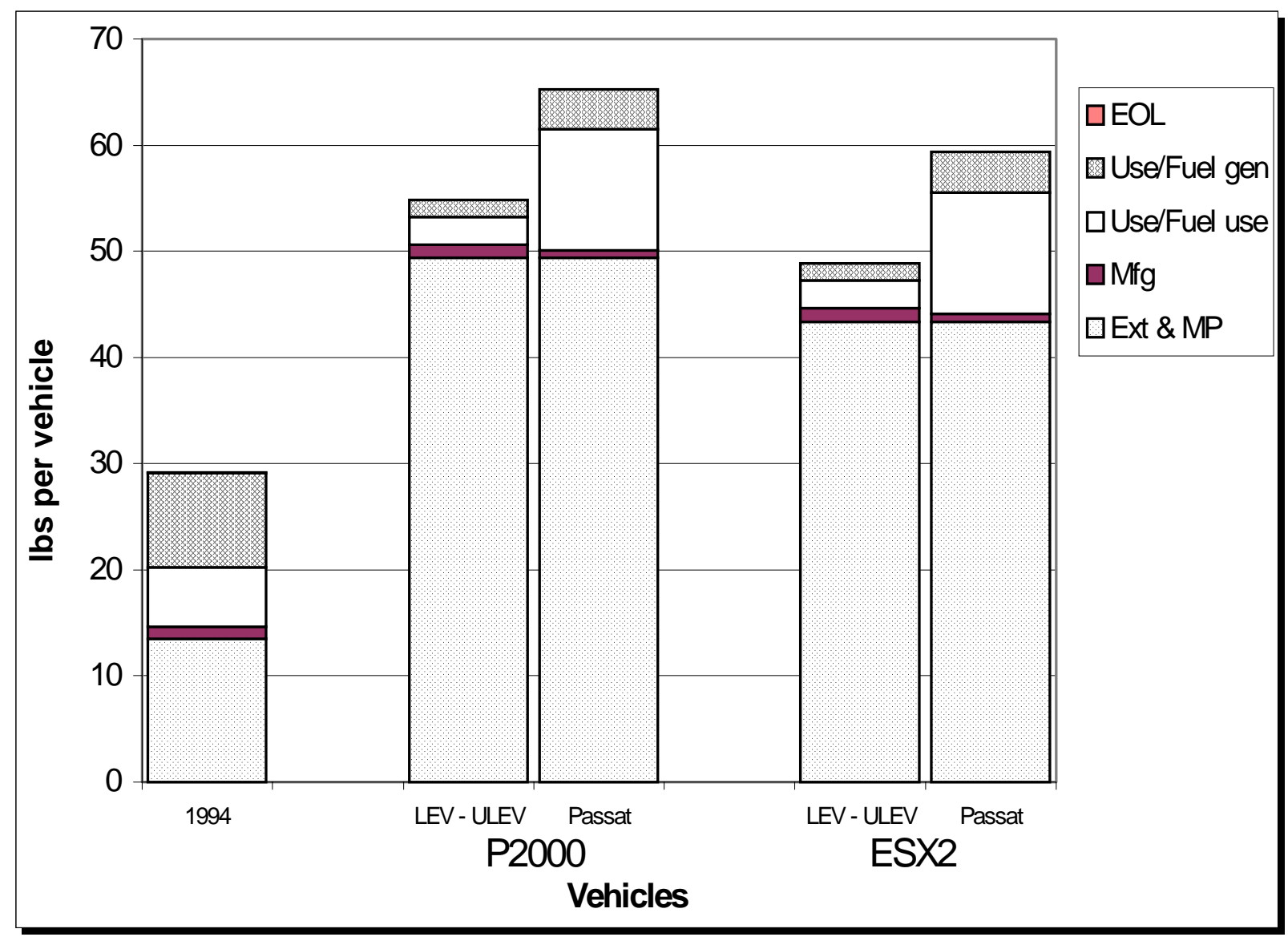

Figure 10. Lifetime Particulate Emissions

For the use/fuel use stage, the PM increase can be directly correlated to the switch to diesel fuel from gasoline. The standards that the fuel and engines are required to meet will significantly effect the PM emissions. If no emissions improvements occur, both the P2000 and the ESX2 can be expected, during vehicle use, to produce twice the PM as the baseline vehicle. This is because diesel engines have traditionally had greater $\mathrm{PM}\left(\right.$ and $\mathrm{NO}_{\mathrm{x}}$ ) emissions than do gasoline engines, a result of the diesel engine's use of compression, rather than a spark, to ignite the fuel. Much time and effort has been put into investigating ways in which these emissions can be reduced. For instance, PM emissions and their subsequent impacts can be reduced by several methods. Traps and catalysts are two examples of aftertreatment technologies. Traps can be used to capture and eventually burn PM emissions. Catalysts for diesel engines attempt to reduce PM emissions by converting them to less harmful compounds (EPA 1999c).

Figure 9 shows that the P2000 and the ESX2's emissions of PM in rural areas could double, while emissions in urban areas could be halved. 


\section{Nitrogen Oxides}

As with PM emissions, the magnitude of the total life-cycle $\mathrm{NO}_{\mathrm{x}}$ emissions depends on the standard used to assess the emissions stemming from P2000 and ESX2's use of diesel fuel (see Figure 11). If one assumes that LEV/ULEV standards will be met (see Sect. 6.2.3), then emissions at the Use/fuel use stage drop slightly. If the Passat-like engine is assumed, then $\mathrm{NO}_{\mathrm{x}}$ at the Use/fuel use stage increases significantly, causing the total life-cycle $\mathrm{NO}_{\mathrm{x}}$ emissions to be greater for the P2000 and ESX2 than for the base vehicle. Because of improved fuel efficiency and the consequent need for less fuel over the lifetime, both prototypes would reduce emissions from fuel generation. As with PM, increased emissions occur during the E\&MP stage due to the use of new materials.

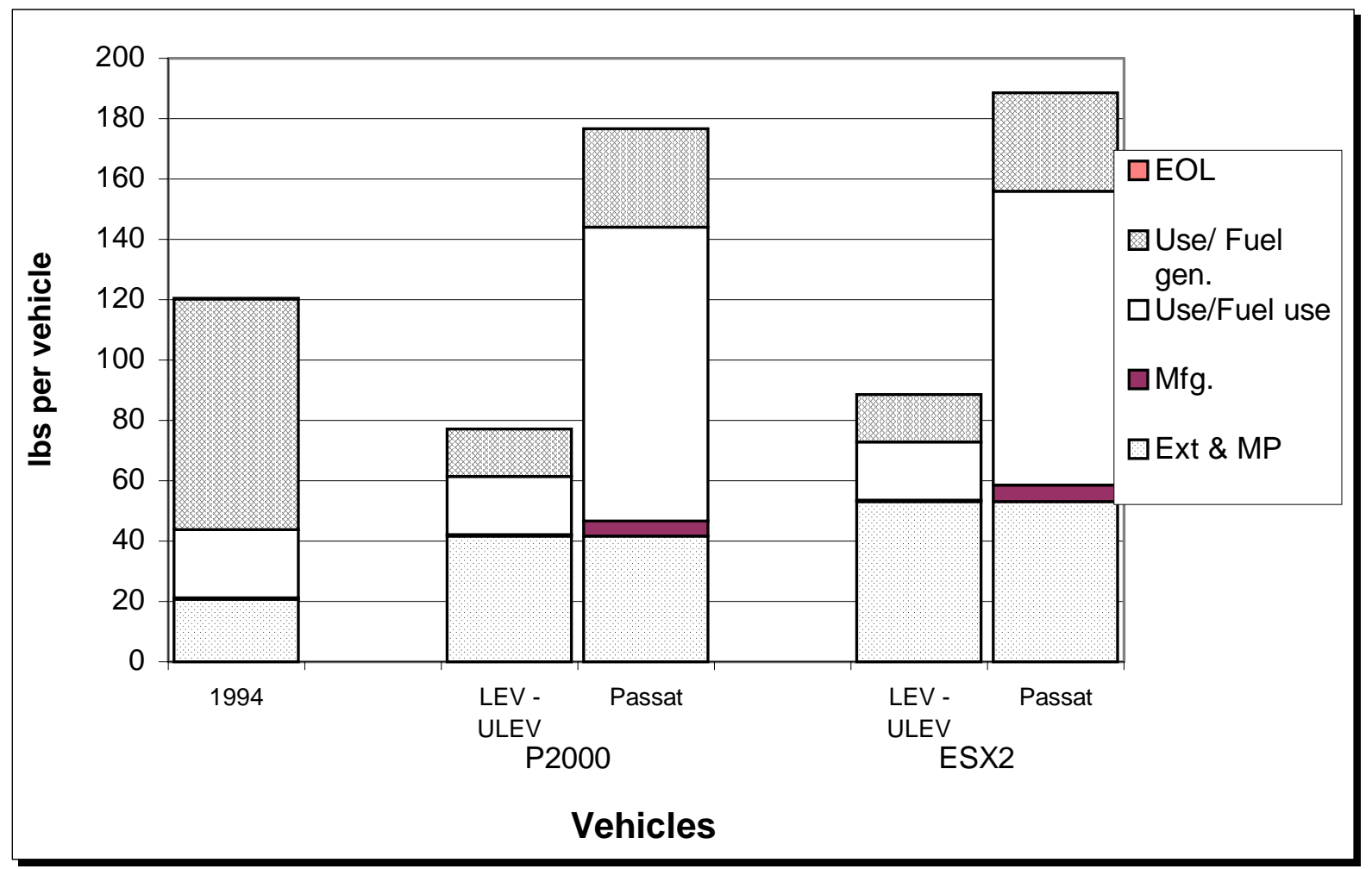

Figure 11. Lifetime $\mathrm{NO}_{\mathrm{x}}$ Emissions

"Diesel particulates and nitrogen oxides, the two most troublesome components of diesel exhaust emissions, have a dramatic, damaging impact on the environment and on our health," states the front page of DieselNet's website in discussing the diesel engine's opportunity to become a "major candidate" for the power plant of the future (DieselNet 1999). Recognizing $\mathrm{NO}_{\mathrm{x}}$ as a potential barrier to expanded use of the diesel engine, the industry and others have been researching ways to reduce $\mathrm{NO}_{\mathrm{x}}$ emissions from diesel. Changes in the fuel itself, as well as the diesel engine, could conceivably bring $\mathrm{NO}_{\mathrm{x}}$ emissions to the $0.073 \mathrm{~g} / \mathrm{mile}$ standard (the average of the LEV and ULEV standards) that would result in the emissions show in Figure 11.

The diesel industry has estimated that through a number of fuel and engine improvements, a $\mathrm{NO}_{\mathrm{x}}$ emissions rate of $0.030 \mathrm{~g} / \mathrm{mile}$ might be achieved. If this were to occur additional reductions in 
$\mathrm{NO}_{\mathrm{x}}$ emissions would result in the Use/fuel use stage, bringing the figure below current gasoline emissions.

In rural environments, changes in $\mathrm{NO}_{\mathrm{X}}$ emissions are expected to be small, with the ESX2 slightly increasing emissions and the P2000 slightly decreasing rural emissions. In urban areas, both prototypes are expected to reduce $\mathrm{NO}_{\mathrm{X}}$ emissions by $60 \%$.

\section{Carbon Monoxide}

Figure 12 shows the lifetime $\mathrm{CO}$ emissions for the three vehicles. The LEV-ULEV vs. Passat pattern of emissions seen in $\mathrm{PM}$ and $\mathrm{NO}_{\mathrm{X}}$ is reversed for CO. CO emissions from the P2000 or ESX2 using a Passat-like engine would be lower that the 1994 vehicle's emissions and substantially lower than the prototypes under the LEV-ULEV standards. The reduction in the E\&MP life-cycle stage can be attributed to the newer materials—aluminum, titanium, and magnesium. The reduction in the use/fuel use life-cycle stage can be attributed to the switch to diesel fuel. Figure 9 shows that $65 \%$ of the increase in $\mathrm{CO}$ would occur in urban areas.

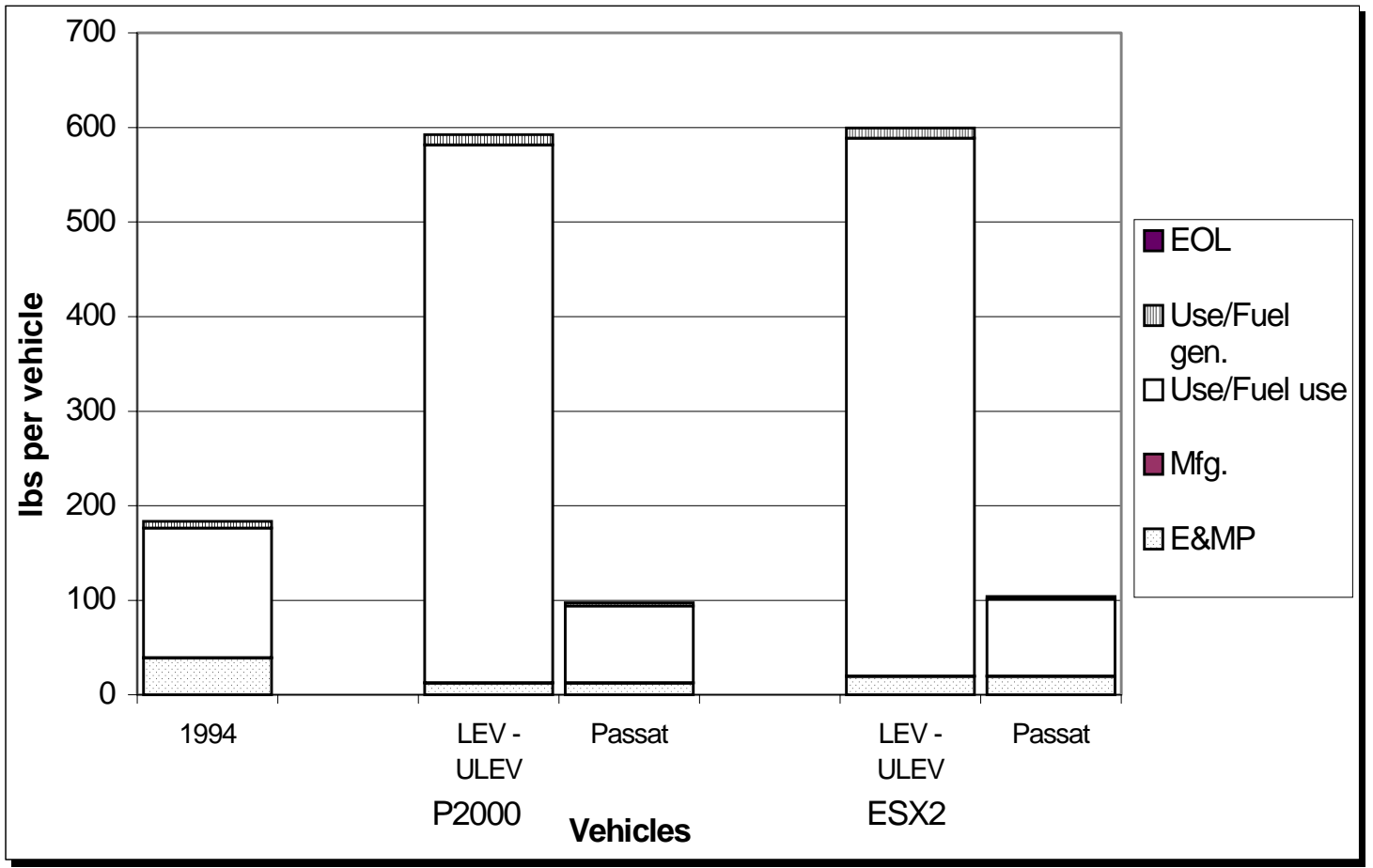

\section{Figure 12. Lifetime CO Emissions}

\subsubsection{Results by Life-Cycle Stages}

Results presented by life-cycle stage are based on the Passat derived emissions values.

\subsubsection{Extraction and Materials Processing}

Table 10 shows the inputs and outputs for the Extraction and Materials Processing stage for the three vehicles. There are no results shown for the consideration of molding the ESX2's PET body panels in color, or for the recycling of those panels, because the upstream differences in 
E\&MP for molding of those panels in color were not evaluated, and the recycling of PET body panels was assumed to impact only the End-of-Life stage (i.e., there was no direct displacement of virgin PET by PET recycled from End-of-Life body panels).

Table 10. Inputs and Outputs from Extraction and Materials Processing (all units are lbs/lifetime unless otherwise noted)

\begin{tabular}{|lr|r|r|}
\cline { 2 - 4 } \multicolumn{1}{c|}{} & 1994 Vehicle & \multicolumn{1}{c|}{ P2000 } & \multicolumn{1}{c|}{ ESX2 } \\
\hline Energy (mmbtu/lifetime) & 31.81 & 62.20 & 65.71 \\
\hline Solid Waste & 3192.47 & 4243.75 & 3703.44 \\
\hline $\mathrm{NO}_{x}$ & 13.52 & 49.41 & 43.37 \\
\hline CO & 16.44 & 41.78 & 53.14 \\
\hline GWP - Total $\mathrm{CO}_{2}$ equivalents & 38.87 & 12.44 & 19.33 \\
\hline
\end{tabular}

An important thing to note from Table 10 is that almost all the values increase from the 1994 vehicle values, with the exception of CO. This life-cycle stage is one of the worst for the $3 \mathrm{XVs}$, due almost completely to the use of new, more energy intensive materials and the increased use of aluminum, which is also energy intensive. In general, the energy use doubles, the solid waste increases on the order of 1,000 and $500 \mathrm{lbs}$ for the P2000 and ESX2, respectively, and the PM, $\mathrm{NO}_{\mathrm{x}}$, and total $\mathrm{CO}_{2}$ equivalents all increase by approximately $100-200 \%$. The effect of the new materials on this life-cycle stage is shown in Figure 13.

Although Figure 13 represents only one of the impact categories (energy), it is indicative of the changes in outputs - solid waste and emissions - at the Extraction and Materials Processing stage. Details of this life cycle stage are available in the Center's report (Center for Clean Products and Clean Technologies 1999).

Figure 13 reveals the energy requirements for the extraction and initial processing of materials utilized to construct the 1994 vehicle and the two 3XVs, broken down by individual energy of materials. The large increase in the use of aluminum and its associated energy use clearly predominates this graph, with increases in the use of magnesium and titanium also showing significant contributions. These are specifically due to material unit energy intensities. Energy intensity values for the primary vehicle materials are shown in Table 11. If the feedstock energy of plastics were included, as is the convention in some LCAs, the plastic unit energy intensity would increase by up to $100 \%$. 


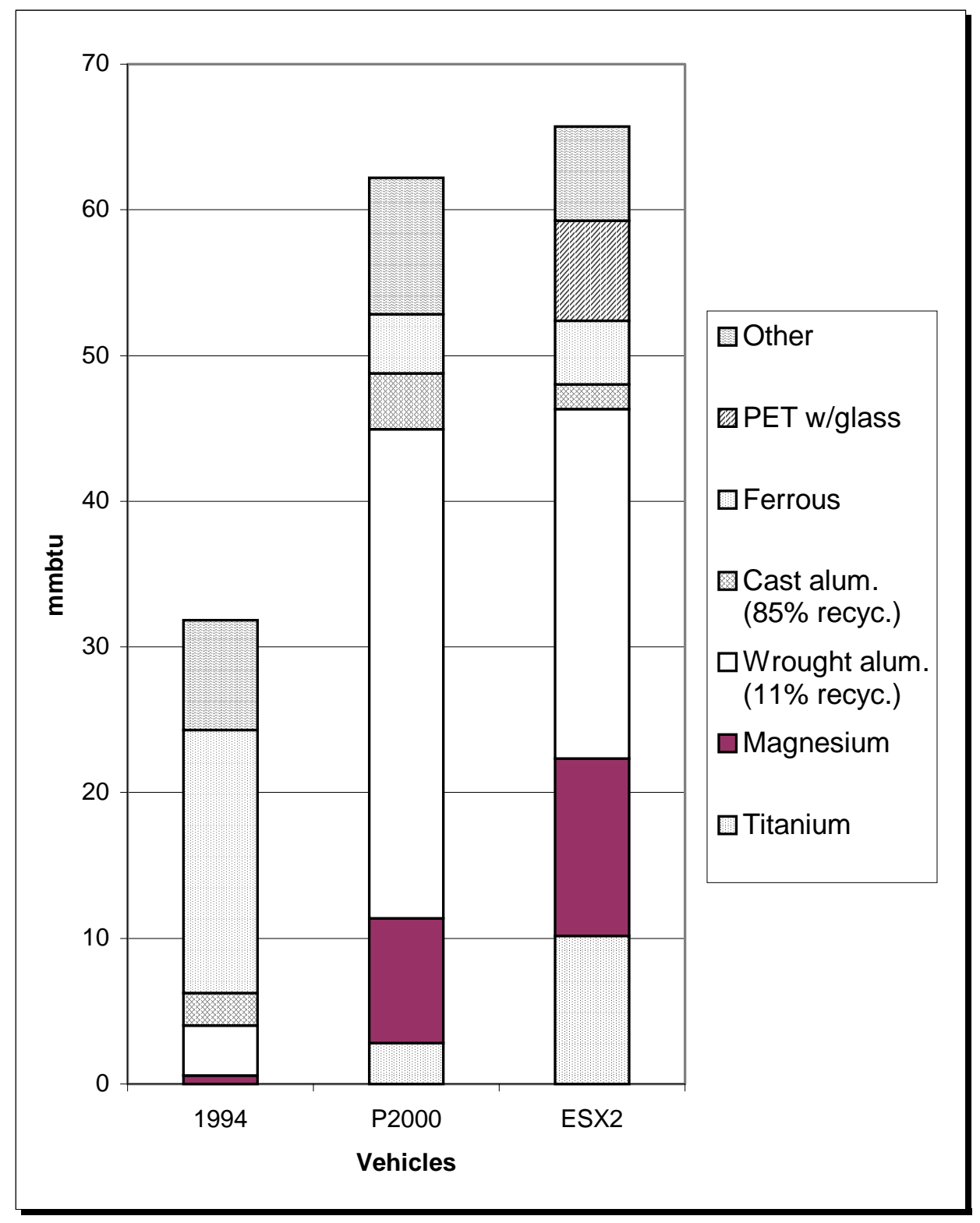

Figure 13. Extraction and Materials Processing Energy Consumption

Table 11. Material Unit Energy Intensities (MJ/kg)

(Excludes feedstock energy)

\begin{tabular}{|l|c|}
\cline { 2 - 2 } \multicolumn{1}{c|}{} & Intensity \\
\hline Titanium & 590.8 \\
\hline Magnesium & 379.3 \\
\hline Wrought Aluminum & 169.0 \\
\hline Cast Aluminum & 32.8 \\
\hline Ferrous & 19.3 \\
\hline Pet with Glass & 40.0 \\
\hline Other Plastics & 69.3 \\
\hline
\end{tabular}


Another issue of concern in this life-cycle stage is the emissions of greenhouse gases as indicated by GWP. Table 12 reveals the individual gases' contribution to GWP at the E\&MP stage. The $\mathrm{SF}_{6}$ emissions are solely associated with the use of magnesium; the $\mathrm{CF}_{4}$ and $\mathrm{C}_{2} \mathrm{~F}_{6}$ emissions (both of which are PFCs) are solely associated with the use of aluminum. Even if $\mathrm{SF}_{6}$ and PFC emissions are eliminated, both the P2000 and the ESX2 would still realize an increase in GWP in this life-cycle stage due to the substantial increase in $\mathrm{CO}_{2}$ emissions.

Table 12. Gases that Contribute to GWP in the Extraction and Materials Processing Life-Cycle Stage (lbs of $\mathrm{CO}_{2}$ equivalents)

\begin{tabular}{|l|r|r|r|}
\cline { 2 - 4 } \multicolumn{1}{c|}{} & \multicolumn{1}{c|}{$\mathbf{1 9 9 4}$ Vehicle } & \multicolumn{1}{c|}{ P2000 } & \multicolumn{1}{c|}{ ESX2 } \\
\hline $\mathrm{CO}_{2}$ & 5,568 & 8,610 & 9,310 \\
\hline $\mathrm{CH}_{4}$ & 155 & 600 & 790 \\
\hline $\mathrm{SF}_{6}$ & 247 & 3,541 & 5,023 \\
\hline $\mathrm{CF}_{4}$ & 248 & 1,708 & 1,178 \\
\hline $\mathrm{C}_{2} \mathrm{~F}_{6}$ & 49 & 339 & 234 \\
\hline Total $\mathrm{CO}_{2}$ Equivalents & 6,267 & 14,798 & 16,535 \\
\hline
\end{tabular}

Even though the E\&MP life-cycle stage is problematic for the $3 \mathrm{XVs}$, it should be noted that throughout these three vehicles' lifetimes, the energy use and generation of $\mathrm{CO}, \mathrm{NO}_{\mathrm{x}}$ and $\mathrm{CO}_{2}$ equivalent air emissions in the E\&MP life-cycle stage only contribute 10 - 40\% of the lifetime totals (i.e., 90 - 60\% of the lifetime totals are generated in other life-cycle stages). Only in the particulate air emissions and solid waste generation categories do the E\&MP percentages of the lifetime total exceed $50 \%$, reaching $72 \%$ and $83 \%$, respectively.

\subsubsection{Manufacturing}

Table 13 shows the inputs and outputs (excluding greenhouse gases) for the manufacturing stage of the three vehicles, plus an option of the ESX2 with molded-in color panels. In reviewing the results of the evaluation for this life-cycle stage, it should be kept in mind that all the results have been scaled to each vehicle's total weight, thus they have the same ratio with respect to one another. The best use of the data is in comparing across life-cycle stages. This holds true for all the data except for the GWP calculations, due to the addition of emissions associated with the use of $\mathrm{SF}_{6}$ (as discussed in the E\&MP methodology section, 6.2.1). $\mathrm{SF}_{6}$ is used as a covergas in the process of casting magnesium during primary production, as well as further downstream in the life cycle during the production of individual components. Table 14 shows the increase in the quantity of magnesium used in manufacturing the three vehicles, as well as the GWP effects. With a GWP of 24,900 times that of $\mathrm{CO}_{2}, \mathrm{SF}_{6}$ is one of the most potent greenhouse gases known.

The MIC savings are small on the global warming front, but more noticeable with regard to energy consumption, air emissions, and solid waste generation values, as seen in Table 13. Comparing only the ESX2 with painted body panels (ESX2) and the ESX2 with MIC (ESX2 [MIC]), an energy savings of $42 \%$ is realized, air emissions are reduced by $20-45 \%$, and solid waste decreases by $45 \%$. These results reflect not only the savings attained in-plant, but also those savings associated with a reduction in electricity use. 
Table 13. Inputs and Outputs of Manufacturing, including Mold-in-Color Savings (all units are lbs unless otherwise noted)

\begin{tabular}{|l|r|r|r|r|}
\cline { 2 - 5 } \multicolumn{1}{c|}{} & \multicolumn{1}{c|}{$\boldsymbol{1 9 9 4}$} & \multicolumn{1}{c|}{$\boldsymbol{P 2 0 0 0}$} & \multicolumn{1}{c|}{$\boldsymbol{E S X 2}$} & $\boldsymbol{E S X 2}(\boldsymbol{M I C})$ \\
\hline Energy consumption (mmbtu) & 11.12 & 6.88 & 7.71 & 4.48 \\
Solid waste generation & 571.33 & 353.57 & 395.78 & 216.58 \\
Air emissions - Particulates & 1.94 & 1.20 & 1.34 & 1.07 \\
Air emissions - CO & 0.61 & 0.38 & 0.43 & 0.29 \\
Air emissions - $\mathrm{NO}_{\mathrm{x}}$ & 7.80 & 4.82 & 5.40 & 2.99 \\
\hline
\end{tabular}

Table 14. Global Warming Potential Effects of Sulfur Hexafluoride ( $\left.\mathrm{SF}_{6}\right)$ (all units are $\mathrm{lbs}$ of $\mathrm{CO}_{2}$ equivalents unless otherwise noted)

\begin{tabular}{|l|r|r|r|r|}
\cline { 2 - 5 } \multicolumn{1}{c|}{} & \multicolumn{1}{c|}{1994} & \multicolumn{1}{c|}{ P2000 } & ESX2 & ESX2 (MIC) \\
\hline Quantity of magnesium used in & & & & \\
vehicle production (lbs) & 6 & 86 & 122 & 122 \\
Mfg. - $\mathrm{SF}_{6}$ alone & 675 & 9,677 & 13,728 & 13,728 \\
Mfg. - Total $\mathrm{CO}_{2}$ equiv. & 3,988 & 11,727 & 16,023 & 15,015 \\
Lifetime $\mathrm{CO}_{2}$ equiv. & 119,903 & 60,943 & 66,976 & 65,968 \\
\hline
\end{tabular}

\subsubsection{Use}

The use stage is concerned with the environmental implications of driving the vehicle over its expected life of 120,000 miles. This life-cycle stage deals with the fuel consumed by the vehicle and the tailpipe emissions produced as a result. The energy and materials required to produce the fuel and the emissions from fuel production are also dealt with in this stage. As both $3 \mathrm{XVs}$ being evaluated are based on the same kind of diesel engine, they are assumed to have identical fuel efficiencies and, therefore, show identical results in the use stage. Moreover, the "Mold-in Color" scenario for the ESX2 does not affect this life-cycle stage.

Based on fuel efficiencies of $26.6 \mathrm{mpg}$ for the 1994 vehicle and $70 \mathrm{mpg}$ for the $3 \mathrm{XVs}$, their lifetime fuel requirement is shown in Table 15.

Table 15. Lifetime Fuel Requirement (gallons)

\begin{tabular}{|l|c|c|}
\cline { 2 - 3 } \multicolumn{1}{c|}{} & $\mathbf{1 9 9 4}$ Vehicle & P2000/ESX2 \\
\hline Gasoline & 4,511 & - \\
\hline Diesel & - & 1,714 \\
\hline
\end{tabular}

The 3XVs use 2,797 fewer gallons of fuel for a $62 \%$ savings over the lifetime of the vehicle. The significantly reduced fuel consumption results in reduced air emissions during use for some types of emissions. However, the change from gasoline to diesel fuel causes some categories of emissions, particularly $\mathrm{PM}$ and $\mathrm{NO}_{\mathrm{x}}$, to increase. 
Energy consumption during the use stage is made up of the heat value of the fuel used and the energy required to produce the lifetime quantity of fuel. The total energy is reduced by about $57 \%$ from the baseline 1994 vehicle, as is seen in Table 16.

Table 16. Energy Consumption in the Use Stage (mmbtu)

\begin{tabular}{|l|r|r|}
\hline \multicolumn{1}{|c|}{ Energy Consumption } & $\mathbf{1 9 9 4}$ Vehicle & \multicolumn{1}{c|}{ P2000/ESX2 } \\
\hline Fuel use & 559 & 238 \\
\hline Fuel generation & 654 & 278 \\
\hline Use-Stage Total & $\mathbf{1 , 2 1 3}$ & $\mathbf{5 1 6}$ \\
\hline
\end{tabular}

The air emissions estimated from EPA test results on 1994 Taurus and Intrepid vehicles for the 1994 vehicle, and from a 1998 Passat for the 3XVs, as described earlier in the methodology, are provided in Table 17.

Table 17. Estimated Use-Stage Emissions (lbs/lifetime)

\begin{tabular}{|l|r|r|r|r|r|r|}
\cline { 2 - 7 } \multicolumn{1}{c|}{} & \multicolumn{3}{c|}{ 1994 Vehicle } & \multicolumn{3}{c|}{ P2000/ESX2 } \\
\cline { 2 - 7 } \multicolumn{1}{c|}{} & Fuel gen. & Fuel use & \multicolumn{1}{c|}{ Total } & Fuel gen. & Fuel use & \multicolumn{1}{c|}{ Total } \\
\hline $\mathrm{CO}$ & 7.36 & 136.80 & 144.16 & 3.13 & 81.27 & 84.4 \\
\hline $\mathrm{NO}_{\mathrm{x}}$ & 76.53 & 22.49 & 99.02 & 32.54 & 97.52 & 130.06 \\
\hline $\mathrm{PM}$ & 8.96 & 5.56 & 14.52 & 3.81 & 11.38 & 15.19 \\
\hline $\mathrm{CH}_{4}$ & 23.71 & 3.44 & 27.15 & 10.08 & 1.63 & 11.71 \\
\hline $\mathrm{CO}_{2}$ & 13,756 & 95,225 & 108,981 & 5,849 & 28,322 & 34,171 \\
\hline
\end{tabular}

As may be observed from the above, the $3 \mathrm{XVs}$ score better than the 1994 vehicle in the $\mathrm{CO}, \mathrm{CH}_{4}$, and $\mathrm{CO}_{2}$ emission categories. When assuming the Passat-based emission rates, the other emissions, namely $\mathrm{NO}_{\mathrm{x}}$ and $\mathrm{PM}$, go up considerably.

The inputs and outputs associated with the generation of gasoline and diesel fuel needed for the driving the vehicles were obtained from the same proprietary, in-house data set used for the major primary materials. The energy required, solid waste generated, and air emissions from the production of gasoline and diesel are shown in Table 18.

Based on the estimated $\mathrm{CO}_{2}$ and $\mathrm{CH}_{4}$ emissions (two greenhouse gases), the GWP in terms of $\mathrm{CO}_{2}$ equivalents was evaluated and is depicted in Figure 14. The contribution of the P2000 and ESX2 to the GWP is significantly lower than that of the 1994 vehicle, and that fuel production plays a minor role, compared to fuel use. 
Table 18. Inputs and Outputs from Gasoline/Diesel Production (all units are $\mathrm{lbs} /$ lifetime unless otherwise noted)

\begin{tabular}{|l|r|r|}
\cline { 2 - 3 } \multicolumn{1}{c|}{} & \multicolumn{1}{c|}{ 1994 Vehicle } & \multicolumn{1}{c|}{ P2000/ESX2 } \\
\hline Energy (mmbtu/lifetime) & 653.67 & 277.93 \\
\hline Solid Waste & 188.97 & 80.35 \\
\hline $\mathrm{PM}$ & 8.95 & 3.81 \\
\hline $\mathrm{NO}_{x}$ & 76.53 & 32.54 \\
\hline $\mathrm{CO}$ & 7.36 & 3.13 \\
\hline $\mathrm{CO}_{2}$ & 13756.75 & 5849.13 \\
\hline $\mathrm{CH}_{4}$ & 23.71 & 10.08 \\
\hline
\end{tabular}

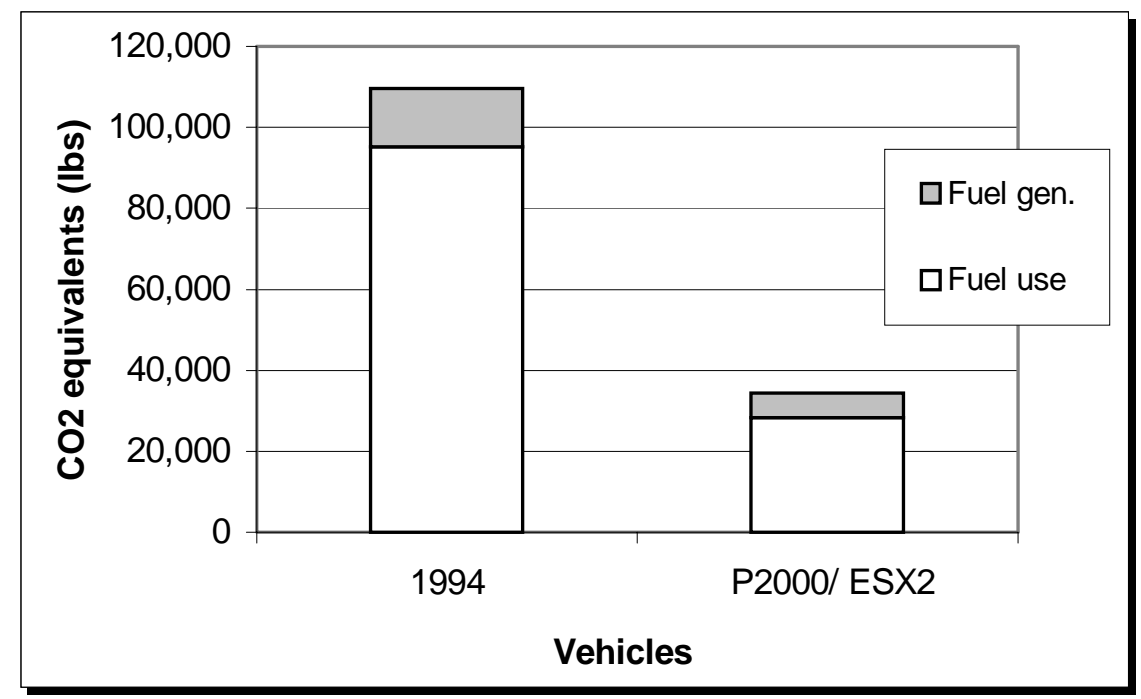

Figure 14. Global Warming Potential - Use Stage

Overall, in the use stage, it may be noted that the use of $3 \mathrm{XV}$ s results in significant reduction in energy, solid waste, and certain air emissions, particularly those that contribute to GWP.

Emissions of $\mathrm{NO}_{\mathrm{x}}, \mathrm{PM}$, and $\mathrm{CO}$ at the use stage are correlated to the fuel used-diesel-and the emission standards that will be in place at the time.

\subsubsection{End-of-Life}

Figure 15 shows the end-of-life solid waste generated. The P2000 produces less ASR than the 1994 vehicle. However, the ESX2 turns out to be better than the 1994 car only if the PET body panels can be recycled. It may be noted that the solid waste quantities shown include the waste produced during the electricity generation process. However, the waste from electricity generation is $2 \%$ or less of the total in each case. 


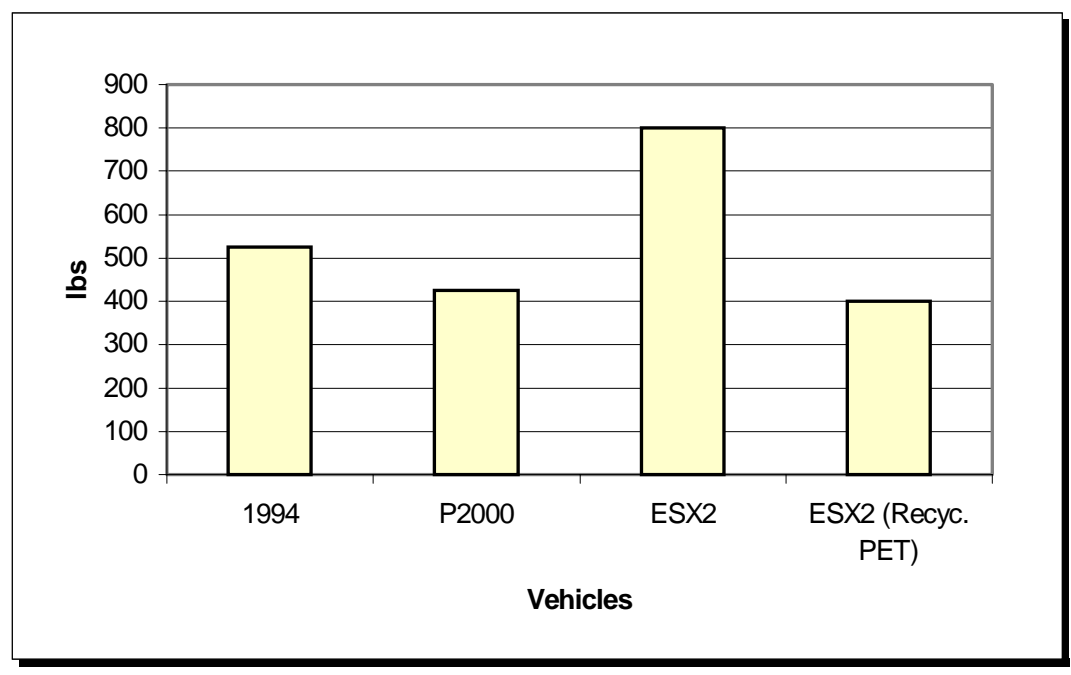

Figure 15. End-of-Life Solid Waste Generation

The energy consumed at end-of-life is almost all electricity. The different vehicle's energy consumption at end-of life is compared in Table 19; air emissions considered are shown in Table 20.

Table 19. End-of-Life Energy Consumption (mmbtu)

\begin{tabular}{|c|c|}
\hline Vehicle & Energy \\
\hline 1994 & 0.1062 \\
\hline P2000 & 0.0873 \\
\hline ESX2 & 0.1003 \\
\hline
\end{tabular}

Table 20. Air Emissions from Electricity Generation: End-of-Life Stage (lbs)

\begin{tabular}{|l|r|r|r|}
\cline { 2 - 4 } \multicolumn{1}{c|}{} & $\mathbf{1 9 9 4}$ & \multicolumn{1}{c|}{$\boldsymbol{P 2 0 0 0}$} & \multicolumn{1}{c|}{ ESX2 } \\
\hline Particulates & 0.01336 & 0.00826 & 0.009252 \\
\hline $\mathrm{CO}$ & 0.00574 & 0.00355 & 0.003978 \\
\hline $\mathrm{NO}_{\mathrm{x}}$ & 0.11633 & 0.07199 & 0.080584 \\
\hline $\mathrm{CO}_{2}$ equivalents & 44.0413 & 27.2546 & 30.50892 \\
\hline
\end{tabular}

Table 20 shows that the global warming gases, expressed in $\mathrm{CO}_{2}$ equivalents, are the most significant of all air emissions from electricity generation. Nevertheless, the air emissions in the end-of-life stage are a minuscule fraction of the total lifetime emissions. 


\subsection{Lifecycle Evaluation Conclusions and Recommendations for Future Research}

In summary, it appears that both the P2000 and ESX2 hold promise as more efficient and less environmentally burdensome modes of transportation for the new century. This evaluation specifically results in the key conclusions listed below.

- In the areas of energy consumption and GWP, considerable gains will be realized through the use of the $3 \mathrm{XVs}$; reductions of over $50 \%$ are seen both categories.

- With the important and positive work being done on the solid waste front to reduce as much as possible the quantity generated from manufacturing through end-of-life, the gains are notable. However, with over $90 \%$ of total lifecycle solid waste coming from extraction and materials processing, there is still much room for improvement through the use of recycled materials, wiser choices of $3 \mathrm{XV}$ primary materials, or better waste management practices in the upstream processes.

- This evaluation indicates that there are significant opportunities to reduce of PM and $\mathrm{NO}_{\mathrm{x}}$ output of the $3 \mathrm{XVs}$ at the E\&MP and Use stages. At the use stage, the emissions are highly sensitive to the assumptions about which standards for diesel emissions will be applicable at the time of $3 \mathrm{XV}$ production. $\mathrm{CO}$ is also sensitive to these assumptions. For PM, the most concerted effort will have to be applied to finding ways to reduce PM generated during E\&MP. The most obvious way is to utilize more recycled materials than are currently used. For $\mathrm{NO}_{\mathrm{x}}$ emissions, opportunities for reduction are greatest at the use stage.

From these conclusions, the following recommendations for future work are made to help the $3 \mathrm{XV}$ s become less environmentally burdensome in all aspects of their life cycle. There are many ways to improve the environmental footprint of the $3 \mathrm{XVs}$, and the options available are discussed below.

\section{Reductions in hybrid-vehicle diesel engine emissions}

Much work is currently being done to improve diesel engine performance. Fuel delivery is one way emissions can be reduced through improving the process of injection of the fuel into the compression chamber. Changing the air intake dynamics can also have the effect of reducing emissions, with EGR reducing $\mathrm{NO}_{\mathrm{x}}$ emissions specifically. Aftertreatment is also providing several different ways to reduce tailpipe emissions from the $3 \mathrm{XV}$ s by using technologies like particulate filters to collect $\mathrm{PM}$ and lean $\mathrm{NO}_{\mathrm{x}}$ catalysts to convert $\mathrm{NO}_{\mathrm{x}}$ to more benign compounds.

\section{Improvements to existing diesel fuel}

There are several changes that fuel manufacturers can make during the fuel production processes to decrease pollution generated during fuel burning. Of these, significant sulfur-content reduction and increase in the cetane number appear to be the most attractive ways to reduce the generation of all pollutants, including $\mathrm{PM}$ and $\mathrm{NO}_{\mathrm{x}}$.

\section{Use of alternative fuels}


Over the last ten years, many different fuels have been tested in attempts to reduce emissions, sometimes increasing the sustainability of the fuel generation process itself. Good examples include ethanol and biodiesel, which both utilize raw materials coming from renewable sources, decreasing the portion of nonrenewable petroleum required. Methanol, which may be obtained either from natural gas, coal or biomass, costs less than gasoline or diesel and results in fewer emissions. Additionally, compressed natural gas, dimethyl ether and Fischer-Tropsch (a natural gas-derived fuel) have been tested and improved for use as fuels; however some limitationsprimarily cost—exist in using these fuels.

\section{Research on hybrid vehicle batteries}

Of the available battery technologies that have been further developed for use in electric vehicles, the most promising appears to be the lithium-ion battery, due to its higher energy densitygreater power in a lighter package. However, it appears that these developing technologies will require further life-cycle evaluation to ensure that the benefits they offer do not produce more environmentally damaging effects in other life-cycle stages.

\section{Use of alternative power sources}

Alternative power sources seem to be the greatest "leapfrog technologies" available to move the $3 \mathrm{XVs}$ significantly further in their fuel efficiency. The brightest technology currently being developed and refined is fuel cells, which generate almost no pollutants during use. Fuel cells utilize hydrogen as the basic raw material that can be obtained from several different sources, including, but not limited to, gasoline and pure hydrogen, allowing for greater flexibility in bringing fuel-cell-powered vehicles to the market. Additionally, newer power source technologies like gas turbines, flywheels, ultracapacitors, and hydropneumatics are maturing into usable technologies that can further increase the operating efficiency of $3 \mathrm{XVs}$.

\section{Use of recycled/alternative materials}

This evaluation found that the use of lighter-weight materials, including primarily aluminum, titanium, and magnesium, has a trade-off. As environmental burdens are reduced in the use stage, burdens are increased significantly in the E\&MP life-cycle stage. The increased fuel efficiency gained through the use of these lighter-weight materials is offset by a much greater energy demand per unit mass of product produced and a substantially greater quantity of air emissions and solid wastes generated. There are several options available to improve the situation, including increasing the recycled content of the selected materials (which reduces the need for virgin ore and significantly decreasing the required production energy); finding ways to reduce the impacts from production of these materials; or using different materials (like carbon fiber composites).

Further evaluation of the life-cycle impacts of these materials or other materials chosen for use in the $3 \mathrm{XVs}$ will be necessary to evaluate these trade-offs.

\section{Solid waste reduction}

Solid waste reduction can be achieved in several ways including the following:

- Evaluate recyclability of glass-reinforced PET plastics; 
- Use materials with more recycled content; and

- Develop technologies to recover and recycle plastics in a more cost-effective manner.

In general, the $3 \mathrm{XVs}$ are expected to make significant strides toward improving the automobile's environmental footprint. However, to continue to move in that direction, automakers will have to work more closely with their supply chains. Through these partnerships, the automobile industry should be able to meet the PNGV goals and move another step closer to a more sustainable future for the automobile. 


\section{CONCLUSIONS AND RECOMMENDATIONS FOR FUTURE RESEARCH}

The analyses show that the introduction and market penetration of the $3 \mathrm{XV}$ prototypes considered here could occur, given attention to a small number of potentially significant issues.

What is required to produce the materials for the vehicles - the raw materials and the production capacity_are available for most alternative materials. There are no major differences in material supply issues for the two prototype vehicles. In cases were production capacity must be increased, capital investment requirements appear manageable for the respective industry. However, the huge increase in lithium production is potentially problematic, as are prices for some lightweight materials, e.g., aluminum and titanium. Since the program aims to have 3XVs maintain current prices, it is important to determine how low the prices of new lightweight materials have to be to achieve the vehicle-price goals. Conducting lifecycle analyses of lithium and carbon fibers could provide information needed for the next stage of $3 \mathrm{XV}$ development.

There appear no single show-stoppers with respect to vehicle repair and use and market acceptability, although a combination of factors may negatively affect market acceptability. These factors could include higher prices for vehicle repair and insurance especially in the early years of $3 \mathrm{XV}$ introduction and consumer concerns about the safety of vehicles made of lightweight materials. This latter concern could be fueled by the steel industry's television advertising campaign that strongly implies that automobiles constructed of steel are safer than those constructed of other materials. Research focusing on consumers acceptance of these vehicles would examine how consumers trade-off sticker price for life-cycle costs when purchasing the vehicles, would determine how low the prices of $3 \mathrm{XVs}$ need to be to have them penetrate the market successfully, and would determine if an accumulation of acceptability issues will threaten $3 \mathrm{XVs}$ ' ability to gain market share.

With high rates of vehicle recycling occurring currently, and even higher rates likely, 3XVs will affect the recycling industry. Each component of the industry stands to experience an increase in its profitability if a number of technical challenges, ranging from improving disassembly to recycling PET, are met. Accordingly, research on the intelligent disassembly of automobiles and other separation and recycling technologies is warranted to achieve the PNGV goal of $80 \%$ recycling.

Examining the $3 \mathrm{XV}$ prototypes' potential environmental impacts over the vehicle's lifetime shows that the P2000 and ESX2 have comparable positive environmental effects, including significant reductions in GWP and energy consumption. However, the new materials and the diesel-fueled engines may contribute to notable increases in $\mathrm{SF}_{6}$, NOx, and particulate matter emissions. Negative effects, i.e., an increased environmental burden, occur for most inputs and outputs in the extraction and materials processing life-cycle stage. It is deemed necessary, therefore, to examine ways to reduce those outputs that have significant increases, especially SF6 in the production of magnesium and particulate matter emissions in the production of aluminum. 
Overall, the analyses highlight what areas require the attention-planning, research, and technology development — of the PNGV program to assure easy transitioning to 3XVs. 


\section{REFERENCES}

American Automobile Manufacturers Association (AAMA) 1997. Motor Vehicle: Facts \& Figures, Washington, DC.

Bucholz, K. 1997. “Ford's P2000,” Automotive Engineering, pp. 68-69, May.

Center for Clean Products and Clean Technologies 1999. "Life-Cycle Environmental Evaluation of Aluminum and Composite Intensive Vehicles," University of Tennessee, March 5.

The Composites Institute (CI) 1998. “1997 Statistical Report,” New York, NY.

CRU International Ltd. (CRU) 1996. "Magnesium: Chronic Tightness or Overcapacity? Demand, Supply, and Costs to 2005," London, United Kingdom.

Das, S., T.R. Curlee and S.M. Schexnayder 1997. "Materials Used in New Gerneration Vehicles: Supplies, Shifts, and Supporting Infrastructure.” ORNL/TM-13491, Oak Ridge National Laboratory, Oak Ridge, TN, August.

Das, S., T.R. Curlee, D.W. Jones, P.E. Leiby, J.D. Rubin, S.M. Schexnayder, D.P. Vogt and A.K. Wolfe 1999. "Supporting Infrastructure and Acceptability Issues for Materials Used in New Generation Vehicles," ORNL/TM-13731, Oak Ridge National Laboratory, Oak Ridge, TN, March.

DeLong, D. J. 1994. “Carbon Fiber economics/Applications," paper presented at the Gorham/Intertech Conference, July 21.

Department of Commerce (DOC) 1997. "Current Industrial Reports: Non-Ferrous Castings," Report No. MA33E(96)-1, Bureau of the Census, Washington, DC, August.

Department of Commerce (DOC) 1998. "Survey of Plant Capacity: 1996," Report No. MQC1(96), Bureau of the Census, Washington, DC, April.

DieselNet 1999. http://www.dieselnet.com

DOE (U.S. Department of Energy) 1997. Program Analysis Methodology: Office of Transportation Technologies B Quality Metrics'99, OTT Analytic Team, Office of Transportation Technologies, Washington, DC, December.

Ducker Research Company, 1998, Report on Aluminum Content in 1999 North American Passenger Cars and Light Trucks, November 18.

EEB (Energy Engineering Board) 1992. Automotive Fuel Economy: How Far Should We Go? National Research Council, Washington, DC.

EIA (Energy Information Administration) 1998. Annual Energy Outlook 1998: With Projections to 2020, DOE/EIA-0383(98), (also available from the website: www.eia.doe.gov/oiaf/aeo98/ homepage.html) Office of Integrated Analysis and Forecasting, U.S. Department of Energy, Washington, DC, January.

Environmental Protection Agency (EPA) 1998. "Characterization of Municipal Solid Waste in the United States: 1997 Update," EPA530-R-98-007, Municipal and Industrial Solid Waste Division, Office of Solid Waste, May. 
EPA 1999a. http://www.epa.gov/OMSWWW/gopher/Cert/Veh-cert/Cert-Tst/

EPA 1999b. http://www.epa.gov/OMSWWW/gopher/Cert/MPG/98guide.txt

EPA 1999c. OMS Fact Sheet. http://www.epa.gov/reg3artd/vehic/noxfact2.htm

Gambogi, Joseph 1998, “Minerals Yearbook 1997: Titanium,” http://minerals.er.usgs.gov/minerals/pubs/commodity/titanium/670497.pdf, United States Geological Survey.

Graff, G. 1995. "In-mold Color Coating Readies for Industry Debut,” Modern Plastics, Feb., p.52.

Hadley, S.W., S. Das, and T.R. Curlee 1998, A Cost Assessment of Titanium Production Technologies for Automotive Applications, Draft, Oak Ridge National Laboratory, April.

High Performance Composites (HPC) (1998). May/June 1998, p. 22-23.

Katrak, F., P. Dimitrios, and J. Morton 1997, "Steel vs. Aluminum vs. Polymers: The Battle for Automotive Body Applications for the $21^{\text {st }}$ Century," Presentation to the Metal Bulletin's $12^{\text {th }}$ International Aluminium Conference, Rio De Janeiro, Brazil, September 9.

Kelly, K.E., J.G. Overly, M.L. Socolof, and G.A. Davis 1998. "Environmental Evaluation of Molding Body Panels in Color." SAE Southern Automotive Manufacturing Conference \& Exposition.

Leach, R.E. 1995. Personal communication. Center for Composites Manufacturing Technology, Oak Ridge National Laboratory, Oak Ridge, TN, August 7.

Maples, J. 1998. Personal communication to Sujit Das, Oak Ridge National Laboratory, Oak Ridge, TN, June 16.

McDermott, J. 1998a. "Competing Through Process Technology," Composites Fabrication, April, pp. 20-36.

McDermott, J. 1998b. "Updating the Demographics of the Composites Industry: Are There Enough of U.S. to Go Around?," Composites Fabrication, October, pp. 8-72.

Modern Plastics 1996. "Eastman Sees Much Growth in PET Use,” p.12, July.

Modern Plastics 1998. “Resins'98,” Vol. 75, No. 1, January, pp. 64 and 76.

Ng, G. K. J.C. Miller and M.B. Tessieri 1999. "Aluminum Usage in the PNGV and its Impact on the Recycling Infrastructure," SAE paper no. 1999-01-0674, paper presented at the 1999 SAE International Congress and Exposition, held on March 1-4, 1999, Detroit, Michigan.

Ober, Joyce 1998, “Minerals Yearbook 1997: Lithium,” http://minerals.er.usgs.gov/minerals/pubs/commodity/lithium/450497.pdf, United States Geological Survey.

Oswald, L. J. 1998. DiamlerChrysler Corporation, Madison Heights, MI. Personal communication with Sujit Das, Oak Ridge National Laboratory, Oak Ridge, Tennessee, September 1, 1998 
Owens Corning Fiberglass Corporation (OFC) 1996. Owens Corning Composites Capacity Increase Backgrounder. Toledo, Ohio, January.

Owens Corning Fiberglass Corporation (OFC) 1998. Owens Corning: 1998 Fact Book. Toledo, Ohio, January.

Pinfold, P. 1998. "Spartan Light Metal Products-A Diecaster's Chronicle Progress," Light Metal Age, Vol. 56, No. 5-6, pp. 40-45, June.

Plunkert, Patrica A., 1998 "Minerals Yearbook 1997: Aluminum" http://minerals.er.usgs.gov/minerals/pubs/commodity/aluminum/050497.pdf, United States Geological Survey.

"Polycarbonate Expansion," The Plastic Distributor and Fabricator Magazine, Volume 18, Issue 4, Article 903, http://plasticsmag.com/ta000903.htm

Prescott, R. 1996. Personal communication to Sujit Das, Akzo Nobel, Fortafil Fibers, Inc., Rockwood, Tennessee, June 12.

Raffelsberger, et. al. 1995. "Fuel System for the Future High Speed Long Life DI Diesel Engines with the Suitable Electronic Control." Total Life Cycle Conference, SAE.

Resolve Inc. 1995. "Policy Dialogue Advisory Committee to Develop Options for Reducing Greenhouse Gas Emissions from Personal Motor Vehicles," draft final report, Washington, DC, Aug.

Sherman, Andy, "What Industry Needs," Final Report from Titanium Industry Workshop July 30-31, 1997, Welches, Oregon, ASME International, Washington DC, pp. 91-104.

The Society of the Plastics Industry, Inc. (SPI) 1998. Personal communication with Sujit Das, Oak Ridge National Laboratory, Oak Ridge, TN, Aug. 10.

Sorge, M. 1995. “They're Spinning used Fiberglass into Gold: Phoenix Fiberglass," Ward's Auto World, Vol. 31, No.5, p. 85, May.

Technology Administration 1999. PNGV website. http:/www.ta.doc.gov/pngv/introduction/ intro.htm

Tessieri, M. 1997. "Overview of Automotive Aluminum Scrap Recycling in North America," Alumitech'97 Proceedings, $2^{\text {nd }}$ International Conference and Trade Exposition, held on May 20-23, Atlanta, GA.

U.S. Dept. of Energy (DOE) (1998). "Metalcasting Industry Technology Roadmap," sponsored by Cast Metal Coalition, Washington, DC, Jan.

United States Council for Automotive Research (USCAR) 1999. "U.S.CAR Bubbling About Plastics Separation for Recycling," available at http://www.uscar.org/techno/flotation.htm.

United States Geological Survey (USGS) 1998. "Magnesium: Minerals Information, Reston, VA. USCAR website. http://www.uscar.org/techno/tsp.htm

Wang, M, M. Mintz, M. Singh, K. Stork, A. Vyas, and L. Johnson 1998. “Assessment of PNGV Fuels Infrastructure - Phase 2 Report: Additional Capital Needs and Fuel-Cycle Energy and 
Emission Impacts," The Center for Transportation Research, Argonne National Laboratory, Argonne, IL, August.

Werst, Bill 1998. Director, Society of Advanced Composite Materials Association, Personal communication with Sujit Das, October. 